Illinois State University

ISU ReD: Research and eData

Theses and Dissertations

2-24-2016

\title{
Arts integration: Establishing teacher candidates' self-efficacy when engaging with the arts
}

Michael J. Vetere III

Illinois State University, mjvetere@ilstu.edu

Follow this and additional works at: https://ir.library.illinoisstate.edu/etd

Part of the Fine Arts Commons, Other Education Commons, and the Theatre and Performance Studies Commons

\section{Recommended Citation}

Vetere III, Michael J., "Arts integration: Establishing teacher candidates' self-efficacy when engaging with the arts" (2016). Theses and Dissertations. 552.

https://ir.library.illinoisstate.edu/etd/552

This Dissertation is brought to you for free and open access by ISU ReD: Research and eData. It has been accepted for inclusion in Theses and Dissertations by an authorized administrator of ISU ReD: Research and eData. For more information, please contact ISUReD@ilstu.edu. 


\title{
ARTS INTEGRATION: ESTABLISHING TEACHER CANDIDATES’ SELF-EFFICACY WHEN ENGAGING WITH THE ARTS
}

\author{
Michael J. Vetere III
}

\section{Pages}

Many teacher candidates who enter teacher education programs have received altered curricula that addressed the new common core of reading, writing, and mathematics (Beveridge 2010). This new common core curriculum neglects the importance of arts education. These students who have not been exposed to arts education, are reluctant to engage in the arts and fully participate in an arts education course as part of their teacher preparation (Hallam, Gupta, \& Lee, 2008). These teacher candidates exhibit a low level of arts engagement and arts teaching self-efficacy and are therefore less confident with engaging and teaching the arts (Garvis, 2009). The lack of engagement with quality arts experiences in adolescence and university settings may perpetuate the lack of creativity and dedication for creating quality educators who contribute to arts education (Eisner, 2002).

This mixed method research study has examined the role of arts integration courses in the preparation of teacher candidates' self-efficacy on teaching and engaging in the arts. This study adds to mixed-method research as it relates to self-efficacy and preparing teacher candidates to teach the arts after taking an arts integration course. The 
findings of this research contribute to the overall effectiveness and reliability of art integration in the classroom. The researcher found that teacher candidates who enter an arts integration course had a wide variety of exposure to the arts from no experience to school curriculum, extra-curricular activities, and community arts experiences. Prior to taking an arts integration course, the students indicated a neutral level of arts selfefficacy. At the conclusion of the semester-long courses on arts integration students' self-efficacy improved to a positive level of self-efficacy in engaging with and teaching the arts with the greatest change in vicarious experiences.

KEYWORDS: Arts Education, Arts Integration, Common Core, Self-efficacy 


\title{
ARTS INTEGRATION: ESTABLISHING TEACHER CANDIDATES' SELF-EFFICACY WHEN ENGAGING WITH THE ARTS
}

\author{
MICHAEL J. VETERE III
}

A Dissertation Submitted in Partial

Fulfillment of the Requirements

for the Degree of

\section{DOCTOR OF EDUCATION}

School of Teaching and Learning

ILLINOIS STATE UNIVERSITY

2016 
Copyright 2016 Michael J. Vetere III 


\section{ARTS INTEGRATION: ESTABLISHING TEACHER CANDIDATES' SELF-EFFICACY WHEN ENGAGING WITH THE ARTS}

MICHAEL J. VETERE III

COMMITTEE MEMBERS:

Nancy Latham, Chair

Lydia Kyei-Blankson

Kyle Miller

Alan Bates 


\section{ACKNOWLEDGMENTS}

Thank you to my committee for your guidance and support. I feel fortunate to have been mentored by such talented and positive faculty members. Thank you Dr. Nancy Latham for your inspiration and confidence in me to successfully complete a doctorate. To my methodologists, Dr. Lydia Kyei-Blankson and Kyle Miller thank you for your critical eye, patience, and time spent on assisting me shape my document, your responsiveness have been truly appreciated. I would also like to thank Dr. Alan Bates for being a sounding-board and problem solver, I am grateful for your time and attention in helping me craft my study. In addition, I also want to thank the faculty members who have been by teachers during my journey. Through your instruction I have acquired knowledge and skills that will benefit me throughout years to come.

I also owe gratitude to my colleagues in the School of Theatre and Dance at Illinois State University who encouraged me and to those who acknowledged the time and work it took to achieve this personal goal. I would also like to thank my fellow doctoral students, your friendship and support have been truly appreciated and I look forward to our future collaborations. I also wish to thank my dear and beneficial friend Samantha Maggio for her generous contributions to both my mind and spirit. I appreciate your patience, brainstorming, and proofreading. I could not have achieved this accomplishment without you! 
I am deeply indebted, in countless ways, to my siblings for their love and support over the past years. To my twin, Katie Roberts, thank you for listening to my frustrations and offering an encouraging word. Thank you to my brother, Timothy Vetere, whose gift of language and understanding of research helped me work though challenging times. To my sister, Emily Dow, I cannot thank you enough for being a phone-call away, reading my work, talking with me throughout the days, and offering suggestions and advice. I am appreciative for your love and support.

Last, but not least, I would like to thank and dedicate this dissertation to my parents, Michael and Terry Vetere. I am incredibly honored to have such generous and loving parents. Your commitment and value to education is truly remarkable and I am so grateful to follow in your footprints. Thank you for being such positive role-models and extraordinary educators. I cannot thank you enough for your love and support, I am so grateful to be your son.

M. J. V. III 


\section{CONTENTS}

\section{Page}

ACKNOWLEDGMENTS $\quad$ i

CONTENTS

TABLES vi vi

FIGURES vii

CHAPTER

I. THE PROBLEM AND ITS BACKGROUND 1

Theoretical Framework $\quad 3$

Problem Statement $\quad 6$

Purpose of the Study $\quad 11$

$\begin{array}{ll}\text { Research Questions } & 12\end{array}$

$\begin{array}{ll}\text { Significance of the Study } & 12\end{array}$

$\begin{array}{ll}\text { Definition of Terms } & 13\end{array}$

Definition of Study Terms 14

Assumptions and Limitations $\quad 14$

$\begin{array}{ll}\text { Chapter Summary } & 15\end{array}$

II. REVIEW OF SIGNIFICANT RESEARCH 16

$\begin{array}{ll}\text { Social Cognitive Theory } & 17\end{array}$

Behavior, Personal Factors, and Environment 19

$\begin{array}{ll}\text { Self-Efficacy } & 22\end{array}$

Performance Accomplishments 24

Vicarious Experiences $\quad 25$

Verbal Persuasion $\quad 26$

$\begin{array}{ll}\text { Psychological States } & 27\end{array}$ 
$\begin{array}{lr}\text { Self-Efficacy of Teachers } & 28\end{array}$

Background of Arts in Education 31

Arts Integration $\quad 35$

Through and With $\quad 37$

Arts Integration in Content Areas $\quad 39$

Collaboration $\quad 40$

Student Achievement with Arts Integration $\quad 42$

Barriers to Arts Integration $\quad 47$

Teacher Preparation and Professional Development 52

Arts Efficacy $\quad 58$

$\begin{array}{ll}\text { Conclusion } & 64\end{array}$

III. METHODOLOGY 66

Research Design $\quad 66$

Data Collection \& Instrumentation 68

Research Setting and Participants $\quad 70$

$\begin{array}{ll}\text { Ethical Considerations } & 72\end{array}$

$\begin{array}{ll}\text { Analysis Procedure } & 73\end{array}$

IV. DATA ANALYSIS AND RESULTS 75

Summary of the Demographic Variables 76

Findings $\quad 79$

$\begin{array}{ll}\text { Research Question 1 } & 79\end{array}$

Arts Focused Classes in School $\quad 86$

Extra-Curricular Activities $\quad 87$

Community Arts Experiences 87

Research Question $2 \quad 88$

Mastery Experiences Written Responses 106

Vicarious Experiences Written Responses 107

Verbal/Social Persuasion Written Responses 109

Physiological State Written Responses 110

Research Question 3 111

Research Question 4

Confidence in Integrating the Arts 113

Level of Creativity 114

Confidence in Arts Abilities 115 
A Feeling of More Confidence/Comfortability/

V. SUMMARY, DISSCUSSION, IMPLICATIONS, LIMITATIONS, AND RECOMMENDATIONS

Discussion

Implications and Recommendations for Practice

Recommendations for Future Research

Limitations

Conclusions 


\section{TABLES}

$\begin{array}{lll}\text { Table } & \text { Page }\end{array}$

1. Demographic Characteristics of Participants 78

2. Pre- Survey Response Percentages for Q1-Q5 81

3. Pre- Survey Response Percentages for Mastery Experience (Q6-Q11) 90

4. Pre-Survey Response Percentages for Vicarious Experiences (Q12-Q16) 95

5. Pre-Survey Response Percentages for Verbal/Social Persuasion (Q17-Q22) 100

6. Pre-Survey Response Percentages for Physiological State (Q24-Q28) 103

$\begin{array}{ll}\text { 7. Pre/Post Comparison } & 112\end{array}$ 


\section{FIGURES}

Figure

Page

1. Participant Mean Scores per Area

84

2. Pre-Survey Composite Mean Scores 


\section{CHAPTER I}

\section{THE PROBLEM AND ITS BACKGROUND}

The role of the arts, in our lives, serves as a catalyst to learning and aesthetic development. Children naturally acquire knowledge about their world through the creative arts: drama, music, dance, and visual arts (Ruppert, 2006). Young children learn naturally about the world through their senses and the materials in their surroundings (McLeod, Sensorimotor Stage, 2010). They model adults' behavior and pretend to adopt characteristics that resemble the people around them similar to actors in drama (Bandura, 1997). Children and adults make and hear music while naturally moving their bodies to sounds, which is, fundamentally, dance (Kaufmann, 2006). Individuals also express themselves through visual elements including but not limited to drawing, painting, and even sculpting (Koster, 2014). All of these manifestations and expressions are fundamental explorations of the arts and learning.

Throughout our lives, the arts can lay a strong foundation for individuals to develop personally, academically, and inter-personally. When children and adults experience the arts they develop skills and dispositions that are intrinsically motivating and stimulating. The arts are possibly, "the most powerful instruments available to us for the fulfillment of life" (Hallam, Gupta, \& Lee, 2008, p. 269). The arts allow individuals to express emotions, experience a sensory awareness, as well as heighten our awareness of others and our surroundings (Brouillette, 2010). Yet, by the time a child has reached 
public school the arts have become less valuable within the school curriculum because of the impending needs of No Child Left Behind Act, the Common Core Curriculum, Race to the Top, Every Child Succeeds Act and the economic demands for student achievement in non-arts related material (Ashford, 2004; Beveridge, 2010; Civic Impulse, 2016; National Governors Association Center for Best Practices \& Council of Chief State School Officers, 2010; No Child Left Behind Act of 2001, 2002). The focus of the development of the child has been sharply altered to address the common core of reading, writing, and mathematics (Beveridge, 2010). The arts became less pressing and pushed to the wayside. Students were conditioned to believe that the arts are a "fun activity" used as an incentive to bribe children to complete their "remedial class work" (Beveridge, 2010, p. 5). Therefore, the arts were often marginalized and treated as extracurricular activities instead of having value in their own merit, even though some artcentered activity is often graded in schools (Alter, Hays, \& O'Hara, 2009).

Those children, who graduated from public schools, where little of the creative arts have been implemented, later choose a variety of careers including the field of education. Many teacher candidates, who have not been exposed to arts education, are reluctant to engage in the arts and fully participate in an arts education course as part of their teacher preparation (Hallam, Gupta, \& Lee, 2008). These teacher candidates and teachers exhibit a low level of arts engagement and arts teaching self-efficacy and are therefore less confident with engaging in the arts. The lack of engagement with quality arts experiences in adolescents and university experiences may perpetuate the lack of creativity and dedication for creating quality educators who contribute to arts education (Eisner, 2002). Developing and creating quality arts experiences for university teacher 
candidates is crucial to the future integration of the arts in education for, and with, young children (Ozdemir \& Cakmak, 2008; Wright, 1985). In addition, studies on teacher candidates' self-efficacy in arts integration courses at state universities have not been investigated using mixed-method research. Through analysis of university arts education courses that teach the arts to teacher candidates, it will be evident through both quantitate and qualitative means the successes and pitfalls of educating arts-minded educators. This study examined the role of arts integration courses in the preparation of teacher candidates' self-efficacy on teaching and engaging in the arts.

\section{Theoretical Framework}

This study used Albert Bandura's work in social cognitive theory as a framework. Bandura stated that the environment causes behavior, and the behavior also influences the environment (Bandura, 1986; 1988; 1997; 2001). This theory attempted to explain physiological changes in behavior as it is affected by individuals, others, and the environment. The purpose of social cognitive theory is to understand and predict individual and group behavior and is used to identify methods in which behavior can be modified or changed (Bandura, 1986).

In social cognitive theory individuals are "contributors to, rather than the sole determiners of, what happens to them" (Bandura, 1997, p. 3). Therefore, individuals have the ability to affect their own behavior and the environment in a purposeful manner (Bandura, 2001). Social cognitive theory has identified how cognitive, behavioral, personal, and environmental factors interact to determine behavior (Bandura, 1986; 1997). These factors work together through a process of reciprocal determinism that suggests that the individual's beliefs about themselves are based on human behavior, 
personal factors, and environment that mutually interact and serve as determinates of each other (Bandura, 1986). Therefore, "How people interpret the results of their own performance attainments informs and alters their environments and their self-beliefs which, in turn, alter subsequent performances" (Pajares, 1997, p. 2). Bandura elaborated by noting that the learner is not independent of their environment but also interacts with and learns from their environment (Bandura, 1977). These determinates do not however equally or simultaneously influence each other but depend on the influence of the activity, the circumstance, and the individual on the situation (Bandura, 1986). To address this concept, Bandura formulated the notion of self-efficacy.

Tschannen-Moran et al. (1998) has defined teacher efficacy as a, "teacher's belief in his or her own capability to organize and execute courses of action required to successfully accomplish a specific teaching task in a particular context” (p. 233). When teachers have a high sense of self-efficacy they are able to execute engaging lessons that allow for student learning. Gibson and Dembo (1984) first identified a difference in high-efficacy and low-efficacy teachers when it came to teaching styles with their instrument, the Teacher Efficacy Scale. One of the key differences they noted existed in how the teachers' classes were conducted. High-efficacy teachers spent more time in whole-group instruction, monitoring and checking the students' work and preparation, while low-efficacy teachers spent over half of their time in small-group instruction as well as student independent learning. When students were engaged in large-group work rather than independent learning they were more likely to stay on target and focus on the information being presented. In addition, high-efficacy teachers had a tendency to guide students towards correct answers by asking more questions and offered more praise for 
correct answers and less criticism for incorrect answers (Gibson \& Dembo, 1984; Taylor \& Noumanis, 2007). High-efficacy teachers were noted to be more flexible in their teaching while lower-efficacy teachers struggled with lessons that did not proceed as planned (Gibson \& Dembo, 1984; Bordelon et al., 2012). Additionally, studies have also demonstrated that the preparedness of a teacher affects the level of self-efficacy the teacher maintains when in the classroom (Gibson \& Dembo, 1984; Zientek, 2007). When teachers are more prepared to work with and teach children appropriate material they feel a stronger sense of self-efficacy.

Tschannen-Moran, Woolfolk Hoy, and Hoy (1998) identified a framework for the development of teacher self-efficacy that was based on Bandura's four sources of efficacy (Bandura, 1977; 1986). These four sources of self-efficacy are: mastery experiences, vicarious experiences, verbal/social persuasion, and physiological states. This framework has suggested that the interaction between a teachers' analysis of teaching and their self-assessment of their teaching ability results in self-efficacy. This analysis, therefore, made it "necessary to assess one's strengths and weaknesses to the requirements of the task at hand" (Tschannen-Moran, Hoy, \& Hoy, 1998, p. 228). This continual reflection helps teachers identify personal goals, amount of effort, and level of persistence in teaching students (Tschannen-Moran \& Hoy, 2001; Tschannen-Moran, Hoy, \& Hoy, 1998). Teachers with high self-efficacy are more open to new ideas and are more open to discover new ideas to help students learn (Tschannen-Moran \& Hoy, 2001). In addition, teachers with a strong sense of self-efficacy exhibit more commitment and attention to planning and organization and are more willing to try new teaching approaches to assist in student learning (Allinder, 1994; Tschannen-Moran \& Hoy, 2001). 
By using social cognitive theory and the construct of self-efficacy, this study has investigated how individuals' behavior is influenced and affected through the reciprocal influences of cognition, environmental, and behavioral influences of an arts integration course offered to teacher candidates. This research further examined any change in teacher candidates' perceptions of self-efficacy, as it related to the teaching of the arts, within an arts education course as part of the teacher candidates' preparation to becoming a licensed teacher.

\section{Problem Statement}

With the decline of quality arts experiences in elementary, secondary, and university settings, it is unlikely that teacher candidates will have the opportunity to execute constructive and positive arts-learning experiences in their future classrooms (Beveridge, 2010). This decline of arts experience and the reciprocity of learning and teaching the arts has had impactful consequences for arts education. However, it is known that teacher candidates who engage in arts education are more likely to develop skills and dispositions that directly correlate with arts-learning or the experiences of learning the art form (Davies, 2009; Garvis, Twigg, \& Donna, 2011). When children are exposed to a curriculum that is engaging, innovative, and constructive they develop a higher level of cognitive, affective, and social abilities (Furman, 2000). The arts are a vehicle to these higher level results, however the use of the arts are not implemented to support the curricula and learning. Without the arts seamless integration into the curriculum, children cannot learn through and with the arts.

The No Child Left Behind Act (NCLB) has caused a large decline of arts-based education and exposure to the arts for these teacher candidates in their middle and 
secondary education (Ashford, 2004; Heilig, Cole, \& Aguilar, 2010). Without concentrated time and support for arts education for teacher candidates, they will not be prepared to develop curricula that is constructive and impactful for their students using the arts. Arts-learning experiences will not take place in the school classroom without teachers who are educated in the arts. The consequences may result in students' lower engagement, skill decline, and knowledge of the arts will suffer. Therefore, it is important to identify and determine the level of teacher candidates' self-efficacy in teaching and engaging in the arts to better understand their preparedness to teach the arts.

As more and more individuals matriculate through the school system under Common Core the more streamlined our education will become. Teachers may become less inclined to offer new and creative ways of teaching that involve the arts. The arts may, therefore, be marginalized from the schooling of young children altogether causing a decline of arts-educated citizens (Heilig, Cole, \& Aguilar, 2010). Arts educated citizens offer both intrinsic values and contributions to creative thinking that ignite new ways of thinking and knowing that are beneficial to a variety of vocations (Eisner, 2005). Elliot Eisner states, "the experience the arts make possible is not restricted to what we call the fine arts" (Eisner, 2004, p. 9). Teacher candidates can benefit from the arts by engaging their students in numerous subjects with arts-rich material. The arts have encompassed everything we do from television, to products we purchase, to music on the radio. Yet, if we do not have a foundation of arts education then individuals will not be able to see the multiple connections the arts offer in many different fields of study (Eisner, 2004). 
Engaging in arts experiences provides teacher candidates with opportunities to witness the values and intrinsic benefits the arts have on learning (Samuelsson, Carlsson, Olsson, \& Pramling, 2009). A strong foundation in the arts provides students new forms of thinking which can be beneficial in various curricular areas; these forms of thought can include aims, belief, vision, relationship, and visual literacy (Eisner, 2005). These forms are difficult to teach in core subject areas whereas the arts provide a simple approach to teach these thought processes. Research has demonstrated a causal link between academics and intrinsic growth in beliefs and values. Russell-Bowie points out that "students and teachers noted that many children had developed academically, emotionally, socially, and artistically as a result of being involved in the creative arts learning experiences" (Russell-Bowie, 2009, p. 303). Therefore, it has proven crucial to have a foundation in the arts as it results in affective development.

Many teacher candidates and practicing teachers do not have or have limited formal education when it comes to the arts in education. However, they have been encouraged to use the arts in their teaching (Brien, 2011; Eisner, 1988). Teacher candidates often felt a "lack of confidence, motivation, and knowledge...in delivering arts education" (Garvis, 2009, p. 23). This notion has been shown to be congruent with Alter, Hays, and O'Hara, who found that teachers lack the confidence to teaching the arts (2009). They stated, "teachers tended to avoid speaking about areas within the creative arts where they believed they did not have adequate skills and knowledge" (Alter, Hays, \& O'Hara, 2009, p. 26). This attitude towards the arts limits the potential that teacher candidates will use and engage with the arts in their future classrooms with young children. Therefore, it is important to identify teacher candidates' self-efficacy, as it 
relates to implementing the arts, as a low level self-efficacy will affect confidence in teaching and engaging with the arts. A low-level efficacy teacher candidate will be reticent to teach the arts, which will impact their students learning and adoption of the arts into their lives.

Teacher candidates are often fearful of teaching and using the arts (Davies, 2009). Studies have concluded that teacher candidates who engage with the arts are more likely to develop and encompass lessons that increase enjoyment in teaching and learning, selfesteem, and confidence in teaching (Davies, 2009; Garvis, Twigg, \& Donna, 2011). Teacher candidates who have incorporated the arts develop an intrinsic motivation in their students to learn more about the subject matter presented (Alter, Hays, \& O'Hara, 2009; Davies, 2009; Garvis, Twigg, \& Donna, 2011). Through exposure and education, teacher candidates become more comfortable in integrating the arts.

For teacher candidates to engage with the arts fully they must develop a sense of self-efficacy related to teaching and implementing the arts. Bandura regards self-efficacy as how an individual feels, thinks, motivates themselves, and behaves (Bandura, 1997). Therefore, the "higher the sense of self-efficacy, the greater the perseverance and the higher the chance that the pursued activity will be performed successfully" (Garvis, 2009, p. 24). When a teacher candidate is confident in their knowledge and execution of that knowledge they are able to execute effective arts curriculum.

Arts experiences, such as engaging in and witnessing the arts, enhance teacher candidates' understanding of the importance of learning through the arts (Davies, 2009). Teacher candidates are often faced with challenges of knowing about the arts-subject 
matter and how to teach the arts when engaging students in their future classrooms. Confidence, motivation, and knowledge of the subject matter are important qualities to develop in the teacher candidate. Therefore, arts education and quality arts experiences are crucial to emerging teacher candidates (Garvis, Twigg, \& Donna, 2011). For example, an action based research study (Pool, Dittrich, \& Pool, 2011) examined the theoretical framework of Howard Gardner's multiple intelligences as it related to artsbased learning when developing lesson plans. The study looked at teacher candidates' perspectives and understanding of arts-based teaching through an arts-teaching model and how their experiences facilitated or hindered student learning. The authors' noted, “Teacher candidates often receive knowledge of multiple intelligences (MI) yet rarely are presented a mode or method to address MI in lessons" (Pool, Dittrich, \& Pool, 2011). Therefore, the authors demonstrated an arts-based lesson, with teacher candidates, which focused on how "multiple intelligence theory and arts-based integration might affect student learning and their professional practice" (Pool, Dittrich, \& Pool, 2011). The teacher candidates who were exposed to quality arts-based education were able to model and adopt the practices for their future classrooms. The arts offered an opportunity for the teacher candidates to see a constructive venue of dissemination of learning with young students heightening various forms of thought.

In addition, Davies (2009) conducted a research study where teacher candidates participated in a week-long case study (p. 631) which involved collecting their opinions, attitudes, and beliefs of integrating the arts into the classroom curriculum through the creation of a performance piece at an area museum. Participants believed experiences in cross-disciplinary arts experiences could enhance their abilities and "quench their fears" 
of integrating the arts in their future classrooms (Davies, 2009). This idea of participating in the arts helped identify the opportunities the arts can have on learning. Gadsden, from the University of Pittsburgh, agreed with the reciprocal nature of the arts and learning. She believes, “... arts in education, denoting the centrality of art as both precipitator and repository of learning, teaching, and schooling; and the arts and education, denoting the reciprocal and interactional relationship that exists between the two areas of inquiry" is central to learning (Gadsden, 2008, p. 30).

In summary, due to NCLB and common core, practicing teachers and teacher candidates often do not experience the arts in the school environment as they once did (Ashford, 2004; Beveridge, 2010). Schools have chosen to streamline their curriculum and exclude the arts from their classroom agenda and place a more focused attention on tested subjects (Parsad \& Spiegelman, 2012). However, with arts in all aspects of our lives it may be difficult to ignore the influences of the arts on education. When teachers engage in quality arts experiences they see the direct contributions the arts can contribute to learning in the schools (Davies, 2009; Gadsden, 2008; Pool, Dittrich, \& Pool, 2011). In addition, teachers' ability to connect with the arts more positively affects their participation and confidence in the arts (Russell-Bowie, 2009).

\section{Purpose of the Study}

The purpose of this investigation was to determine the role of arts integration courses in the preparation of teacher candidates' self-efficacy in utilizing the arts in their future classrooms. Teacher candidates often have little confidence in participating in the arts and exhibit low self-efficacy when teaching the arts (Russell-Bowie, 2010). By 
examining the students' self-efficacy prior to and after taking an arts integration course, the researcher determined the effectiveness of the course on teacher candidates' selfefficacy and confidence in teaching and engaging in/with the arts. This study also intended to examine the impact of an arts integration course on students' perceptions of self-efficacy in teaching the arts. This study examined students' prior experience in the arts to determine their overall preparation.

\section{Research Questions}

The following questions guided this study:

1) What is the level of teacher candidates' prior experiences with the arts?

2) What are teacher candidates' levels of teaching arts self-efficacy prior to enrolling in an arts integration course?

3) Does teacher candidates' levels of arts teaching self-efficacy change as a result of participation in an arts integration course?

4) How do teacher candidates describe changes in their perceived self-efficacy experience in an arts integration course?

\section{Significance of the Study}

This study is intended to inform administrators, university/college educators, and teacher candidates on the effect of arts integration courses in the preparation of teacher candidates to teach and integrate the arts subjects. By examining teacher candidates' involvement and connection with the arts, an understanding of the role of the arts can be viewed more effectively. This study will benefit future teacher educators who are engaged in teaching the arts to early childhood and elementary schools teacher candidates by identifying the benefits of an arts integration course. 
The results of this study have added, through publication and presentations, to the greater body of literature and inform teachers, administrators, families, and teacher candidates of the effectiveness and reliability of art integration in the classroom. The results of this study could influence how pre-service teachers are educated on teaching the arts in their classrooms. In addition, this study has aided to the deficiency in mixedmethod research in the literature as it relates to self-efficacy and preparing teacher candidates to teach the arts. This study also added to the gap in literature regarding the impact of an arts integration course on teacher candidates' self-efficacy, as no other study has been conducted which looks at the overall change in self-efficacy after taking an arts integration course.

\section{Definition of Terms}

\section{Definitions of Study Variables}

In this study the variables included self-efficacy, attitudes, and perceptions. These terms have been defined as follows:

Self-efficacy refers to "beliefs in one's capabilities to organize and execute the course of action required to produce given attainments" (Bandura, 1997, p. 3).

Attitude refers to an expression of approval or disapproval towards a person, place, thing or event. It may also refer to a" person's perspective towards a specified target and a way of saying and doing things and also implies the manner, disposition, feeling, position etc. with regards to a person or thing" (attidudes., (n.d.))

In this paper, perceptions were associated with the act of perceiving through senses or an "intuitive recognition or appreciation" (perceptions, (n.d.)). 


\section{Definitions of Study Terms}

For the purpose of this study the researcher has defined the following terms:

Arts Integration. In this paper, this term has followed the definition created by The Kennedy Center's Changing Education Through the Arts (CETA) program. This term refers to students engaging in a creative process which connects an art form (theatre, music, dance, and/or visual arts) and another subject area (e.g., mathematics) and meets in-depth objectives in both." (Silverstein \& Layne, 2010).

Arts Education. This term refers to a comprehensive and sequential education in separate and distinct artistic disciplines (music, dance, theatre, visual arts).

Arts in Education. For this paper, arts in education will refer to the inclusion of arts learning in conventional education.

Aesthetic Education. This term denotes the education of perception or the act of making sense out of art (theatre, dance, music, visual arts). Aesthetic education helps students develop the ability to utilize the arts as a way of making sense of the experience.

Common Core Curriculum. This term has also been used throughout the paper as Core Curriculum or Common Core. This term has followed the definition created by the US Department of Education. The Common Core Curriculum is a set of high-quality academic standards in mathematics and English language arts/literacy (National Governors Association Center for Best Practices, 2010).

\section{Assumptions and Limitations}

Creswell (2003) defined a limitation as a potential weakness of the study. This study was limited by the current number of students who enrolled in an arts integration 
course at the onset of the study. The number of participants over one semester is not a determinate of a long-range study or a comparative grouping. In addition, an equal balance of race, ethnicity, and gender is limited by the students who chose to enroll in the course at the time of the study. Additionally, there is an assumption that respondents in this study have answered the questions accurately and truthfully.

As a student/educator in the arts, I had the realization that my relationship with the course may have held bias and the participants may have been influenced by my involvement in their survey responses and lesson plans. To minimize bias an outside individual administered the survey portion of the research. In addition, thematic coding and analysis was implemented to reduce and acknowledge researcher bias in concluding the results. In conclusion, these limitations may have limited the possibility that findings of this study may not be transferable to other contexts.

\section{Chapter Summary}

As teacher candidates matriculate through their preparation program, it is important to understand the political and economic landscape from which these individuals have come. When individuals are provided with positive arts experiences they are more willing to explore and engage with the arts in their future vocation. This study will examined the role of an arts integration course in the preparation of teacher candidates. Furthermore, the study has identified if there were changes in the teacher candidates' self-efficacy in teaching and engaging in the arts before and after taking an arts integration course. 


\section{CHAPTER II}

\section{REVIEW OF SIGNIFICANT RESEARCH}

This literature review dealt with understanding self-efficacy as applied to the development of teacher candidates, as well as the integration of arts in schools. In this chapter, I first review the literature discussing social cognitive theory and then examine aspects of self-efficacy and teacher self-efficacy. Next, research on the history of arts in education was discussed, followed by arts integration. The review then examines student achievement with arts integration, barriers to arts integration, learning environments with arts integration, followed by teacher preparation, and professional development. The last section includes arts self-efficacy in relationship to the self-efficacy of teacher candidates.

Broad searches of the literature were conducted on social cognitive theory, selfefficacy, and arts integration. Computerized academic search engines were used to locate the research. These included EBSCO; JSTOR; and ProQuest. To narrow the search, keywords were used in the search engine to streamline the results; these included: social cognitive theory, self-efficacy, arts education, teacher efficacy, arts integration, and arts in the classroom. In addition, the World Wide Web was used and searches were completed using Google, which assisted in the identification and citations of the research and locating position papers, advocacy documents, and government websites. Lastly, 
snowballing citations were also used to identify and locate pertinent research that the search engine did not identify. The following is a synthesis of these findings.

\section{Social Cognitive Theory}

In the early 1970 s many practitioners of child development and learning theory believed behavior was acquired and regulated through a cognitive process (Bandura, 1977). These beliefs stemmed from the ideas that individuals learned through three mediums: the self, the environment, and the future (Sincero, 2011). It was recognized that individuals learned about the world through observation and experience. However, there was a growing interest in the physiological changes that occurred to individuals during performance-based activities. Albert Bandura, a psychologist at Stanford University, developed and formalized a theory known as Social Cognitive Theory that addressed these physiological changes (Bandura, 1986). Social Cognitive Theory (SCT) aimed to broaden Social Learning Theory by building on the cognitive aspect of Cognitive Behavioral Theory to include aspects of observational learning and vicarious learning as it related to mental processing (Bandura, 1971).

This theory derived from a landmark study (Bandura, Ross, \& Ross, 1961) that investigated the social behaviors of children through observation and imitation. Using a Bobo doll and an assortment of other toys, children who observed adults aggressively interacting with the Bobo doll had a tendency to imitate the aggressive behavior when left to play with the toys independently. This behavioral action demonstrated that children learn social behavior through the process of "observational learning" (Bandura, Ross, \& Ross, 1961). Observational learning refers to the subconscious or conscious adoption of information and behavior by observing other individual's behaviors (Bandura, Grusec, \& 
Menlove, 1966). Individuals had a tendency to model the behavior of other individuals that they interacted with and observed. When an individual observed others they acquired knowledge of rules, skills, strategies, beliefs, and attitudes (Bandura, 1986; 1977). After the observation or receiving the information, the individual will mentally process the information and then may or may not reflect the observation or knowledge in their behavior or action (Bandura, 1986). As a result of the Bobo doll study, both positive and negative behaviors were adopted by the participants as a result of observational learning. Therefore, it was determined that observational learning affected behavior.

The notion of mentally processing the information gained through observation and choosing what or how to act is crucial to SCT. The concept of having the ability for an individual to influence one's behavior is referred to as agency (Bandura, 2006). One of the aims of SCT is that individuals become able to reflect and self-analyze (Bandura, 1971). This agency to reflect and self-analyze assists in determining individuals' actions or behavior. SCT recognizes the importance of agency that enables people to have the ability to influence their own behavior in a purposeful, goal-directed approach (Bandura, 2001). When teacher candidates matriculate through a teacher preparation program they are often encouraged to reflect and decipher events to determine their own course of action during their education (Schussler, Stooksberry, \& Bercaw, 2010). Therefore, agency "enable(s) people to play a part in their self-development, adaptation, and selfrenewal" over the course of time (Bandura, 2001, p. 2). SCT acknowledges the importance of time as it "involves not just the acquisition of new behaviors, but also of knowledge, cognitive skills, concepts, abstract rules, values, and other cognitive constructs," which may not be immediate (Denler, 2014, p. 1). 
These social and cognitive interactions are reciprocal in nature and inform each other which in-turn affect behavior. The individual's behavior, personal factors, and environmental elements influence one another to form a "triadic reciprocity" (Bandura, 2001). The triadic reciprocity allows the individual to "measure the control of their own thoughts, feelings, motivations and actions" (Bayron, 2013, p. 69). All three of these influences are intertwined and affect each other which determines an individual's action. For example, "classroom learning is shaped by factors within the academic environment, especially the reinforcements experienced by oneself and by others. At the same time, learning is affected by students' own thoughts and self-beliefs and their interpretation of the classroom context" (Denler, 2014, p. 1). SCT assists in the development and understanding of how individuals learn about their world and how they grow and create knowledge. This also includes how an individual chooses to behave through psychological processing. The elements of behavior, personal factors, and environment are explained in the following text.

\section{Behavior, Personal Factors, and Environment}

SCT identifies behavior as an individual's action through the reciprocal integration of personal factors, cognition, and the environment (Bandura, 1977; 1986). This reciprocal nature of learning is the primary influence on behavior. Behavior can therefore be described as anything that can be observed, measured, and repeated (Bicard, Bicard, \& IRISCenter, 2012). For behavior to be executed, behavior individuals must know what the behavior is and how to perform the skill (Baranowski, 1989). Regarding behavior, Bandura (1988) stated, "people have to make decisions about what courses of action to pursue and how long to continue what they have undertaken” (p. 280). 
Individuals exhibit behavior only after they have mentally processed the action and made personal judgments on when, how, and if to perform the behavior. (Bandura, 1988). An individual can then choose to act on the action which, in-turn, demonstrates the behavior.

One way in which behavior can be informed is through personal factors. These personal factors can be influenced by how an individual's ability to learn are subject to individual's intentions, beliefs, self-perception, and by observing others (Bandura, 1997). Bandura (1997) noted:

Personal factors may also influence the courses of action people choose to pursue, how much effort they put forth in given endeavors, how long they will persevere in the face of obstacles and failures, their resilience to adversity, whether their thought patterns are self-hindering or self-aiding, how much stress and depression they experience in coping with taxing environmental demands and the level of accomplishments they realize (p. 3).

Therefore, individuals' thoughts and emotions are influential factors that affect behavior. When individuals felt confident in accomplishing a task, they were able to engage in the activities with more confidence (Bandura, 1988). The same is also true when an individual feels less-confidant, anxious, or unprepared to accomplish a task. These individuals may not succeed or their accomplishments may be limited (1988).

Consequently, positive methods in dealing with stress and depression or the notion of resilience can help individuals cope with difficult tasks.

In addition, SCT suggests that an individual's behavior can be learned through observations and interactions with other individuals. Bandura believed that much of an individuals' learning occurred in social situations (Bandura, Grusec, \& Menlove, 1966). 
When an individual receives feedback or information from another, they process the information as it relates to their interpreted and demonstrated behavior (Bandura, 1971).

Behavior is also affected by the environment. Bandura $(1986 ; 1988 ; 1997 ; 2001)$ explained that SCT positions that the environment causes behavior and the behavior also causes influences in the environment. Individuals are not merely observers of their environment but active participants in their surroundings. Therefore, individuals are able to construct the results they perceive through their relationships between "environmental events in the world around them" and their actions (Bandura, 2001, p. 7). They are able to mentally process the situation and produce a positive or negative outcome.

The environment refers to the external sources that influence behavior and can be divided into three different, yet interrelated forms: imposed, selected, and created (Bandura A., 1997). An imposed environment is both the physical and social environment in which an individual is placed. Although the imposed environment is often not able to be drastically changed it can be viewed positively, neutrally, or negatively which must be selected and activated upon by the individual (Bandura, 1978). Physical work environments are often imposed environmental strains in which individuals must cope. Yet, the environment can be selected and acted upon. Bandura stated, "The environment does not come into being until it is selected and activated by appropriate action" (Bandura A., 1997, p. 163). Individuals have the option to reap the advantages of an environment or choose to accept the burden from the implications of the environment. The created environment refers to the individual's ability to "create social systems that enable them to exercise greater control over their lives" (Bandura, 1977, p. 163). These created environments enable individuals to create interpersonal and 
interrelated situations with their environments that do not otherwise exist. The relationship between the three forms of environments (imposed, selected, and created) are interrelated and affect each other. Ultimately, individuals have the agency to choose and alter their surroundings as the environment also affects the individual.

The triadic reciprocity between behavior, personal factors, and environment is a valuable foundation to understand how SCT informs teacher candidates' action through the "mental processes involved in perceiving, attending to, remembering, thinking about, and making sense of the people in our social world" (Moscowitz, 2005, p. 3). When teacher candidates are exposed to opportunities to observe, reflect, and demonstrate action related to the tasks of teaching they are able to formulate methods of understanding and behaving. Teacher candidates are informed by their classroom environments and their personal experiences observing and participating in learning and teaching. These events are coupled with their thoughts and feelings which then demonstrate an action or behavior. Together the action can be evident through an individual's self-efficacy or confidence in their teaching ability. The following section identified the components that are related to the formation of self-efficacy.

\section{Self-Efficacy}

Bandura's (1977) theoretical foundation of self-efficacy assumed that individuals are capable of human agency or the ability to act and make choices. According to Bandura (2006), individuals are "self-organizing, proactive, self-regulating, and selfreflecting" (p. 164). Humans are able to influence themselves and their life circumstances. Self-efficacy has been defined as, "the belief in one's capabilities to organize and execute the courses of action required to manage prospective 
situations" (Bandura, 1995, p. 2). When an individual is said to have a perceived selfefficacy they are able to work with "the conviction that (they) can successfully execute the behavior to produce the outcomes" (Bandura, 1977, p. 193). People are therefore active contributors to their own lives and not simply onlookers or products of their situations. When people believe that their actions can create outcomes they have an incentive to perform an action (Bandura A., 1997). Self-efficacy, therefore, drives a person's motivation and actions, and can be applied to the motivation and actions of teacher candidates.

Self-efficacy is different than the notion of self-concept or self-esteem. Selfefficacy refers to personal judgments about an individual's ability while self-concept and self-esteem are based on an individual's feelings of self-worth as they relate to the values of society (Bandura, 1986). For example, the knowledge and skills an individual possesses play a critical role in what an individual chooses to do or not do. When an individual performs a particular behavior it is interpreted as a more positive or a more negative experience by that individual. The perceived outcome can then form a foundation for an individual's skill or self-efficacy towards that desired behavior (Bandura A. , 1997). Individuals also have the capability to believe that they can either succeed or not succeed in a given action or behavior. When an individual believes they can succeed in a given task without the necessary skills they are still believed to have a higher sense of self-efficacy (1997), which is why self-efficacy is a useful concept to translate knowledge and skills into action. Self-efficacy has four main sources for development: performance accomplishments, vicarious experiences, verbal persuasion, 
and physiological states (Bandura, 1977). The following elaborated on each of these sources of self-efficacy development.

\section{Performance Accomplishments}

Performance accomplishments are events or experiences that an individual executes either positively or negatively. These sources of efficacy accomplishment may also be referred to as mastery experiences (Bandura A. , 1997). When an individual has a positive experience engaging in a task their efficacy is raised as well as their confidence in the task. The opposite is also true, when an individual has a negative experience the person's self-efficacy towards that task is lowered and a sense of failure occurs (Bandura, 1977). This source of self-efficacy is often referred to as the most beneficial or valuable attribute in developing positive self-efficacy.

When the perception of a given task or performance has been successful the individuals' future experience of the given task or performance will be successful. In turn, when an individual fails at a given task or performance it will reinforce the negative aspect of their future performance as it may be unsuccessful (Tschannen-Moran, Hoy, \& Hoy, 1998). When an individual is about to try something new they will most likely boost their sense of self-efficacy if it is a task similar to an event that they have already accomplished successfully (Bandura A. , 1997). A persons' sense of self-efficacy changes during the individuals' skill development, but their self-efficacy is ultimately enhanced when the individual sees a positive improvement in their ability over time (Bandura A. , 1997). For example, when a teacher candidate practices a skill such as writing lesson plans their skills improve resulting in a stronger sense of self-efficacy. 
Flores (2015) recognized the importance of practical experience when it comes to enhancing a teacher candidate's teaching self-efficacy. Through surveying thirty teacher candidates at a state university, she determined that general efficacy and personal science teaching efficacy increased due to hands-on teaching experiences with youth. Therefore, the positive and practical performance enhanced the teacher candidates' self-efficacy (Flores, 2015).

\section{Vicarious Experiences}

An individual can also develop high or low self-efficacy through vicarious experiences. Through observation, an individual can compare their abilities to other individuals and their self-efficacy or confidence may be raised or lowered (Bandura, 1977). The individual must decide what types of actions they adopt from viewing others perform a task and determine if it will be effective or not for their own performance (McCown, Driscoll, \& Roop, 1996). Efficacy is also determined through the relationship the individual has with another individual. The closer the relationship between the individuals the stronger impact on self-efficacy each individual will experience (Tschannen-Moran, Hoy, \& Hoy, 1998). Individuals are able to observe and model behavior that can either raise or lower their level of self-efficacy.

Schunk (1983) demonstrated that children who struggle to achieve a goal when they hold the goal at an attainable level experience a strong sense of efficacy once the goal is attained by their peers. The observation of their peers achieving the attainable goal helps to reinforce their belief that they will also be able to achieve the goal resulting in a higher level of efficacy. In turn, when a goal is unchallenging Miller (1993) found that there was a negative correlation between high self-efficacy perception and 
motivation. Individuals must be able to set goals that are attainable by others as well as themselves to develop a stronger sense of self-efficacy towards that given task.

Vicarious learning experiences have been used to increase students' self-efficacy by observing more advanced or skilled individuals perform those tasks. Through these observations, students' learning may be accelerated (Bandura, 1986; Ertmer, et al., 2003; Davies, 2009). For example, teacher candidates who observe experienced teachers positively engage with children are more likely to increase their own self-efficacy to be competent in pedagogical tasks such as engaging with children.

\section{Verbal Persuasion}

Through verbal persuasion, an individual's self-efficacy can either be improved or diminished (Bandura, 1977). Positive appraisal such as encouragement can assist in an individual's accomplishment of a task which improves their self-efficacy whereas disapproval will lower an individual's sense of efficacy when attempting a task (Bandura, 1977; Mellor, Barclay, Bulger, \& Kath, 2006). Therefore, when a student receives encouragement from parents, teachers, and peers they can boost their self-confidence which can affect academic capabilities (Usher \& Pajares, 2008). This outside encouragement benefits a developing child when they are not yet able to produce selfappraisals. Children will then benefit from other individuals through their positive appraisal (Usher \& Pajares, 2008). Individuals who receive positive appraisal often initiate a task, attempt new methods to accomplish a task, and try harder to succeed in a given task (Bandura, 1986). 


\section{Psychological States}

Lastly, psychological states may also influence an individual's sense of efficacy related to a task. A psychological state refers to an individual's bodily sensation and how they perceive an emotional arousal (Bandura, 1977). When an individual is confronted with tasks that may cause anxiety or agitation, such as presenting in-front of a group of people, an individual must cope with these uncomfortable feelings. A debilitating reaction will lower efficacy whereas a confronting reaction will raise self-efficacy that is related to the task (Bandura, 1977). Emotions affect behavior and can provide insight into the individual's abilities to accomplish or perform a given task or skill (Frenzel, Becker-Kurz, Pekrun, \& Goetz, 2015; Goddard, Hoy, \& Hoy, 2000).

Of the four influences on self-efficacy, psychological states or emotional arousal is deemed to have the least influence on self-efficacy. Bandura suggested that individuals function best when their physiological arousal is neither too high nor too low and increasing individuals' physical and emotional well-being strengthens self-efficacy (Bandura A. , 1997). Individuals' ability to change their moods can affect their selfefficacy and drive achievement. Yet, an individual's psychological state fluctuates drastically from moment-to-moment, which considerably changes an individuals' selfefficacy (Frenzel, Becker-Kurz, Pekrun, \& Goetz, 2015).

Bandura's (1977; 1997) four sources of self-efficacy including performance accomplishments, vicarious experiences, verbal persuasion, and physiological state assist in establishing the level of self-efficacy an individual possesses. The following section examines how a teachers' sense of self-efficacy affects their teaching and, in-turn, their students' achievement and their individual self-efficacy as educators. Subsequent 
sections examines the background of arts education and the efficacy of teaching the arts in the classroom.

\section{Self-Efficacy of Teachers}

A teacher's sense of self-efficacy is an important construct for practicing teachers. Tschannen-Moran and Hoy (2001) referred to teacher's self-efficacy as a "judgment of his or her capabilities to bring about desired outcomes of student engagement and learning, even among those students who may be difficult or unmotivated" (p. 783). A teacher's self-efficacy belief acknowledges that when a teacher evaluates their abilities they construct an idea of their own pedagogical self-efficacy and acknowledge change in their students' outcomes or behavior (Gibson \& Dembo, 1984). Shaughnessy (2004) also acknowledged that a teacher's sense of self-efficacy is "their perceptions about their own capabilities to foster students' learning and engagement" (Shaughnessy, 2004, p. 154). This personal acknowledgment of an individual's understanding of their teaching abilities is a factor in determining their effect on student learning. Therefore, self-efficacy, as it relates to teachers and teaching, refers to two separate constructs: personal teaching efficacy and general teaching efficacy (Gibson \& Dembo, 1984; Hoy \& Woolfork, 1990). Both of these forms reflect the notion of Bandura's self-efficacy as they refer to the individuals' belief in their own capabilities, in the form of teaching, to produce a positive outcome or course of action; in this case: teaching (Bandura, 1995).

Personal teaching efficacy refers to "teachers own feeling of confidence in regard to teaching abilities (Protheroe, 2008, p. 43). When a teacher has confidence in their pedagogical skills they present a high sense of teaching self-efficacy. Teachers' sense of personal-teaching self-efficacy may affect their beliefs, ideas, activities, and the amount 
of effort they exert in their planning and execution of instruction. According to Hoy (2000), beginning teachers with a higher sense of self-efficacy and confidence "rated the quality of their preparation higher and the difficulty of teaching lower than those who were less efficacious" (p. 6). A study conducted by Allinder (1994) sought to discover the relationship between instructionally-relevant behaviors and attitudes. A total of 437 questionnaires of a teacher efficacy scale and teacher characteristic scale were completed by teachers and was analyzed using factor analysis. The personal self-efficacy study concluded that "teachers who had greater belief in their ability to teach were also more likely to try different ways of teaching... (and were more) confident and enthusiastic about teaching" (Allinder R. , 1994, p. 92). The results were similar to an earlier study by Woolfolk and Hoy (1990) where they examined 182 prospective teachers' sense of efficacy as it related to their beliefs about control and motivation. The results determined that "those with high personal efficacy are more humanistic than those with low personal efficacy" (Woolfolk \& Hoy, 1990, p. 87). This notion is an important construct as it has identified a stronger sense of relationship and connection to teaching and education. Teachers with a low personal self-efficacy in teaching may expend less effort in the classroom (Allinder R. , 1994).

A teacher's general self-efficacy, as it relates to effort in the classroom, may affect student learning. A student's motivation and achievement is affected when the teacher's self-efficacy is either raised or lowered (Bandura, 1997; Goddard, Hoy, \& Hoy, 2000; Tschannen-Moran, Hoy, \& Hoy, 1998;). When the teacher is engaged and exhibits a high sense of self-efficacy their students are more apt to adopt a stronger sense of selfefficacy in learning and reach their goals. Gibson and Dembo (1984) acknowledged that: 
Teachers who believe student learning can be influenced by effective teaching, and who also have confidence in their own teaching abilities, should persist longer, provide a greater academic focus in the classroom, and exhibit different types of feedback than teachers who have lower expectations concerning their ability to influence student learning (p. 570).

Goddard, Hoy, and Hoy (2000) reinforced this notion through a study in an urban classroom where a group of teachers within the school exhibited a high level of teaching self-efficacy. The researchers conducted their study using multilevel analysis to determine if a collected teacher self-efficacy influenced student learning in math and reading. The results concluded that a collective teacher self-efficacy related to their students' achievement in mathematics and reading (Goddard, Hoy, \& Hoy, 2000). This study was similar to research conducted by Bandura (1993), who pioneered the notion of teachers' general self-efficacy. Bandura (1993) concluded that student achievement was positively affected by their collective positive self-efficacy among teachers. This collective sense of high self-efficacy among teachers, that reflected positive student learning, was also found in a later study by Goddard, LoGerfo, and W. Hoy (2004). Their findings concluded that a collective efficacy was a stronger predictor of student achievement than any other variable.

A teacher's sense of self-efficacy is an important factor in determining the success of a classroom teacher as well as their students. When teachers feel positively about their skills and the execution of those skills as educators their personal self-efficacy is enhanced. In addition, when a teacher possesses a high sense of self-efficacy their general self-efficacy is heightened causing students to achieve academically. The 
following section switches focus from social cognitive theory and self-efficacy to the background of the arts in education.

\section{Background of Arts in Education}

Historically, the arts have been implemented and excluded in the curriculum of school-age children in America (Heilig, Cole, \& Aguilar, 2010). The arts of music, theatre, visual arts, and dance have long been regarded as necessary and important components to the education of youth (Silverstein \& Layne, 2010). When children are exposed to the arts they are able to develop skills in sensory perception, creativity, an understanding of the social world, increase cognitive development and foster critical thinking and problem solving (Anderson, 2003; Brien, 2011; Eisner, 2002). The arts are a beneficial component to learning about the world cognitively and affectively. Theorist and practitioner Elliot Eisner was an advocate for arts education believing that arts education should contribute to the school curriculum and not for the curriculum (Aprill, 2001; Eisner, 2002). Eisner recognized two specific components of arts-based education. First, the emphasis on developing the arts discipline and second to include arts-specific education to inform individuals for various avocations (Eisner, 2002).

The first major shift that promoted the arts in the curriculum occurred around the turn of the century (Kliebard, 2004). In the 1900s, the United States embraced the arts as an opportunity for the middle class to enjoy and engage with the arts (Heilig, Cole, \& Aguilar, 2010). These opportunities were triggered by John Dewey's progressive education completed at the University of Chicago. He believed that, "arts are indeed experience, and that access to arts education opens processes of inquiry that expand a child's perception of the world and create venues for understanding and action (Heilig, 
Cole, \& Aguilar, 2010). As Dewey's child-centered education gained popularity, the arts found its way into the curriculum and were embedded in the education of children (Goldblatt, 2006).

During the Great Depression and the war years the arts began to retreat from the school curriculum (Efland, 1989). School districts tightened their budgets and streamlined their curriculum. Therefore, many arts programs went by the wayside in the schools across the country (Efland, 1989). During the 1950s, the economy was rebounding and contributions to the arts in education began to increase causing more funding for arts in education (Bauerlein \& Grantham, 2009).

The US Office of Education, in the 1960s, focused "research and curriculum projects in the visual, literary, and performing arts" (Heilig, Cole, \& Aguilar, 2010, p. 138). This attention to the arts and the education of the arts in the school setting allowed for the formation of the National Endowment for the Arts (NEA) under President Lynden Johnson (Bauerlein \& Grantham, 2009). It was during this time, Frank Hodsoll was named the head of the NEA and advocated for "sequential curricula, comprehensive testing, improved data gathering, improved teacher quality, the recruitment of outstanding teachers, and increased educational responsibility" (Heilig, Cole, \& Aguilar, 2010, p. 138). These ideas however paralleled that of the Department of Education's publication titled A Nation at Risk in 1983 (United States, 1983).

Soon after the release of A Nation at Risk the Department of Education worked with the NEA to determine the "condition of arts education in America's schools" (Learning Through the Arts, 2002, p. 5). The results determined that the arts were seen 
as extra-curricular and the role of the arts in education was not determined (Heilig, Cole, \& Aguilar, 2010). Therefore, the leaders were unable to come to an agreement on what young learners should know and be able to perform in the arts. Later during the Bush era the arts regained strength in education and became formalized in the national education goals in 1994 and were listed among the core subjects to be taught in the classrooms (Learning Through the Arts, 2002).

Then, the No Child Left Behind Act of 2001 reformed the education system in America (No Child Left Behind Act of 2001, 2002). This law aimed to "close achievement gaps between high- and low-performing students; minority and nonminority students; and disadvantaged and more advantaged students" (Sabol, 2010, p. 1). The arts were included as part of the core curriculum and were regarded as a necessary and valuable contribution to the education of young learners (Eisner, 2004). Prior to 2001, the school curriculum often included separate class periods for painting, singing, dancing, and performing, yet no formal federal law made it mandatory for the arts to be taught in the core curriculum (Gullatt, 2007).

Yet, with the No Child Left Behind Act schools have been subjected to mandated high-stakes testing in reading, writing, and mathematics to meet adequate yearly progress (AYP) (No Child Left Behind Act of 2001, 2002). By meeting AYP, schools are able to keep their federal funding and schools that do not meet AYP are put on probation and funds are restricted (Beveridge, 2010). As a result, non-tested subjects, such as the arts, have been pushed by the wayside or integrated in other subjects so that the tested subjects of mathematics, reading, and writing are emphasized to meet AYP (Beveridge, 2010). According to the Center for Education Policy, the time spent on arts classes in schools 
has decreased by nearly half from 2001-2007 (Loveley, 2007). As a result many practicing teachers today have either abandoned the arts in their classroom or have moved to integrate the arts into their core-subjects of reading, writing, and mathematics (Alter, Hays, \& O'Hara, 2009; Ashford, 2004; Davies, 2009; Heilig, Cole, \& Aguilar, 2010).

However, since the arts are still part of the No Child Left Behind Act schools as well as universities and colleges are finding new ways of integrating the arts (Heilig, Cole, \& Aguilar, 2010; Sabol, 2010). A report issued by the President's Committee on the Arts and the Humanities called for schools to reinvest in arts education to develop more creative schools (Dwyer, 2011). One way in which schools can connect with creativity in their classrooms is to integrate the arts in their classrooms. Dwyer (2011) noted, "further development of the field of arts integration will depend on initiatives undertaken by institutions of higher education (for both pre-service and in-service education)" (p. 50). Colleges and universities are looking at ways to educate their teacher candidates on arts integration (Garvis, Twigg, \& Donna, 2011; Pool, Dittrich, \& Pool, 2011).

In June 2012, North Carolina passed a bill that requires teacher preparation programs to "ensure that pre-service elementary teachers are prepared to integrate the arts across the curriculum" (Ebert, 2013, p. 1). This law, first of its kind, requires teacher preparation programs in the state of North Carolina to prepare students to integrate the arts across many subjects including reading and mathematics instruction as well as the ability to assess the students in their classrooms on the arts (Ebert, 2013). Although no research has emerged regarding the preparation of teachers on arts integration many 
schools across North Carolina have adopted models for arts integration. The next section examines arts integration and the benefits of the arts in the classroom setting.

\section{Arts Integration}

The fine arts or simply stated arts include drama/theatre, music, movement/dance, and visual arts (Eisner, 1998). The arts have been used in education in multiple manners from teaching the arts as a subject in itself to the arts being used as a tool for cross-curricular enhancement. Eisner believed students should have a basic understanding of the arts, which includes creating art and understanding the social and historical ramifications in which the art was created (Eisner, 2002). By having knowledge of these factors, individuals are able to engage in more educated discourse regarding various topics of study. Davis (1999) acknowledged the interconnectedness of the arts and its effect on student learning in an educational venue. He stated that what "the arts uniquely do is inform and synthesize all aspects of what we as humans perpetually strive to understand" (Davis, 1999, p. 27). When individuals have a basic understanding of the arts they are able to "create his or her own world view, make meaning out of and value the world views of others, and experience and appreciate the quest for understanding and expression that identifies us as human beings" (Davis, 1999, p. 27). The arts are a gateway to learning about oneself and the world.

Through the arts, children develop and learn about the world through "distinct aesthetic modalities - through their bodies, through sensual language, and through the visual" (Dimitriadis, Cole, \& Costello, 2009, p. 362). The arts allow for the interconnectedness of learning that fosters knowledge. Students use these multiple modalities to engage more fully with the classroom material and enhance their knowledge of the 
arts. This connection of the arts with classroom material is often referred to as arts integration. An Arts Education Partnership 2002 National Forum referred to arts integration as "the effort to build a set of relationships between learning in the arts and learning in the other skills and subjects of the curriculum" (Deasy, 2003, p. 2). This definition has been interpreted in different manners. Some individuals have placed emphasis on the assessment of the arts while others refer to integration as differentiated instruction or the integration of social processes rather than a specific content (Burnaford, Brown, Doherty, \& McLaughlin, 2007).

According to The Kennedy Center ArtsEdge document (2010) arts integration refers to "an approach to teaching in which students construct and demonstrate understanding through an art form. Students engage in a creative process which connects an art form and another subject area and meets evolving objectives in both" (Silverstein \& Layne, 2010, p. 1). Overall, when children are exposed to curriculum that is engaging, innovative, and constructive they develop a higher level of cognitive, affective, and social abilities (Brouillette, 2010; Furman, 2000; May, 2013). Using the arts integration model, teachers are able to infuse the arts within the other subjects to educate children about the arts as well as non-arts subjects simultaneously.

Three categories have emerged under the classification of arts integration (Burnaford, Brown, Doherty, \& McLaughlin, 2007). These categories include: arts integration as learning "through" and "with" the arts, arts integration as a curricular connections process, and arts integration as collaborative engagement (Robinson, 2013). These three categories are the primary ways in which the fine arts are integrated across the curricula. The following sections elaborate on the three subcategories of arts 
integration and the way they can be interpreted and implemented in the school environment.

\section{Through and With}

Arts integration as learning "through" and "with" the arts refers to the aspect that individuals can learn concepts and ideas through a relationship between the arts and different subject disciplines (Burton, Horowitz, \& Abeles, 2000). Research has been conducted to examine how the role of the arts affects the transfer of knowledge (Catterall, 1998; 2005; Hetland \& Winner, 2000). Catterall (2005) stated two central theoretical factors to learning through and with the arts that reinforce the transfer of knowledge and information through and with the arts. These two components are 1) "Arts learning and experiences, to varying degrees, reorganize neural pathways, or the way the brain functions" and 2) "The development and re-organization of brain function due to learning in the arts may impact how and how well the brain processes other tasks" (p. 7). These theories help articulate the transferable ability the arts have on learning at the "neuronal level" and the continued need for more neuroscientific evidence (Catterall, 2005, p. 7).

Several studies have been implemented that demonstrate neural connections to learning in the arts (D'Esposito, 2008; Dietrich, 2004; Schlegel, et al., 2015). One study in particular conducted by Posner, Rothbart, Sheese, and Kieras (2008) justified the neural pathways that are said to exist when individuals learn through and with the arts. Their study consisted of testing the motivation of youth who performed computerized exercises of conflict resolution with praise and rewards against a control group. The researchers used electroencephalograms (EEGs) to collect and record electrical activity in 
the brain. The results indicated that the neuronal network was altered and intelligence test scores were higher than the control group when attention training was implemented. They concluded that "arts training could work through the training of attention to improve cognition for those with an interest and ability in the arts" (Posner, Rothbart, Sheese, \& Kieras, 2008, p. 2). This study demonstrated Catterall's (2005) notion that neural pathways reorganize to improve brain function. He also offered the belief that "transfer from learning in the arts to other domains may emerge as comprehension of the impact of arts-related neurological development on individual abilities to accomplish non-arts tasks" (Catterall, 2005, p. 6).

Restructuring of neural pathways with and through arts integration allows for transferable knowledge. Spelke (2008) examined the connection between music and mathematics with three experiments. Each experiment included six tests for young people to assess their capabilities in mathematics as well as to connect "pairs of systems" to one another (Spelke, 2008, p. 18). Participants had varying levels of musical training and were compared to one another within the tests. The results of the study concluded that individuals with intensive music training had better core mathematical skills in geometry and they outperformed students with less training in mathematics. This study demonstrated that there is a connection between the arts and the ability to cognitively perform other tasks. Further research on neural studies as it relates to cognitive neural pathways, as well as relational brain-functioning, are explained more in-depth later in the review of literature under student learning. 


\section{Arts Integration in Content Areas}

Arts integration as a curricular connections process calls on the notion of connecting certain elements of curriculum across content areas. This process is different than "through" and "with" the arts as it allows for curricular design implementation where individuals can learn the arts and non-arts material simultaneously rather than the notion of transfer of information which is connected to learning "through" and "with" the arts (Burnaford, Brown, Doherty, \& McLaughlin, 2007). Arts integration, as a curricular connection, is evident when there are clear objectives and goals in place for both the arts and non-arts subjects and students are able to meet objectives and goals of both areas of study (Collins \& Chandler, 1993; Ruppert, 2006). Gullatt (2007) suggested that using the arts as an entry point to academic disciplines will allow for a "stronger" connection to the material.

Baker (2013) used field ethnographic description and passive observation to "identify behavioral correlates of cognitive and intellectual functioning as well as to capture how state standards are integrated within arts-based instruction” (p. 1). Her observation of instructional discourse between teachers and students lasted for threemonths after which she concluded that there was an effect on student learning when the arts were taught in thematic-driven and project-based learning. The analysis revealed that "through arts integration, hierarchical implementation of instructional objectives including use of context and culture can be incorporated across instructional units to promote cognitive variables related to intellectual development” (Baker, 2013, p. 14). Therefore, the arts and non-arts subjects can be taught and yield a beneficial learning opportunity. Grument (2004) also remarked on the benefit the arts can play in learning. 
She noted that "the arts, and the interest immediacy, and feeling that accompany them, are extended throughout the curriculum" (Grumet, 2004, p. 49).

The arts provide learners an opportunity to look deeper into the material being presented by asking questions about complex ideas relating to human ideals and the world. The arts can enhance the classroom curriculum by connecting core curriculum learning content with the arts to demonstrate understanding of the lesson and arts material (Aprill, 2001; Collins \& Chandler, 1993; Dimitriadis, Cole, \& Costello, 2009; Stuht \& Gates, 2007).

\section{Collaboration}

The third technique, arts integration as collaborative engagement, reinforces the idea that the arts are a cooperative process. Booth (2003) recognized the importance of a teaching artist or artist-in-residence to assist in arts education. He defined a teaching artist as "a practicing professional artist with the complementary skills and sensibilities of an educator, who engages people in learning experiences in, through and about the arts" (Booth, 2003, p. 11). An individual who is professionally trained can offer grounded content in the arts and represent the community-at-large. When schools collaborate with teaching artists and work collaboratively with the arts students will be able to "claim ownership of the newly processed information in addition to becoming a tool for application for the new knowledge to other areas" (Gullatt, Research Links the Arts with Student Academic Gains, 2007, p. 18). Other research has recognized the importance of parents and the community in planning and implementing arts integration (Alter, Hays, \& O'Hara, 2009; Davis, 1999). Integrating the arts in a collaborative engagement allows for 
teachers the opportunity to engage with artists and the community that they might not otherwise be able to do in their curriculum.

Catterall (1999) concluded that the classroom environment is more conducive to learning when the arts are included by recognizing a positive change in school climate from his school community surveys. He stated "climate includes qualities such as principal leadership, focus on instruction, positive colleagueship, and widespread participation in important decisions (Catterall, 1999, p. 52). The learning atmosphere fosters a more positive and enjoyable environment. Stevenson and Deasy (2005) supported this claim in their case-study. The researchers noted that the learning environment was transformed when schools integrated the arts into their curricula. The classroom environment became more student-centered and provided a more productive environment to foster academic, social, and personal development for students (Stevenson \& Deasy, 2005). Students demonstrated more responsibility and a sense of creative freedom from the mundane (2005).

Whether the arts are taught independently, cohesively in the curriculum, or infused in other subjects, the arts offer opportunities for learning and interaction. Through various definitions and processes of arts integration, it is clear the arts offer students an opportunity to enrich their lives and assist in their education (Americans for the Arts, 2014). The following section examines student achievement with the various forms of arts integration. Specifically, evidence provided on the use of the arts in education to increase intelligence and learning as well as the benefits the arts provide with at-risk youth. 


\section{Student Achievement with Arts Integration}

Elliot Eisner (1974) called for a renewed evaluation of arts programming in schools. Since that time, numerous landmark studies have been conducted to determine the cognitive growth and the effects of the arts on learning. Deasy (2002) compiled these studies in a paper that summarized over 60 studies that addressed the arts and learning achievement. This collection addressed a range of skills gained from the arts to the success of cognitive growth to involvement in social development (Keinanen, Hetland, \& Winner, 2000; Podlozny, 2000). From these studies, Catterall (2002) drew a direct connection between the arts and critical thinking, problem-solving, spatial reasoning, and empathy. Stevenson (2006) concluded that these studies need to "explore more deeply the nature of work in the arts and the contexts and conditions that the arts offer for learning to shed more light on how and why students are engaged in and develop cognitively and socially in the arts" (p. 3). Therefore, a stronger connection to cognitive learning is necessary for further understanding of the impact of the arts and learning.

Melnick, Witmer, and Strickland (2011) found that "most thought occurs at a level well below conscious control and awareness and involves a continual stream of sensory information" (p. 155). The sensory information triggers the cognitive brain and assists the processing of information. This processing of information is referred to as a process of transfer. Transfer of learning occurs when "learning in one context or with one set of materials impacts on performance in another context or with other related materials" (Perkins, 1992, p. 1). The arts offer a link between the emotional and personal connections to cognitive growth (Gullatt, Research Links the Arts with Student Academic Gains, 2007). Catterall (2005) called upon the notion of transfer as a process for 
individuals to develop skills and cultivate learning using the arts and in more than one content area such as literacy or mathematics. He stated, "At the level of neurofuction, learning experiences unequivocally impact future learning experiences" (Catterall, 2002, p. 163). When individuals are engaged in the arts they vicariously improve their ability to progress in other subject material (Catterall, 2002). This suggests that when youth participate in arts activities they are subconsciously exposed to learning about subject matter and social interactions of which they may not have otherwise been exposed.

A collection of studies have been completed and compiled by leading neuroscientists from seven renowned U.S. universities to support the cognitive link of the arts and learning (Asbury \& Rich, 2008). This collective study examined the question "Are smart people drawn to the arts or does arts training make people smarter?" The researchers used brain imaging studies and behavioral assessment to ascertain that there is a "tight correlation" between engaging in the arts and improved skills in cognition and attention for learning (Asbury \& Rich, 2008). In addition, these studies also identified participants' improvement in their memory, their ability to manipulate information, attention to spatial awareness, an increased level of aesthetics, and a more positive temperament (Asbury \& Rich, 2008). These studies have scientifically proven through brain image analysis that information processing occurs in different parts of the brain and engaging in the various art forms allows for mental connections between different components of the brain that otherwise would not be made without engaging in the arts (Asbury \& Rich, 2008). 
Sousa (2006) acclaimed that there are improved abilities of cognition in children who engage with the arts. He determined that arts instruction has an impact on cognitive, social, and emotional development. He also noted that students who engage with the arts benefit from more opportunities than those students who do not have arts programming (Sousa, 2006). For example, Melnick, Witmer, and Strickland (2011) also found in their research that students" "involvement in the arts has a positive relationship with higher student achievement at some level...(and)...when arts programs are eliminated altogether, achievement scores tend to decrease (p. 161). Their research demonstrated a direct correlation to the arts, opportunity, and learning by examining test scores and the level of engagement in the arts.

Test scores have also improved in major cities that have increased efforts to integrate the arts. In 1992 the Chicago Arts Partnerships in Education (CAPE) was formed in the Chicago Public Schools. This program supplied funding for the arts in the Chicago schools. In a landmark study conducted by Catterall (1999) he examined the impact of having the arts in the Chicago Public schools. In this study, he looked at a variety of in-school and out-of-school arts education programs to determine their effects on student learning. He concluded that there was a strong case in the results of scores in reading and math with students who engage with the arts. There was a fundamental increase in the test scores of the children engaged in the arts over a six-year period (Catterall, 1999). Adomat (2012) agreed that there is an improvement in student learning when youth are engaged in the arts. She conducted a study in children identified as needing reading support. She used drama to increase understanding and comprehension of text through visual representation of key elements within a story. Students showed 
significant improvements in all measures of reading and writing and $80 \%$ were released from intervention by year's end (Adomat, 2012).

In Dallas, Texas students are immersed in the arts in the public schools and it has been determined that student achievement has improved as a direct correlation of integrating the arts (Reardon, 2005). The school has worked with local artists, administrators, and the city government to infuse the arts into the classroom since 1998. Students who have engaged with the arts in the school program in Dallas have demonstrated an average increase of 10 points on the statewide reading test between third and fourth graded compared to a three point increase in a control group (Reardon, 2005). The Arts Education Partnership (2006) reported that there were benefits founded in a three-year study of elementary, middle and high schools. These benefits included higher standardized test scores as well as increased motivation, improved behavior and school attendance. In a global view, Gouzouasis, Guhn, and Kishor (2007) examined data from British high school students in three British Columbian cohorts and found a positive correlation between achievement in music courses and achievement in the core academic subjects. This has demonstrated that the benefits of arts education transcend a domestic conversation.

Children who are considered at-risk have also shown an increase in academic achievement by engaging in the arts. A study conducted by DeMoss and Morris (2002), looked at eight schools along with the 19 CAPE schools, in the Chicago Public School system, which offered arts integration curriculum in their classrooms. The schools ranged in diversity from magnet schools to under-served social and economic schools, 
however, all but one school "enrolled a lower percentage of students who qualified for free and reduced-price lunches than the city side average" (DeMoss \& Morris, 2002, p. 6). Students from lower-income environments have demonstrated less motivation and less demanding higher order reason and responses in their academic progress (DarlingHammond \& Bransford, 2005). The results of the study through qualitative analysis of pre- and post-writing samples determined that the students who engaged in the arts demonstrated a stronger analytical approach to the subject matter (DeMoss \& Morris, 2002). Students were able to go "beyond the practical, moving into realms that could affect their actions and values in positive ways" (DeMoss \& Morris, 2002, p. 10).

Brown, Benedtt, and Armistad (2010) reinforced DeMoss and Morris' notion of the benefits of arts on learning with at-risk youth by conducting a research study using a quasi-experimental design to determine school readiness. Two preschools were targeted which taught children at-risk, one infusing the arts and the other using traditional teaching methods. The results demonstrated that the children who received arts instruction were better prepared in the areas of receptive vocabulary and language development for public school entry then those students who did not receive arts instruction (Brown, Benedett, \& Armistad, 2010). When teachers help children develop understanding for the material their students are able to learn more effectively and demonstrate a stronger connection to the subject matter (Darling-Hammond \& Bransford, 2005). If children do not connect to the material they have a difficult time relating to that material. At-risk youth benefit from finding understanding and meaning by engaging in the arts. A report on the Power of Art articulated the effectiveness the arts have as intervention strategies for children at-risk (Anderson, Walch, \& Becker, 2004). Youth 
are able to demonstrate ideas more effectively, reflect on current states-of-being, and formulate techniques to solve problems by engaging in the arts (Anderson, Walch, \& Becker, 2004). Often times the arts can assist students who do not connect with the "formal" curriculum (Dimitriadis, Cole, \& Costello, 2009). Through the arts children develop and learn about the world through "distinct aesthetic modalities - through their bodies, through sensual language, and through the visual" (Dimitriadis, Cole, \& Costello, 2009, p. 362). The arts allow for the inter-connectedness of learning, fostering knowledge. Students use these multiple modalities to engage more fully with the classroom material and enhance their knowledge of the arts. The classroom environment is changed by this notion with students more readily attentive to learn (Dimitriadis, Cole, \& Costello, 2009; Stevenson \& Deasy, 2005). Such studies have provide evidence that the arts can benefit the most vulnerable populations of students.

This section concluded that when youth are exposed to arts-rich experiences their attention and dedication to learning increases. Test scores have been found to increase as well as a stronger connection and purpose towards education and learning. Yet, the implementation of the arts into schools comes against several barriers. The next section will examine the barriers to arts integration including the political landscape, school testing, the crowded curriculum, and monetary assistance.

\section{Barriers to Arts Integration}

The political landscape has instituted challenges and hurdles for the arts in education. These challenges and hurdles have long been part of the history of arts education in America, yet in 2001, the No Child Left Behind Act (NCLB) went into 
effect which reformed the Elementary and Secondary Education Act (ESEA) of 1965. With the implementation of this new law, the arts became included as a subject area where all children are to benefit from a well-rounded rigorous arts curriculum (Sabol, 2010). The act aimed to "close achievement gaps between high- and low-performing students; minority and non-minority students; and disadvantaged and more advantaged students" (Sabol, 2010, p. 1). This provided an opportunity for the arts to be seen as a credible, valuable subject matter for young learners as it would allow access to the arts for all children regardless of class or identity.

Schools across the country began to reform their classroom curriculums to meet NCLB; however, the schools needed to address adequate yearly progress (AYP) in which federal funding is allocated to schools. AYP is based on reading, writing, and mathematics skills and does not include the arts (Editorial Projects in Education Research Center, 2011). In addition, competitive grants through the Race to the Top program through the US Department of Education rewarded states that adopted the policies and measures of Common Core (Onosko, 2011). Schools are required to test their students on these three content areas. Schools that do not meet AYP are placed on probation and funding is restricted (Ashford, 2004; Beveridge, 2010). These changes have caused schools to reevaluate their priorities to meet AYP. As a result, non-tested subjects, such as the arts, have been pushed by the wayside or integrated in other subjects (Beveridge, 2010). In a report issued by the Department of Education in 2012 theatre and dance as course offerings went from 20 percent of schools in America making these art forms available in 2000 to only three percent in 2010 (Parsad \& Spiegelman, 2012). Also, more 
than 40 percent of secondary schools in America did not require coursework in the arts as a requirement for graduation (Parsad \& Spiegelman, 2012).

According to the Center on Education Policy, "school time spent in arts classes has decreased by nearly half since NCLB was passed in 2001" (Lovley, 2007, p. 1). This overpowering swing created by NCLB has reduced the arts in the classroom curriculum (Parsad \& Spiegelman, 2012). As schools are forced to achieve AYP the arts have been placed on the backburner (Beveridge, 2010). According to the report by Illinois Creates schools have demonstrated a decline in arts education (Arts Alliance Illinois, 2009). The report indicates a third of the schools in Illinois are without any arts education in their schools (Arts Alliance Illinois, 2009). In addition, Parsad and Spiegelman (2012) identified an "equity gap" when it came to the availability of arts instruction in lower socio-economic schools compared to more affluent schools. These individuals are graduating from high schools without exposure or any knowledge of the arts and the possibilities to create art through music, drama, visual arts, or dance/movement. As students begin to graduate high school and enter teacher preparation programs and the work force, many have experienced fewer quality arts experiences in their elementary and secondary education resulting in less arts informed students (Heilig, Cole, \& Aguilar, 2010).

The current crowded public school curriculum puts teachers in a situation where the arts need to be addressed alongside the demands of other learning areas (Dimitriadis, Cole, \& Costello, 2009; Lemon \& Garvis, 2013; Lummis, Morris, \& Paolino, 2014). Teachers must balance the curriculum while finding different and unique ways to integrate and merge the content areas. Alter, Hays, and O'Hara (2009) determined that 
there is a growing gap between "...the expectations of the current curriculum frameworks and the preparation in arts areas that can be provided by initial teacher education courses, particularly at primary school levels" (p. 29). In a report issued by the Farkas Duffett Research Group, 1001 third to twelfth-grade public school teachers were asked to complete a survey on teacher behavior and classroom practice (Common Core, 2012). Particularly, the survey asked how teachers were spending class time, how state testing affected what they did, and what subjects got more attention and which received less. Of those teachers surveyed $81 \%$ reported that "other subjects were getting crowded out by more attention being focused on math and language arts" (Common Core, 2012, p. 1). The report confirmed that students' time for the arts has steadily declined over the past decade. Bornfreund (2013) reinforced the notion of the issue of a crowded curriculum by acknowledging the pressing needs of a complete curriculum that is able to address a multitude of subjects including the arts for a well-balanced education. One teacher remarked, "students are taken out of their elective classes like music, art...so they can take an extra class in reading (Common Core, 2012, p. 4). Teachers are often placed in difficult situations where they must choose what to teach to address student learning.

In addition to choosing what to teach in a crowded curriculum, monetary allocations have declined, teaching positions are being cut, and "teachers of the arts continue to graduate from teacher preparation programs without much prospect for a teaching position in a school" (Lovley, 2007, p. 1). Federal funding for the arts have remained steady at $\$ 146$ million since 2012 (Americans for the Arts, 2014). Yet, funding for arts in education has been capped at 25 million through the Department of Education's Arts in Education program (Issue Brief, 2014). 
With a limited budget, many schools have had to abandon the arts completely from the curriculum even though it is a core curricular subject (Ashford, 2004). Dallas, TX's Arts Partners program acknowledged the fact that the arts need budgetary allotments (Reardon, 2005). The cost necessary to sustain a quality arts program would require the school districts to absorb a third of the cost (Reardon, 2005). In Alabama the top two obstacles, identified by principals, for integrating the arts during the 2012-2013 school year were budget constraints and insufficient personnel (South Arts, 2013). In Chicago, public schools are looking for private donors to pledge monies to support the arts to assist their "cash-strapped" school system without burdening the government (Perez, 2014).

In addition to the tight school budgets, districts who do not meet AYP are placed on probationary status and then if their new goals are not met they risk losing federal funding (Beveridge, 2010). During the probationary period the schools must find funding to raise the scores of their students which, in-turn, affects the non-tested subjects and their importance in meeting AYP (Beveridge, 2010; Chapman, 2004). Many schools have moved to folding the arts into tested subjects such as reading and writing, therefore eliminating arts time-specific education (Beveridge, 2010). When the arts are eliminated from the curriculum students' access to arts-rich learning is diminished.

This section revealed how the arts in education face an uphill battle when it comes to the overwhelming constraints of the political landscape. Youth are pressured to perform well on tested subjects such as math, reading, and writing. Teachers are forced to choose between arts experiences and curricular demands. In addition, the crowded curriculum and monetary allotments have further created barriers for the arts in 
education. The following segment compares and contrasts models of arts training for the non-art classroom teacher as well as looks at how schools are engaging in professional development with their current practicing teachers.

\section{Teacher Preparation and Professional Development}

In order for teachers to effectively use the arts in their classroom they must obtain the knowledge and enthusiasm to engage with the arts in their curriculum. Research has told us that the arts are a valuable tool in the classroom space and assist in the education of students across subjects (Melnick, Witmer, \& Strickland, 2011; Stevenson, 2006; Stevenson \& Deasy, 2005). Yet the teaching of the arts is often undertaken by "generalist trained teachers" and the training of teachers in the arts is often overlooked or under-investigated (Garvis \& Pendergast, 2010). A study conducted by Russell-Bowie and Dowson (2005) surveyed 936 generalist primary teachers across five countries. They found that most "had very little formal background in any of the art forms" (p.7) and that "preservice teachers' background in the creative arts predicts confidence in teaching the creative arts" (p. 9). This finding has suggested that a positive background in the arts affects a teacher candidates' involvement in teaching and using the arts in their future classroom; whereas a negative experience in the arts produces a poor confidence in engaging in the arts.

Limited current research is available on the process of how teacher candidates are trained in arts integration yet the need for arts-minded teachers is paramount in our schools (Eisner, 2004). Garvis (2012) indicated that when teacher candidates are engaged in a supportive environment to investigate and explore the arts as a means to communicate concepts and ideas, teacher candidates find themselves with more 
confidence in teaching the arts. A study conducted by Donahue and Stuart analyzed the implications for preparing teachers to integrate the arts in a cross-curricular manner (2008). When teacher candidates are trained to implement the arts in their teaching they develop the skills necessary to balance a curriculum and find the "relationship between certain, efficient covering of content enshrined in standards and uncertain, messy learning characteristic of uncovering new understanding of the world (Donahue \& Stuart, 2008, p. 353). Teacher candidates are therefore empowered to embrace a connected curriculum.

Pool et al. (2011) believed that the primary goal of a teacher preparation program is "to help pre-service teachers develop pedagogical theory-based tools designed to assist student learning" (p. 1). The arts have the potential to influence teaching practices and student teaching (Gadsden, 2008). The Artful Learning model of arts integration informs participants to address a four-phase learning sequence: experience, inquire, create, and reflect (Artful Learning Inc., 2008). The model is set up for teachers and students to share in the roles of artist, teacher, and scholar to work in an interdisciplinary manner to explore masterworks of art, ask questions, and reflect (Pool, Dittrich, \& Pool, 2011). A report issued in 2009 by the National Center for Research on Evaluation, Standards, and Student Testing and the Center for the Study of Evaluation determined that the program was a useful tool for teachers with a "variety of teaching experience, district and state contextual demands, grade/content areas taught, and student populations" (Griffin \& Miyoshi, 2009, p. 1). However, the assessment methods needed additional support to be viable for the teachers to use in their classrooms (Griffin \& Miyoshi, 2009). 
Pool et al. (2011) used an arts-based hands-on approach based on the Artful Learning model to prepare future teachers in arts integration. The goal of the Artful Learning model is that it prepares teachers and students to work through concept-based approaches and interdisciplinary connections with "teaching and learning centered on the exploration of masterworks, the asking of essential questions, rigorous scholarship, active creation, and deep reflection" (Pool, Dittrich, \& Pool, 2011, p. 2). The 35 participants were enrolled in an educational psychology course at Gettysburg College where the Artful Learning model was implemented. The participants wrote a lesson plan and participated in six reflective writing prompts to discover their understanding of arts-based curriculum and its value on student learning (Pool et al, 2011). The results of this model concluded that the pre-service teachers were engaged and motivated to learn the material and benefited from engaging in the lesson through the four-phase sequence: "experience, inquire, create, and reflect" (Pool et al, 2011, p. 2). The data from this study provided "preliminary evidence to show that using arts-based instruction in a preservice teacher program has promise for fostering better pedagogical decisions to benefit learners at every level" (Pool et al, 2011, p. 9). When teacher candidates are presented with quality arts-based lessons they are able to see the benefits and value the arts can have on student learning.

Elliot Eisner advocated for arts education. He believed that arts education should contribute to the school curriculum (Aprill, 2001; Eisner, 2002). He believed students should have a basic understanding of the arts, which included creating art and understanding the social and historical ramifications in which the art was created (Eisner, 2002). By having knowledge of these factors, individuals would be able to engage in 
more educated discourse regarding various topics of study. One model that encouraged the teaching of the arts by an artist was the Creative Partnerships Program in England from 2002-2011 (Creative Partnerships). This program brought together artists and schools to work collaboratively in implementing arts lessons. Higher Education, the Arts, and Schools (HEARTS) was a model and research project that was implemented based on the Creative Partnership Program to bring together developing teachers and practicing artists in the community (Davies, 2009). This model is an example of how access to artists and the arts can guide practice and enhances competencies in the arts by connecting teachers to their communities.

HEARTS research project sought to identify and codify the value of connecting the arts into the core literature, science, and mathematics curriculum. Davies (2009) noted the program was "...a model of teacher education in which beginning teachers are immersed in an integrated arts experience, working as apprentices alongside more experienced educators and artists, towards becoming a creative planner, effective practitioner, and critical thinker" (p. 631). The study consisted of both qualitative interviews with 58 individuals and quantitative methods with 189 non-arts students completing a pre- and post-survey on arts engagements. The results were analyzed using coding and statistical analyses which demonstrated that teacher candidates' direct experiences, with the arts, enhance and shift the attitudes towards teacher candidates' personal and positive creativity and confidence in the arts (Davies, 2009). Eisner acknowledged the reciprocity and value of the arts as a benefit to all vocations. He stated, "the experience the arts makes possible is not restricted to what we call the fine arts" 
(Eisner, 2005, p. 212). Therefore, a foundation in the arts provides students a new way of thinking which can be beneficial in various curricular areas.

When educators are exposed to quality professional development they acquire the skills and confidence necessary to use the arts in their classrooms. Tschannen-Moran and Hoy (2001) remarked that when teachers are immersed in professional development an awareness of developing self-efficacy will not only help the teacher but improve student learning. The Arts for Academic Achievement (AAA) program in Minneapolis Public Schools demonstrated the value of professional development through arts-partnerships. This program brought together teachers and artists to implement arts-rich curriculum to teach the arts and non-arts subjects. The study included 31 schools during the first year and expanded to 45 schools by the third year. Data was "collected over a three year period through individual teacher interviews, group interviews, observations of classroom instruction and project meetings, and schools' annual reports on their AAA project" (Ingram \& Seashore, 2003, p. 2). Ingram and Seashore (2003) concluded that after teachers engaged in professional development on arts integration through the Arts for Academic Achievement (AAA) program their perceptions of their students' capacities changed. Instruction became more child-focused, instructional strategies were expanded and perceptions about student capacity were expanded (Ingram \& Seashore, 2003). AAA's model was similar to the Creative Partnership program where teachers and artists collaboratively developed instruction that integrated arts and non-arts subjects to positively affect the non-arts discipline and student achievement. 
In contrast to the collaborative community AAA model the Visual Thinking Strategies (VTS) is another model for arts integration (Visual Thinking Strategies, 2014). VTS is an arts method that is initiated and facilitated by the classroom teacher in which students analyze and discuss visual images. Students engage in discourse and problemsolving to engage in the world of the image by examining the questions: What is going on in the picture? What do you see that makes you say that? and What more can we find? (Visual Thinking Strategies, 2014). VTS has been used in schools across the country and in many museums since 1991 for its user-friendly model and engaging responses (Goff \& Ludwig, 2013). One analysis of the VTS model studied 25 experimental and 25 control students in San Antonio Independent School District (SAISD) (DeSantis \& Housen, 2007). The study followed students for three years in grades one through three. The researchers analyzed interviews, questionnaires, museum biographies, material object interviews, and writing samples from both the experimental and the control groups. The results determined a significant change from the experimental group to the control group. The experimental group "transferred critical thinking skills, such as supported observations and speculations, fostered by VTS discussions about art to their individual art-viewing experiences—independent of the group or a teacher. They also transferred critical thinking skills fostered by VTS discussions about art to individual viewing experiences of non-art objects" (DeSantis \& Housen, 2007, p. 6).

The results of the SAISD study were similar to the results found by Curva, et al. (2005). Using pre- and post-assessments researchers used norm-referenced and criterionreferenced tests to measure academic outcomes, and surveys to measure psychosocial development. The results concluded a strong correlation between participants' growth in 
visual literacy and in academic achievement which also led to a stronger development of critical thinking skills (Curva, et al., 2005).

Approaches to arts integration training for pre-service teachers and professional development are diverse and broad. This section articulated the importance of arts education for pre-service teachers and four successful yet different models of artsintegration as well as studies that support their validity. With the inclusion of the arts, teachers have the ability to connect children with subject matter and allow students to become more engaged in learning about their world and the various perspectives that exist (Melnick, Witmer, \& Strickland, 2011).

\section{Arts Efficacy}

For teacher candidates to engage with the arts fully they must develop a sense of self-efficacy related to teaching and implementing the fine arts. Bandura regarded selfefficacy as how an individual feels, thinks, motivates themselves, and behaves (Bandura A., 1997). Therefore, "the higher the sense of self-efficacy, the greater the perseverance and the higher the chance that the pursued activity will be performed successfully" (Garvis, 2009, p. 24). When teacher candidates are confident in their knowledge and execution of the arts they are able to execute effective curriculum once they become a practicing teacher. A high self-efficacy is associated with a mastery of skills and knowledge of the subject (Bandura, 2001). A teacher's self-efficacy in the arts is similar. Once the teacher or teacher candidate garners the skills and knowledge associated with the arts they are able to execute behavior that demonstrates effective and successful arts curriculum. When education and learning experiences in the arts are apparent and 
available to teacher candidates and practicing teachers they develop a stronger sense of self- efficacy in teaching and using the arts in their classroom (Garvis \& Pendergast, 2010; Lemon \& Garvis, 2013; Davies, 2009).

Lummis, Morris and Paolino (2014) designed a mixed methods study with education majors in their first and fourth year of university to discover how prepared the students were to teach the arts. They wanted to know if their teacher candidates' sense of self-efficacy in teaching the arts was affected by their exposure to the arts. The study included 133 individuals who participated in the survey portion and nine individuals in the interview portion. The researchers used a constructivist theoretical framework to determine their results. Ultimately, individuals who had less exposure to the arts in their classwork had a lower sense of self-efficacy in teaching the arts while individuals who had more experiences and more positive involvement in the arts were shown to have a higher level of self-efficacy (Lummis, Morris, \& Paolino, 2014). The questionnaire also determined that "the fourth-year students did not feel prepared to teach dance, drama and media arts in primary schools...(which) could mean these graduate teachers spend less time teaching these disciplines to primary school children and may perpetuate a cycle of limited school-based arts experiences" (Lummis, Morris, \& Paolino, 2014, p. 61). This lack of education, time devoted to the arts, and other demands coupled with positive experiences in the arts disciplines deters teachers from implementing the arts in their classroom environment.

Often times teacher candidates and practicing educators do not have or have limited formal education when it comes to the arts in education; however they are 
encouraged to use the arts in their teaching (Eisner, 1988; Brien, 2011). Oreck (2004) stated,

The inner resources of teachers; their attitudes toward art, creativity, and innovation; their commitment to personal growth; and their educational and life values all need nurturing within the school and in professional development ( $\mathrm{p}$. 67)

When teachers have access to the pedagogy of integrating the arts in their classrooms they are able to develop a higher sense of self-efficacy when it comes to teaching and implementing the arts. In addition, training and professional development in the arts would assist teachers in the "opportunity to improve their knowledge and skills... as well as develop a valuable range of teaching resources" (Alter, Hays, \& O'Hara, 2009, p. 28). Through exposure and education, teachers and teacher candidates become more comfortable in integrating the arts. Oreck (2004) noted that when teachers are interested in engaging with the arts in the classroom their own enjoyment in teaching increases. This therefore increases their overall sense of teacher self-efficacy.

When teachers are not exposed to the arts or have limited access to arts education they often feel a "lack of confidence, motivation, and knowledge...in delivering arts education" (Garvis, 2009, p. 23). Studies have shown that teachers' personal selfefficacy in general teaching increases in their teacher preparation programs, but decreases as they begin teaching and throughout their teaching careers (Hoy \& Woolfolk, 1990; Tschannen-Moran \& Hoy, 2001). This notion is congruent with Alter, Hays, and O'Hara's research that identified that teachers lack the confidence for teaching the arts as 
practicing teachers (2009). They stated that, "teachers tended to avoid speaking about areas within the creative arts where they believed they did not have adequate skills and knowledge" (Alter, Hays, \& O'Hara, 2009, p. 26). Teachers' perceptions of their own artistic abilities affected their confidence and willingness to explore the arts with their students in the classroom.

Researcher Garvis (2012) recognized that those teacher candidates who exhibited poor levels of confidence, when it came to participating in the arts, was based on their prior experience engaging with the arts. She determined that many of the students recalled negative experiences toward the arts in their primary and secondary schooling. Students were told that they "could not sing well" (p. 301) or were limited to opportunities to engage with the arts (Garvis, 2012). To address the poor confidence of the teacher candidates, Garvis, redesigned her course to allow for "pre-service teachers to work through their negative beliefs and realize the importance of the arts and that anyone could engage with the arts" (2012, p. 301). Once her students could see that they were able to participate in the arts with positive results they were then open to address more content on the subjects of the arts and how to use the arts in their future classrooms.

Garvis and Pendergast (2010) acknowledged that there is limited research that "investigates the relationship between past experiences and the efficacy of generalist arts teachers" (p. 30). Their study looked at 201 beginning teachers' experiences and selfefficacy as it related to their individual background in the arts. The results concluded that many of the participants found positive influences in the arts during childhood however as they reached their teenage years they encountered "teacher criticism, negative school 
culture towards the arts and competing subjects" (Garvis \& Pendergast, 2010, p. 38). Pajares (1992) referred to Nespor (1987) by stating that "beliefs have stronger affective and evaluative components than knowledge and that affect typically operates independently of the cognition associated with knowledge" (p. 309). Therefore, prior experiences affect the disposition and confidence of engaging and participating in future tasks (Bandura, 2006).

Many teachers who perceived poor self-efficacy, in the arts, limited or ignored the arts in their classroom (Garvis \& Pendergast, 2010; Lemon \& Garvis, 2013). This attitude towards the arts, limits the potential that teacher candidates will use and engage with the arts in their future classrooms with young children. Ashworth (2012) conducted a study in which she interviewed 19 elementary school teachers and observed their classroom environments. Through purposeful reading and topic coding, she noted that teachers who are not confident in the arts often engaged in art projects that were more holiday craftbased and did not involve in-depth arts experiences (2012). Teacher candidates are often fearful of teaching and using the arts as they perceive themselves as being less talented or non-artistic (Ashworth, 2012; Davies, 2009; Oreck, 2004). This "type of art instruction trivializes arts and gives the perception that they are second-rate additions which can be eliminated quickly with no real damage to the remainder of the curriculum" (Gullatt, 2007, p. 216). Therefore it is important to identify the teacher candidates' self-efficacy as it relates to the implementation of the arts. When teacher candidates have a strong sense of self-efficacy in teaching they are more likely to try new approaches and attempt to engage students who may be perceived to have a lower self-efficacy in learning (Hoy \& Woolfolk, 1990). Teachers who employ the arts are more likely to develop and 
encompass lessons that are enjoyable to be involved with thus sparking an intrinsic motivation for individuals to learn more about the subject matter presented (Davies, 2009; Dimitriadis, Cole, \& Costello, 2009). By using and engaging the arts in a seamless integrated manner into the curriculum it can be a purposeful learning opportunity that is a more holistic experience (Gullatt, 2007).

Teachers' self-efficacy in the arts is affected by the value that is placed on the arts in the classroom. Political endeavors, as well as supervisors and administrators in schools, affects a teacher's self-efficacy in the arts through social influences and feedback from policies and governing bodies (Garvis, 2012). Educational priorities often lie outside the inclusion of the arts (Alter, Hays, \& O'Hara, 2009). When teachers do not receive constructive feedback or acknowledgement of using the arts from supervisors and administration their sense of self-efficacy in implementing the arts diminishes (Oreck, 2004; Garvis, 2012). Pressures to "raise test scores and adhere to standardized curriculum can undermine teachers' creativity and autonomy” (Oreck, 2004, p. 57). Teachers may not feel that their inclusion of the arts is worthy or appropriate. The motivation a teacher exerts, as well as the effort they put forth to include the arts, is affected when the teachers' sense of self-efficacy is low. Bandura (1997) suggested that the higher the sense of self-efficacy, the greater the persistence for activities to be performed successfully. Therefore when policies and leadership counters the work of a teacher who uses the arts in the classroom their sense of self-efficacy in the arts diminishes. 
This section determined that teachers who are exposed to positive and engaging arts experiences develop a stronger self-efficacy when it comes to arts education. When teachers receive poor exposure to the arts they often formulate a lower self-efficacy and resort to less quality arts experiences in their classrooms despite the conclusion that the arts enhance the educational experience. One reason for the separation and non-inclusion of the arts by teachers may be from educational polices and administrative bodies who stress the importance of following a standardized curriculum. Yet, when teachers have a high sense of self-efficacy in the arts they tend to try new approaches to their lessons and their students are able to connect more strongly to the learning (Dimitriadis, Cole, \& Costello, 2009).

\section{Conclusion}

Arts integration studies have strongly suggested connections among the arts and cognitive, social, and emotional development (Russell-Bowie, 2009; Samuelsson, \& et.al., 2009). From the evidence discussed previously, students in schools have benefited from the inclusion and effective use of the arts in the classroom. Teachers who use the arts in their classroom have students who are more engaged and willing to work beyond the lesson time to solve problems, establish relationships, and try new activities.

In addition, schools and teachers must work through a political minefield in the face of the Common Core Curriculum. Teachers must find new and innovative approaches to teaching in a crowded curriculum where emphasis is placed more heavily on tested subjects like reading, writing, and mathematics. Communities are faced with a tightening budget as costs continue to rise and demands on student achievement increases 
in schools. The classroom environment should be a place for exploration and discovery by infusing the arts.

Various models of arts-integration exist for the education of teacher candidates and for professional development for practicing teachers. Schools must decide their best approach by either involving arts practitioners or by educating their teachers on models of arts-inquiry and or balanced integration. The future of arts education is ever evolving and through research a multitude of methods and approaches will emerge. 


\section{CHAPTER III METHODOLOGY}

In this section, the research design, as well as the participants for the research study are explained. Finally, the data collection procedure is explored to articulate how the data was procured along with analysis and limitations.

\section{Research Design}

Research design in a broad sense refers to "a comprehensive plan for conducting an investigation that stretches from the initial research questions though the methods of data analysis, interpretation, and reporting" (Vogt, Gardner, \& Haeffele, 2012, p. v). The research design for this current study included quantitative and qualitative methods instituting surveys, written responses, and artifacts.

Quantitative and qualitative research are both beneficial methods for collecting data. Quantitative methods provide an opportunity for data to be collected using statistics to conclude a finding (Vogt, Gardner, \& Haeffele, 2012). Statistics are beneficial as it assists researchers in determining factual information and can allow for an examination of historical trends through factual historical data. Statistics provide concrete data that backs-up findings. In addition, quantitative methods are beneficial to test theories or hypotheses and reduce and restructure a problem to a limitation (Fraenkel, Wallen, \& Hyun, 2014). This process aides in the refinement of questions and conclusions that are more akin to improved research. Using quantitative methods allow for less subjectivity 
by the researcher and is often considered more reliable and objective (Vogt, Gardner, \& Haeffele, 2012; Fraenkel, Wallen, \& Hyun, 2014).

Qualitative methods, on the other hand, allow for more in-depth data to be collected from the participants in the study to determine categories that are significant (Creswell J. , 2003). Often, the research is not defined by rigid variables and allows for the researcher to examine notions from a broader holistic approach. This data allows the researcher to develop concepts and theories that address how individuals think, feel, and experience their surroundings (Creswell J., 2003). Qualitative research allows the researcher to extract meaning from subjective data to formulate theories and approaches to understanding phenomena. Therefore, the collected data provides a more humanistic approach in discovering the results to the questions to build new theories (Merriam, 2007).

Utilizing both quantitative and qualitative methods allowed for a mixed-method approach to interpret a more holistic approach to understanding the phenomenon that was studied and provided more comprehensive findings to the questions posed in the study (Patton, 2002). Creswell (2015) defined mixed method research as a method in which "the investigator gathers both quantitative and qualitative data, integrates the two and then draws interpretations based on the combined strengths of both sets of data to understand research problems" (p. 2). Combining both methods will provided a more complete and inclusive understanding of the research question than either quantitative or qualitative methods individually. To accomplish the mixed method approach an explanatory sequential design was implemented (Creswell, 2015). This mixed method design allowed for quantitative methods to be implemented first followed by qualitative 
methods to help explain the quantitative results more in-depth (Creswell, 2015; Ivankova, Creswell, \& Stick, 2006). This method was chosen as it has "two distinct phases which build upon each other so that there are distinct, easily recognized stages of conducting the design" to reach an in-depth conclusion (Creswell, 2015, p. 38).

\section{Data Collection \& Instrumentation}

The data necessary for the study was collected using two different methods:

surveys and written reflection. The initial entry survey was conducted at the onset of the semester along with a written reflection and at the conclusion of the semester, during the final week of classes, another written reflection and final exit survey was initiated and collected.

At the beginning of the Fall 2015 semester, participants completed an entry survey during the first week of classes. This survey ascertained the participants' prior experience and impressions of the arts as well as their personal confidence and selfefficacy as it related to the arts before and after students take an arts integration course. This approach was selected for its ability to provide data best obtained directly from participants who could respond to structured questions in a brief format (Vogt, Gardner, \& Haeffele, 2012). The survey was adapted from the Music Performance Self-Efficacy Scale (MPSES) (Appendix C), with permission from the author (Appendix D), which was designed to assess students' self-efficacy in music performance (Zelenak, 2011). The adapted survey (Appendix E) broadened the MPSES survey to not only include music performance but to incorporate all of the arts (music, dance, visual arts, and drama).

The initial survey was developed and tested by Zelenak (2011) and is considered reliable. Through a test-retest method, Zelenak (2011) determined the "correlation of 
results from the first and second administrations of the MPSES was $r=.87$ ” (p. 83). This result yielded a strong correlation between the two tests, yet the researcher noted a small number of participants $(n=14)$ that may have influenced the strength of the correlation. He also determined the internal consistency for reliability. Zelenak (2011) used Cronbach's coefficient alpha to report internal consistency. He noted that, "the closer alpha is to 1.0, the greater the consistency among the scores" (p. 83). The internal consistency for all responses on the MPSES was $a=.88$ which demonstrates a strong internal constancy among the questions.

Surveyed participants examined their self-efficacy regarding the arts using Bandura's four categories of self-efficacy (mastery experience, vicarious experiences, verbal/social persuasion, and physiological state). Participants were able to choose from a zero to ten rating on a scale to quickly and accurately respond to the questions. A sliding 0-10 scale response was used versus a two-way closed-ended question as it was able to provide the best means to measure attitudes of participants and "in terms of the extent to which they agree with them, and so tapping into the cognitive and affective components of attitudes" (McLeod, 2008, p. 1). The survey's versatility also allowed for many variables to be measured without substantially increasing the time or cost (Sincero, Advantages and Disadvantages of Surveys., 2012). Surveys allow for research to be quantitatively analyzed representing a population with little to no observer subjectivity (Sincero, Advantages and Disadvantages of Surveys., 2012). The exit survey was structured in the same manner using the same questions in the same format and was completed at the end of the arts integration course in which the students were enrolled. 
The exit survey was administered during the final week of classes during the Fall 2015 semester.

Since social cognitive theory and self-efficacy involves, "How people interpret the results of their own performance attainments (that) inform and alter their environments and their self-beliefs which, in turn, alter subsequent performances" (Pajares F. , 1997, p. 2) the implementation of self-reflections was necessary for the research. Participants will be asked to write a two-page written response to prompts (Appendix A) at the end of the semester that addressed their self-efficacy and confidence after completing the arts integration course. The written reflection about their experiences in the arts at the end of the semester was initiated by the university teacher. This reflection determined if the participants acquired knowledge of arts integration for their future classroom teachings as well as their level of self-efficacy in integrating the arts. Within this reflection, using prompts, participants have reflected their level of selfefficacy as it relates to participating and teaching the four arts subjects; visual arts, music, dance, and theatre. This data has served to "provide a behind-the-scene look" at the students' personal growth in their own words (Patton, 2002, p. 307).

The analysis of the data through a mixed-method approach has determined a concept or theory that best answered the posed questions (Patton, 2002). Implementing explanatory sequential design has limited discrepancies and limitations posed by the research methods and allowed for consistency (Creswell, 2015; Patton, 2002).

\section{Research Setting and Participants}

For the purpose of this study, the participants consisted of students who were enrolled in an arts integration course during the Fall 2015 academic year, at Illinois State 
University (ISU) in Normal, IL. ISU is Illinois' first public university that was founded in 1857. The university's enrollment is around 20,600 students with approximately 3,000 students in the College of Education and approximately 5,000 students in teacher preparation degrees across campus. The College of Education has been continuously accredited by the National Council of Accreditation of Teacher Education (NCATE) since 1954 and is recognized as the first teacher preparation programs in the country. Students earning a degree in education at the early childhood and elementary level are required to take an arts integration course focusing on one of the four arts (theatre, music, dance, visual arts). For this study, students were elementary or early childhood teacher candidates in their sophomore or junior year. The participants were actively enrolled in one of the three available arts integration courses: theatre, music, visual arts. Three sections of theatre were available, two sections of music, and five sections of visual arts. Dance was not offered during this semester. The arts integration courses were designed to provide students with the opportunity to become more familiar with the arts and to learn how to use the arts in a creative and purposeful manner across disciplines and subject matter. Most of the students were of sophomore and junior class status who had been admitted into the college of education and intend to teach in the early childhood or elementary school environment. The number of available participants is 175 teacher candidates. These individuals all had the opportunity to participate or choose not to participate in the study. All participants and demographics were collected and kept confidential (Appendix B). 


\section{Ethical Considerations}

In order to ensure ethical practices, Institutional Review Board (IRB) permission was obtained prior to the start of the research. To address confidentiality, student names and identification numbers were removed from all documents at the conclusion of the study. Participation in the study was voluntary, and students could choose not to continue with the study at any time. The teacher of record, for the class in which the student is enrolled, was not be present during the surveys nor did the teacher see the student survey responses during the semester in which the student was enrolled. Proper procedures were implemented that follow protocol and permission from the Illinois State University Institutional Review Board (IRB). Risks were minimal and unlikely; however subjects may have felt anxious about responding to questions about their past events in the arts. However, no reports of discomfort were reported to the researchers at any point of the study. Participation in this study possibly benefited the participants by providing an opportunity for self-reflection and analysis on their involvement and use of the arts in their future classrooms.

In addition, since I taught three of the courses that were examined, an outside facilitator, who was CITI trained, administered the survey and collected the reflective essays and lessons to assure anonymity in the courses I instructed. Also, no data was analyzed until after the semester was concluded to assure confidentiality. Likewise, no instructors of the courses saw the data until after it was analyzed in the following semester. These procedures were in-place to ensure ethical practices. 


\section{Analysis Procedure}

The data analysis procedure involved interpreting the data and making sense of the information and the analysis procedure could be used in any context (Fraenkel, Wallen, \& Hyun, 2014). Merriam (2007) stated, "making sense out of data involves consolidating, reducing, and interpreting what people have said and what the researcher has seen and read-it is the process of making meaning" (p. 178). Therefore, the analysis approach has been conducted by implementing analysis that attended to the quantitative and qualitative approach of collecting the data.

To ascertain if there was a change in teacher candidates' level of self-efficacy as a result of participation in an arts integration course classrooms, a quantitative analysis was conducted. Participants completed a survey prior to the start of the arts integration course they were enrolled in, and then completed an exit survey with the same questions which were established at the beginning of the semester. To analyze the information from the scales, a paired sample t-test with an intervention was executed. The paired sample t-test was implemented as the test evaluated "whether the mean of the difference between two variables is different from zero in the population" (Green \& Salkind, 2009, p. 151). This analysis has also been controlled by the level of experience individuals identified in the survey. This test was optimal to determine if there was a change in the participants' selfefficacy after the intervention of taking the arts integration course.

Qualitative methods were used to analyze the participants' perceived self-efficacy experience in an arts integration course. After the participants wrote their reflections they were read and coded using Bandura's theory of self-efficacy to identify key elements. Using Bandura's four pillars of self-efficacy (master experience, vicarious experiences, 
verbal/social persuasion, and physiological state) thematic analysis, using both deductive and inductive approaches, was implemented to determine if there were patterns or evidence of teacher candidates' self-efficacy in arts integration. Thematic analysis is a "method for identifying, analyzing and reporting patterns (themes) within data" (Braun \& Clarke, 2006, p. 79). A thematic analysis was allowed for a detailed analysis of aspects of the data rather than the data overall (Boyatzis, 1998). By using thematic analysis the data has served to "identify or examine the underlying ideas, assumptions, and conceptualizations - and ideologies - that are theorized as shaping or informing the semantic content of the data" (Braun \& Clarke, 2006, p. 84). By analyzing the student's survey responses and reflective writings the findings, both statistically and thematically, were examined to see if there was a significant relevance to the research questions. 


\section{CHAPTER IV}

\section{DATA ANALYSIS AND RESULTS}

The objective of this mixed method study was to examine teacher candidates' self-efficacy, in the arts, through inquiring about their prior participation in the arts and their confidence in teaching the arts. A total of 175 students had the opportunity to participate in the study. Of the eligible participants, $85 \%(\mathrm{~N}=149)$ responded to the preliminary survey and $77 \%(\mathrm{~N}=135)$ responded to the post-survey.

The participants' responded to self-efficacy in the arts surveys and written reflections to written prompts regarding their engagement and involvement with the arts during the first week of classes and during the final week of classes. The results were examined and compared to determine the extent to which the participants' prior experiences with the arts and their self-efficacy level of teaching the arts, prior to enrolling in an arts integration course, differed significantly from their experiences with the arts and their self-efficacy level of teaching the arts after enrolling in an arts integration course. Participants were also asked to respond to written prompts at the beginning of the semester and again at the end of the semester. These prompts were compared and analyzed using deductive and inductive thematic coding to determine if participants' self-efficacy in the arts and teaching the arts shifted with enrollment in the arts integration course. 
The following section begins with presenting the demographics of the participants followed by the results of the participants' answers to the survey and prompt questions with corresponding data.

Next, the findings are presented by research questions (first the quantitative results and then the qualitative responses). The data are presented around Bandura's four pillars of self-efficacy: mastery experiences, vicarious experiences, verbal/social persuasion, and physiological state. Also, the results from the analysis of the qualitative data gathered are used to reinforce the quantitative data gathered from the teacher candidates.

\section{Summary of the Demographic Variables}

The participants of this study were elementary and early childhood teacher candidates in a mid-western state university. All of the participants were enrolled in an arts integration course during the Fall 2015 semester. The arts integration courses included visual arts, drama, and music. It is important to note that dance was not represented as it was not offered during the semester of data collection. The total number of participants was 149. Table 1 presents the demographic variables or background information gathered from the participants. Demographic variables included: gender, age, race, academic level, teaching level major, if the participant was a transfer student, and which arts integration course they were enrolled in during the Fall 2015 semester.

Of the participants, 10 (6.7\%) were male students and 139 (93.3\%) were female students. Age was analyzed as a continuous variable with ages ranging from 19 to 43 , with an average age of $20.5(\mathrm{SD}=2.75)$. 
Again, of the total participants, $130(87.2 \%)$ were white students, $5(3.4 \%)$ were African American, 3 (2\%) identified as Asian, 8 (5.4\%) were Hispanic, 1 (.7\%) were Indian, and $2(1.3 \%)$ identified as multi-racial. These demographics are representative of the student body, as a whole, within the college of education with $83 \%$ reporting as white, 3\% African American, 2\% Asian, and 6\% Hispanic (ISU Factbook, 2015).

To determine their level of education, participants were asked to indicate their class level. Two (1.3\%) individuals indicated their level as freshman, 28 (18.8\%) indicated they were sophomore, $107(71.8 \%)$ were of junior standing, and $12(8.1 \%)$ were senior level. In addition, 63 (42.3\%) indicated that they were transfer students with 86 $(57.7 \%)$ indicating that they were native students.

Of the participants, $24(16.1 \%)$ were early childhood education majors, and 112 $(75.2 \%)$ were elementary education majors. Also, $13(8.7 \%)$ indicated they were in another area of concentration. The areas of study included: bilingual education, family and consumer science, marketing, and speech pathology. Although these individuals do not identify as elementary or early childhood education majors this study will still frame the study as education majors since many of the small percentage of individuals will be working with early childhood or elementary education age students. 
Table 1

Demographic Characteristics of Participants $(N=149)$

\begin{tabular}{|c|c|c|}
\hline Demographic Variable & $\mathrm{N}$ & $\%$ \\
\hline \multicolumn{3}{|l|}{ Gender } \\
\hline Male & 10 & 6.7 \\
\hline Female & 139 & 93.3 \\
\hline \multicolumn{3}{|l|}{ Age } \\
\hline$<20$ & 117 & 78.5 \\
\hline $21-30$ & 29 & 19.5 \\
\hline $31-40$ & 2 & 1.4 \\
\hline$>40$ & 1 & 0.7 \\
\hline \multicolumn{3}{|l|}{ Race } \\
\hline White & 130 & 87.2 \\
\hline Black & 5 & 3.4 \\
\hline Asian & 3 & 2 \\
\hline Hispanic & 8 & 5.4 \\
\hline Indian & 1 & 0.7 \\
\hline Multi-Racial & 2 & 1.3 \\
\hline \multicolumn{3}{|l|}{ Academic Level } \\
\hline Freshman & 2 & 1.3 \\
\hline Sophomore & 28 & 18.8 \\
\hline Junior & 107 & 71.8 \\
\hline Senior & 12 & 8.1 \\
\hline \multicolumn{3}{|l|}{ Transfer } \\
\hline Yes & 63 & 42.3 \\
\hline No & 86 & 57.7 \\
\hline \multicolumn{3}{|l|}{ Major } \\
\hline Early Childhood & 24 & 16.1 \\
\hline Elem. Ed & 112 & 75.2 \\
\hline Other & 13 & 8.7 \\
\hline \multicolumn{3}{|l|}{ Arts Integration Course } \\
\hline Visual Arts & 100 & 67.1 \\
\hline Music & 20 & 13.4 \\
\hline Drama & 29 & 19.5 \\
\hline
\end{tabular}




\section{Findings}

Participants were asked to respond to a 28-question survey titled, Arts Performance Self-Efficacy Scale (APSES). Responses to the items were ranked on a 10point Likert scale ranging from $0=$ strongly disagree to $10=$ strongly agree. The following presents the responses to the survey questions and by research questions.

\section{Research Question 1: What was the level of teacher candidates'prior}

experiences with the arts? In order to determine the students' prior experiences, participants were asked questions in a survey.

Questions 1-5 (Q1-Q5) on the survey directly correspond to the first research question of the study regarding the level of teacher candidates' prior experiences with the arts. Results from the descriptive analysis of survey questions 1-5 are displayed in Table 2.

Of the 149 participants who responded to question number one, which asked the participants to rate their positive experiences participating in the arts (dance, music, theatre, and visual arts) in the past. Of the participants, $34.9 \%$ of the respondents signified that they strongly agree, which was the highest percentage of respondents. The lowest percentage was $0.7 \%$ which was represented equally among three separate responses that included strongly disagree, a ranking of 1 , and not applicable.

Questions 2 through $5(\mathrm{Q} 2-\mathrm{Q} 5)$ asked the teacher candidates to rate their prior positive experiences in each of the arts disciplines; dance, music, theatre, and visual arts, using the same Likert scale. Dance (Q2) had $22.1 \%$ of the participants indicate a response of strongly agree which was the highest percentage of responses and $2.7 \%$ of the participants note a level of 1 , which was the lowest percentage of responses. Music 
(Q3) had the most respondents, 25.5\%, indicate strongly agree and the least amount of respondents at $0.7 \%$ signify strongly disagree and $0.7 \%$ ranking of 1 .

Of the respondents in Theatre (Q4), $14.8 \%$ of the participants responded with a level of 5 , which was the highest amount of respondents and $0.7 \%$ indicated a 1 , which was the lowest amount of responses. Visual Arts (Q5) had $18.8 \%$ of the participants indicate a response of strongly agree, which was the highest percentage of responses and $0.7 \%$ of the participants indicate a level of 1 , which was the lowest percentage of responses. 
Table 2

Pre- Survey Response Percentages for Q1-Q5

\begin{tabular}{llllllllllllll}
\hline \multirow{2}{*}{ Question } & Strongly & & & 1 & 2 & 3 & 4 & 5 & 6 & 7 & 8 & 9 & Strongly \\
& Disagree & & & & & & & & & Agree &
\end{tabular}

1. I have had positive

$\begin{array}{lllllllllllll}\text { experiences participating in } & 0.7 & 0.7 & 2.7 & 1.3 & 4.7 & 6.0 & 6.0 & 8.1 & 19.5 & 14.8 & 34.9 & 0.7\end{array}$

$\infty$ the arts in the past.

2. I have had positive

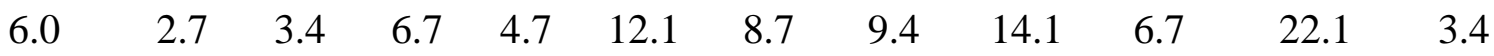

experiences in Dance.

3. I have had positive

experiences in Music.

$\begin{array}{llllllllllll}0.7 & 0.7 & 4.7 & 2.0 & 6.0 & 8.7 & 10.1 & 10.1 & 14.1 & 15.4 & 25.5 & 2.0\end{array}$


Table 2 Continued

\begin{tabular}{|c|c|c|c|c|c|c|c|c|c|c|c|c|}
\hline Question & $\begin{array}{l}\text { Strongly } \\
\text { Disagree }\end{array}$ & 1 & 2 & 3 & 4 & 5 & 6 & 7 & 8 & 9 & $\begin{array}{l}\text { Strongly } \\
\text { Agree }\end{array}$ & N/A \\
\hline $\begin{array}{l}\text { 4. I have had positive } \\
\text { experiences in Theatre. }\end{array}$ & 9.4 & 0.7 & 7.4 & 8.1 & 5.4 & 14.8 & 8.7 & 7.4 & 12.1 & 7.4 & 14.1 & 4.7 \\
\hline 5. I have had positive & 2.7 & 0.7 & 2.7 & 2.7 & 6.0 & 15.4 & 4.0 & 15.4 & 17.4 & 12.8 & 18.8 & 1.3 \\
\hline
\end{tabular}


The mean values were also determined to identify the average positive experiences in the arts in general and each of the arts disciplines. Of the 149 participants who responded to question number one, all but one of the participants indicated an experience participating in the arts with the minimum response of 0 (strongly disagree) to a maximum response of 10 (strongly agree). One of the individuals indicated a response of not applicable to having a positive experience in the arts. The mean score was 7.95 with a standard deviation of 2.3.

Question two (Q2) asked if participants had positive experiences in dance. Five of the participants who answered Q2 indicated that the question was not applicable to their experiences. Of the remaining 144 participants who responded to question 2 , there mean score was $6.43(\mathrm{SD}=3.05)$. Question three $(\mathrm{Q} 3)$ asked the same request regarding music. The responses ranged from strongly disagree (0) to strongly agree (10) from 146 participants with three respondents indicating that the question was not applicable to their prior experience in music. The results indicated a mean difference of $7.36(\mathrm{SD}=2.48)$.

Question four (Q4) referred to participants positive experiences in theatre. Seven of the 149 participants indicated that their prior experiences in theatre was not applicable. Of the remaining participants, the responses indicated a mean value of $5.7(\mathrm{SD}=3.12)$.

Lastly, Q5 asked the same question, but about visual arts. Two of the participants designated that their prior experience in the visual arts was not applicable. Therefore, the mean value of participants who had positive experiences in the arts was $6.99(\mathrm{SD}=2.52)$. Figure 1 depicts the mean value of each of the questions 1-5 in a bar graph format.

Examining all of the arts (dance, music, theatre, and visual arts), the most positive arts experience of the participants resided with music experiences with a mean value of 
$7.36(\mathrm{SD}=2.48)$ (See Figure 1). Whereas the least positive experiences resided in theatre with a mean value of $5.7(\mathrm{SD}=3.12)$. All of the mean scores were generally more positive (mean > 5.5) than negative (mean < 5.5) in regard to the Arts Performance Self-Efficacy Scale (APSES).

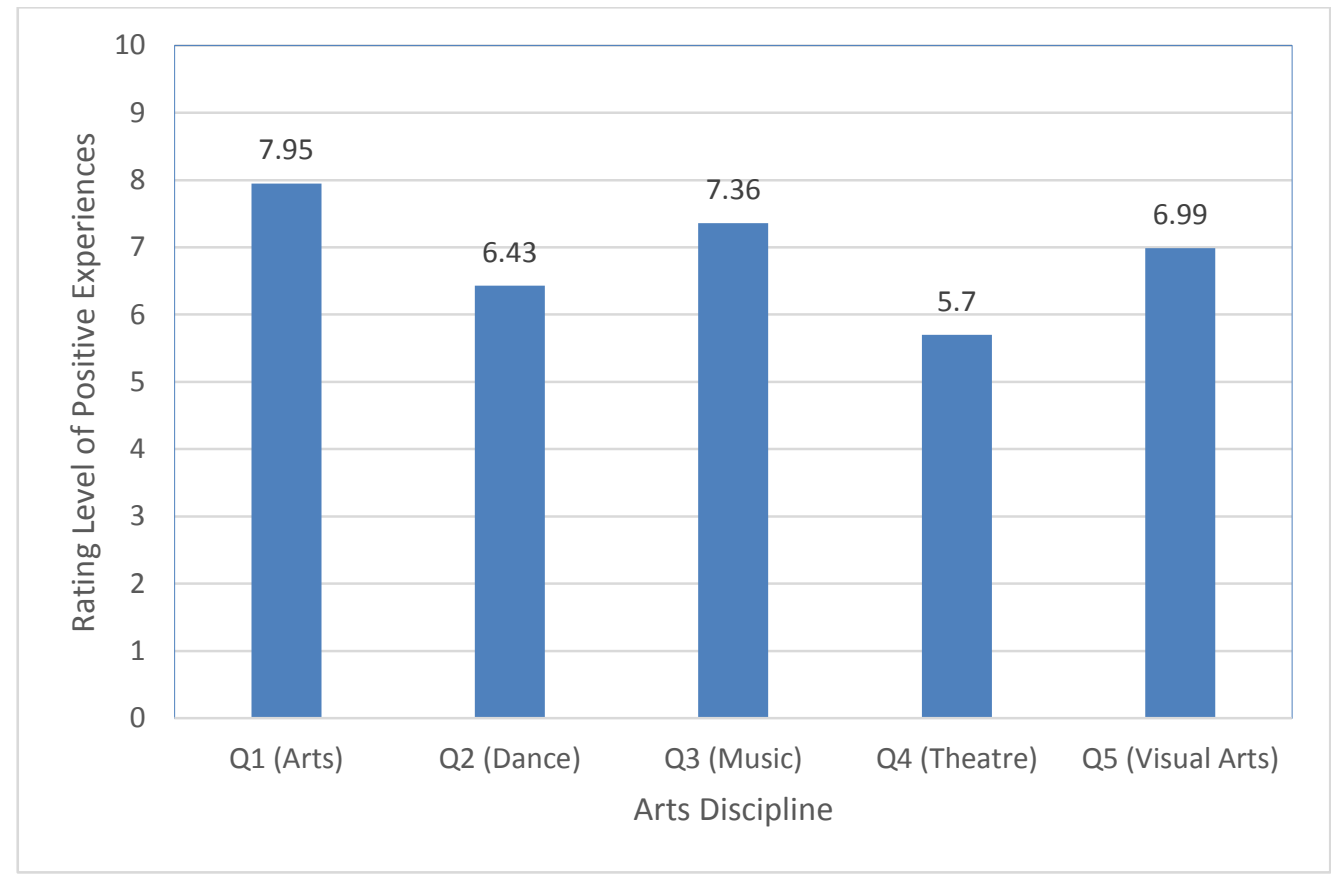

Figure 1. Participant Mean Scores per Area

In addition to the APSES, participants were asked to respond, in writing, to prompts presented to them after completing the survey. Of the 149 participants, 23 individuals completed the written responses, a $15 \%$ return rate.

Upon review of the written responses, it was clear that many of the respondents had positive previous experiences in the arts. One participant noted her experiences as "positive and fun" (ID\# 1056). This rhetoric was repeated in other responses as well. In addition to these positive experiences in the arts, three members noted limited experiences in the arts. One individual (ID\# 1107), recognized that she "haven't had 
many experiences (in the arts)" with another participant echoing the same response stating, "I do not have much experience in the art field" (ID\# 1076). These comments, along with others, signify a lack of student experiences in the arts (music, dance, visual arts, and drama).

Of the participants, two individuals recognized negative experiences in the arts and related those negative experiences to the individuals who had taught the arts courses. One respondent indicated negative experiences in both music and dance by stating, It was a positive experience until my freshman year. My band director that I had my freshman year retired so I had a different one my sophomore year. He made us practice and practice and practice, but I felt like nothing ever got done so I quit after that year. I did dance at a dance studio down the street from my house. I did tap for about 13 years and jazz for 14 years. There were times when it was negative because the teacher would sit on a chair and tell us what to do and get mad at the class when we can't figure it out since she didn't show us. She would also get mad at us for not learning as much as we needed to during that class because she would talk to the parents for half the class (ID\# 1008).

Another participant also remarked about a negative experience related to visual arts and attributed that experience towards the instructor. The participant remarked, "I had one very negative experience in middle school when my art teacher was very negative towards my project and after that I just never desired to try anymore" (ID\# 1017). All of the participants, who responded to the written prompts, noted an experience or a limited opportunity to engage in the arts. 
To understand participants' experiences in the arts, the data demonstrated where the participants experienced the arts. Based on the patterns of responses, individuals' responses to prior experiences in the arts were grouped into three experiences; arts focused classes in school, extra-curricular activities, and community arts experiences. The following section elaborates on each of these types of experience.

\section{Arts Focused Classes in School}

In the school environment, approximately two-thirds of the respondents indicated that they had experienced the arts in their elementary, junior high school, and/or high school. One participant wrote, "I started playing violin in 4th grade and continued throughout high school. It was a very positive experience due to the great arts programs in my schools" (ID\# 1112). Other participants also had an encounter with arts in their school. They stated:

Throughout elementary school and middle school it was mandatory to take these classes per year. Even though it was mandatory I always enjoyed playing instruments in my music class, making a something out of clay in art, or singing something silly in chorus (ID\# 1036).

In junior high and high school I participated in choir. My experience in choir were mainly positive, I loved performing everything that we had practiced in front of my friends and family. I had wonderful directors as well that helped form my positive experience. I have also been involved in theatre for about 3 years. I was a part of the chorus in Annie my senior year of high school (ID\# 1004). 
These quotes demonstrate that some participants' K-12 schools provided a range of mandatory experiences in music, art, and theater. As seen in these quotes, some students recalled curriculum related involvement, which was positive and enjoyable.

\section{Extra-Curricular Activities}

Participants also recognized their experiences in the arts during extra-curricular activities. One of the respondents remarked, "I was a cheerleader for 14 years and dancing was a part of that task, so in a way, that is a slight contribution to my experiences in art" (ID\# 1076). Another individual recognized the correlation between speech and theatre stating, “... along with being heavily involved with acting. I competed on the speech team all 4 years in high school..." (ID\#1014). It is evident that while some students experienced the arts in their school's mandatory curriculum, others sought out extra-curricular involvement engaging in aspects of the arts for several years.

\section{Community Arts Experiences}

Participants also remarked about their prior experiences in the arts as it related to their communities. Two of the individuals recognized their park district by stating, "I danced for all of elementary school at my Park District and I enjoyed it, but was not very skilled" (ID\#1112) and, "I participated in dance through the park district as did with my friends" (ID\# 1056). While a third participant remarked on her experience in theatre camps by stating, "I participated in multiple theatre camps throughout my childhood, performing in The Jungle Book, Red Riding Hood, Cinderella, and Aladdin" (ID\# 1010). Another individual took professional classes in dance; this teacher candidate stated,

In the past, I have had quite a few experiences with the arts. Starting at the very young age of about 3, I was involved with dance lessons. I started off doing tap 
and ballet, but as I got older I just practiced jazz, hip-hop and modern. I really enjoyed my experience in dance classes (ID\# 1149).

Overall, the responses indicate that there is a wide range of experiences of arts engagements from the survey participants. These experiences include arts courses in schools to extra-curricular activities to community opportunities. Of the respondents, many indicate a feeling of enjoyment or positive experience when reflecting on their arts experiences. The following section examines the results for the second research question from the study.

\section{Research Question 2: What are teacher candidates' level of self-efficacy prior to} enrolling in the arts integration course?

The responses to survey items 6 through 28 on the Arts Performance SelfEfficacy Scale (APSES) were used in answering research question 2. These questions were formulated based on Bandura's four pillars of self-efficacy: master experience, vicarious experiences, verbal/social persuasion, and physiological state.

Questions 6-11 (Q6-Q11), on the survey, directly correspond to mastery experiences in the arts. Of the 149 participants, 144 individuals answered Q6 which addressed the level of positive experiences performing or presenting art in large groups of five or more. Five of the students indicated that the question was not applicable. The highest percentage of responses indicated that $22.1 \%$ of the respondents signified that they strongly agree. The mean value of the 144 answered questions from Q6 was 6.91 $(\mathrm{SD}=2.86)$. 
Of the participants, $19.5 \%$ designated a level of 8 for question 7 (Q7), which was about performing or presenting art by themselves or in small groups of four or less. A total of 147 participants responded with two participants indicating that the question was not applicable. The mean difference for $\mathrm{Q} 7$ was $6.31(\mathrm{SD}=2.89)$. For question eight, 26.2\% identified strongly agree regarding their positive experiences performing simple arts tasks. All 149 participants responded to Q8 with a mean result indicating a 7.69 with a standard deviation of 2.17 .

Positive experiences executing complicated arts tasks was the focus for Q9 with $14.1 \%$ responding at a level of 6 . The total of individuals who responded to Q9 was 147 with two entities responding with not applicable. The mean value of Q9 was 5.56 $(\mathrm{SD}=2.88)$. Q10 had a $100 \%$ response rate with $21.5 \%$ who responded with strongly agree for overcoming challenges related to the arts through hard work and practice with a mean value of 6.93 ( $\mathrm{SD}=2.51)$. Lastly $20.8 \%$ of the 138 participants indicated strongly agree with 11 participants indicating that the question was not applicable for Q11, which asked about a practice routine to help them prepare for a performance or presentation in the arts. The mean result was $5.48(\mathrm{SD}=3.17)$.

Questions 6-11 of the survey also had a low percentage indicated for each of the questions under mastery experience. Of the responses, $0.0 \%$ of the respondents indicated a level of 1 for Q6; $1.3 \%$ of individuals answered either a level of 1 or not applicable for Q7; $0.0 \%$ responded with a level of 1 or not applicable for Q8; $1.3 \%$ of the participants indicated a level of not applicable for Q9; 0.0\% responded not applicable for Q10; and $3.4 \%$ of the responses were distributed among a level of 1,2 , and not applicable (See Table 3). 
Table 3

Pre- Survey Response Percentages for Mastery Experience (Q6-Q11)

\begin{tabular}{|c|c|c|c|c|c|c|c|c|c|c|c|c|}
\hline Mastery Experience & $\begin{array}{l}\text { Strongly } \\
\text { Disagree }\end{array}$ & 1 & 2 & 3 & 4 & 5 & 6 & 7 & 8 & 9 & $\begin{array}{l}\text { Strongly } \\
\text { Agree }\end{array}$ & N/A \\
\hline 6. I've had positive & & & & & & & & & & & & \\
\hline experiences performing or & 5.4 & 0.0 & 4.7 & 5.4 & 2.7 & 7.4 & 6.7 & 16.1 & 15.4 & 10.7 & 22.1 & 3.4 \\
\hline $\begin{array}{l}\text { presenting art in a large } \\
\text { group }(5+)\end{array}$ & & & & & & & & & & & & \\
\hline 7. I have had positive & & & & & & & & & & & & \\
\hline presenting art by myself, or, & 7.4 & 1.3 & 4.7 & 2.7 & 6.0 & 13.4 & 8.7 & 11.4 & 19.5 & 10.1 & 13.4 & 1.3 \\
\hline
\end{tabular}


Table 3 Continued

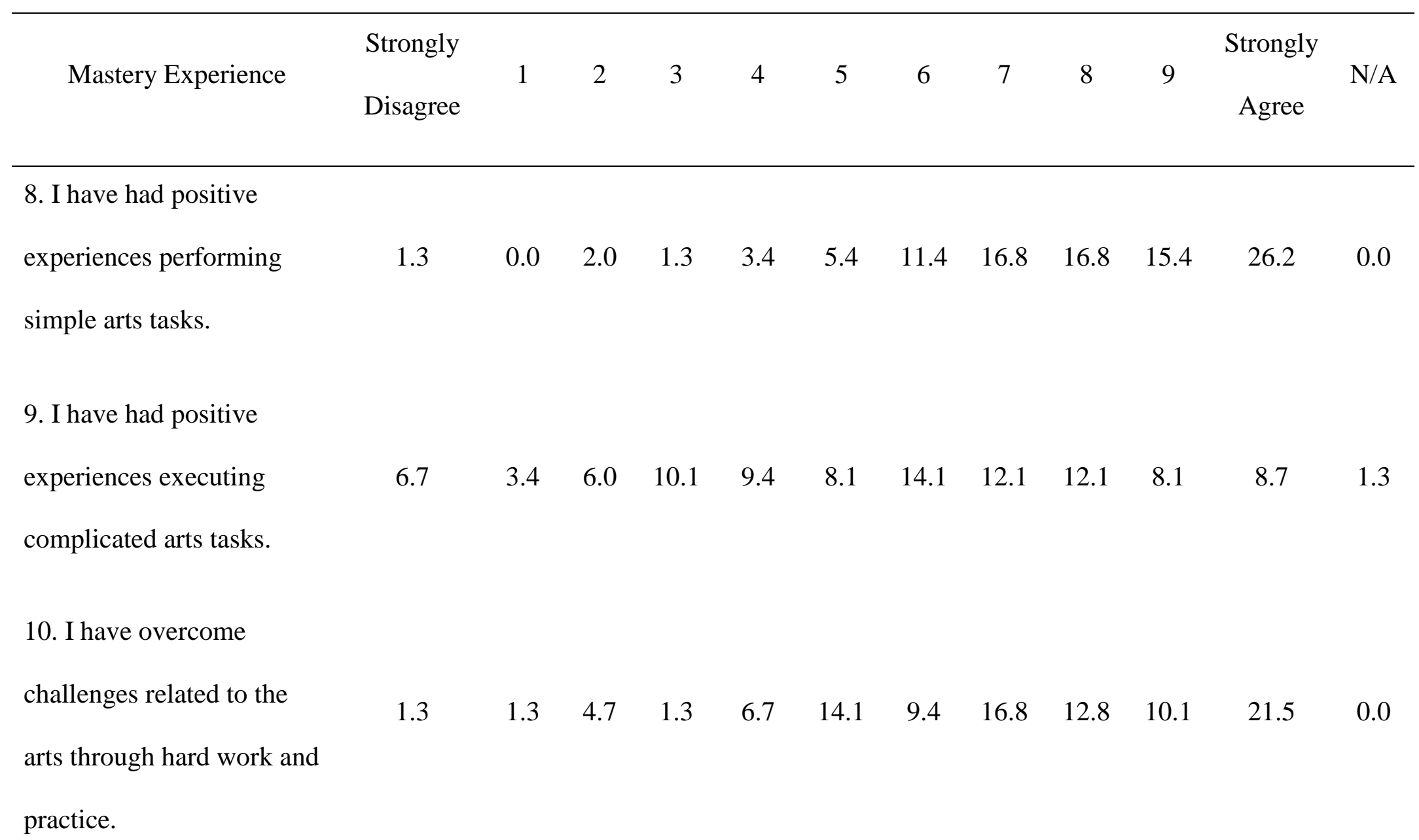


Table 3 Continued

\begin{tabular}{|c|c|c|c|c|c|c|c|c|c|c|c|c|}
\hline Mastery Experience & $\begin{array}{l}\text { Strongly } \\
\text { Disagree }\end{array}$ & 1 & 2 & 3 & 4 & 5 & 6 & 7 & 8 & 9 & $\begin{array}{l}\text { Strongly } \\
\text { Agree }\end{array}$ & N/A \\
\hline 11. I have used a practice & & & & & & & & & & & & \\
\hline routine to help me prepare & 5.4 & 3.4 & 3.4 & 5.4 & 4.7 & 9.4 & 7.4 & 12.8 & 12.1 & 12.1 & 20.8 & 3.4 \\
\hline for my performances or & & & & & & & & & & & & \\
\hline presentatior & & & & & & & & & & & & \\
\hline
\end{tabular}


Questions 12-16 (Q12-Q16), on the survey, directly correspond to vicarious experiences in the arts. The highest percentage of participant responses, $14.8 \%$, signified that they strongly agree for Q12, which asked if they improved in their arts performance skills by watching professional artists perform well. Of the participants, 146 answered Q12 with three of the students indicating that the question was not applicable. The mean value was 5.43 ( $\mathrm{SD}=3.2)$. Question 13 had 148 individuals respond with one participant who indicated that the question was not applicable. From the responses, $16.8 \%$ of the participants designated a level of 8 which asked if they had improved their arts performance skills by watching other students in their classes perform well (Q13). The mean difference was 6.12 with a standard deviation of 2.8 .

Question 14 had $18.1 \%$ of the 148 participants respond at level 7 and strongly agree, which asked if they used other students' work as a model to improve their arts integration skills. One person indicated that the question was not applicable and the mean value was $6.66(\mathrm{SD}=2.64)$. Question 15 asked if the participants had compared their performance skills with their peers. All but one of the participants responded with $19.5 \%$ responding at a point of strongly agree with a mean result of 7.05 and a standard deviation of 2.46. Lastly, $14.1 \%$ of the participants indicated a level 5 for Q16, which referred to watching other students of similar arts ability to themselves perform an arts lesson plan and then decide whether they could, or could not, perform the same lesson. The mean result was $5.48(\mathrm{SD}=3.17)$.

Questions 12-16 had low percentage indicated for each of the questions under vicarious experience. Of the respondents, 2\% indicated a level of not applicable for Q12; $0.7 \%$ of individuals answered a level of not applicable for Q13; $0.7 \%$ responded with a 
level of 1 or not applicable for Q14; $0.7 \%$ of the participants also indicated a level of 1 or not applicable for Q15; and 2\% of the responses signified a level of 1 for Q16 (See Table 4). 
Table 4

Pre- Survey Response Percentage for Vicarious Experiences (Q12-Q16)

\begin{tabular}{llllllllllllll}
\hline & Strongly & 1 & 2 & 3 & 4 & 5 & 6 & 7 & 8 & 9 & Strongly \\
Vicarious Experiences & Disagree & & & & & & & & Agree &
\end{tabular}

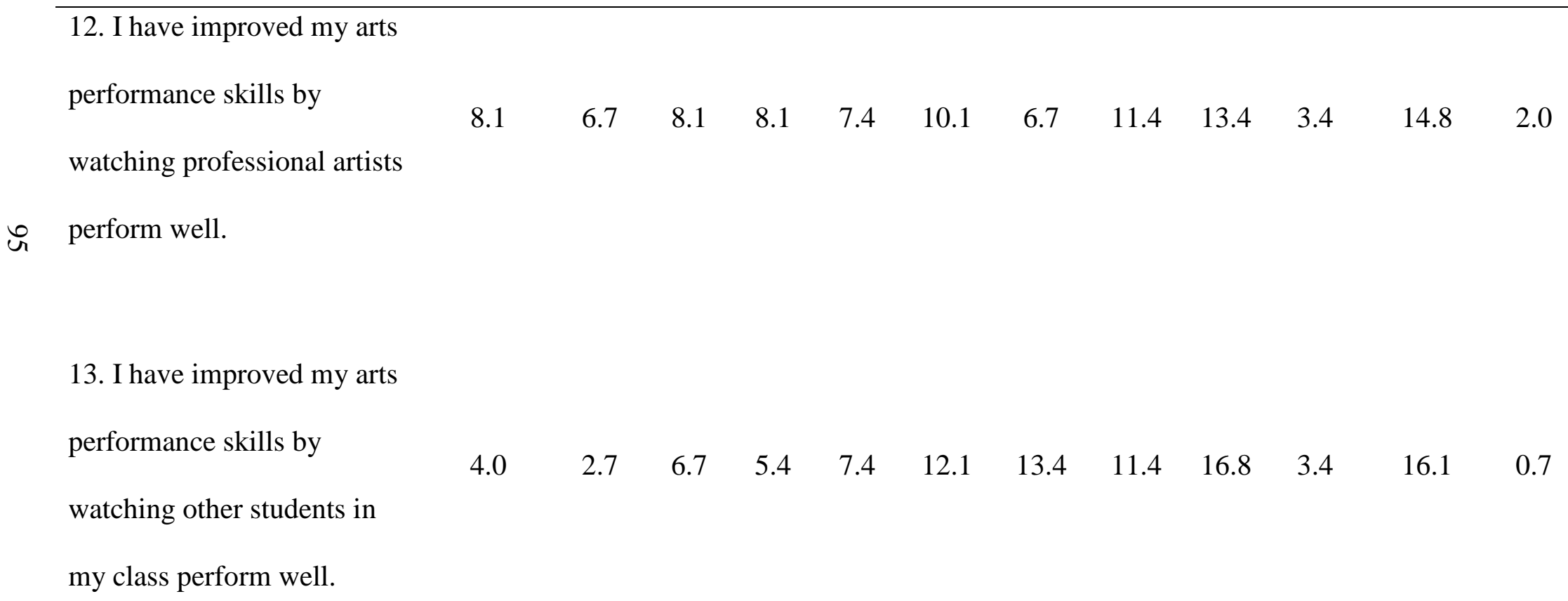


Table 4 Continued

\begin{tabular}{|c|c|c|c|c|c|c|c|c|c|c|}
\hline & Strongly & & & & & & & & \multicolumn{2}{|c|}{ Strongly } \\
\hline Vicarious Experiences & Disagree & 2 & 3 & 4 & 5 & 6 & 7 & 8 & 9 & N/A \\
\hline
\end{tabular}

14. I have used other

students' work as models to

$\begin{array}{llllllllllll}2.7 & 3.4 & 3.4 & 4.0 & 4.0 & 11.4 & 11.4 & 18.1 & 16.1 & 6.7 & 18.1 & 0.7\end{array}$

improve my arts integration

skills.

๑ 15. I have compared my

performance skills with

those of other students who

0.7

2.

$4.0 \quad 3.4 \quad 1.3$

12.8

10.7

$14.8 \quad 17.4 \quad 12.1$

19.5

0.7

are similar in arts ability to

me. 
Table 4 Continued

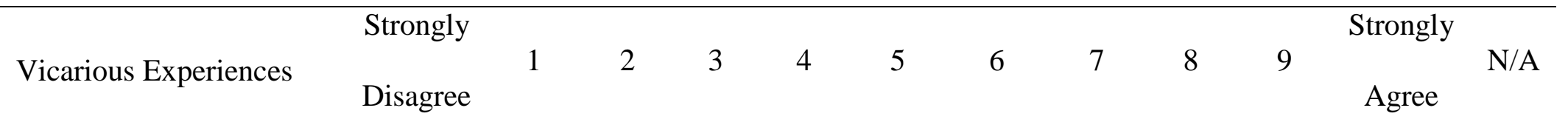

16. I have watched other

students of similar arts

$\vartheta \quad$ ability as me perform an arts

lesson plan, and then

$10.1 \quad 2.0$

decided whether I could, or

could not, perform the same

lesson. 
Questions 17-22 (Q17-Q22) correspond to verbal/social persuasion in the arts. Of the participants, the highest percentage of responses referred to whether their friends thought that they were a good performer/artist (Q17) at 16.8\% signifying a level of 8 . Of the 148 participants who answered Q17, one of the students indicating that the question was not applicable. The mean value of the 148 answered questions from Q17 was 6.05 ( $\mathrm{SD}=2.71$ ). For question 18, 147 participants respond with two participants who indicated that the question was not applicable. Of the responses, $19.5 \%$ of the participants designated a level of 8 , which asked if their family believed that they performed well in the arts. The mean difference was 6.65 with a standard deviation of 2.86 .

When asked if their arts teachers had complimented them on their arts skills, $15.4 \%$ identified strongly agree of the 145 who responded to Q19 with four people noting that the question was not applicable. The mean value was 6.02 and a standard deviation of 3.10. Of the participants, $13.4 \%$ responded at a level of 6 for people telling them that their practice efforts improved their arts skills (Q20). For Q20, 146 participants responded with a mean value of $5.82(\mathrm{SD}=3.08)$ with three individuals recognizing that the questions was not applicable. When asked if they had received positive feedback on arts performance evaluations, $20.1 \%$ responded with strongly agree (Q21). The mean result of the 144 respondents was $6.9(\mathrm{SD}=2.8)$. Lastly, $16.1 \%$ of the participants indicated a level 5 if they had met or exceeded other people's expectations of being a good arts integration teacher for Q22. The final question (Q22) for verbal and social persuasion had 137 responses indicating a mean result of 5.25 with a standard deviation of 3.11 with 11 participants signifying that the question was not applicable. 
Questions 17-22 of the survey also had a low percentage indicated for each of the questions under verbal/social persuasion. Of the responses, $0.7 \%$ of the entities indicated not applicable for Q17; 1.3\% of individuals answered either a level of not applicable for Q18; 2.7\% responded with a level of 1 or not applicable for Q19; a low amount, 2\% of the participants, indicated a level of not applicable for Q20; 0.7\% responded with a level of 4 for Q21; and an equal divide of $2 \%$ of the respondents identified at a level of 3 and 4 for Q22 (See Table 5). 
Table 5

Pre- Survey Response Percentages for Verbal/Social Persuasion (Q17-Q22)

\begin{tabular}{|c|c|c|c|c|c|c|c|c|c|c|c|c|}
\hline & Strongly & & & & & & & & & \multicolumn{3}{|c|}{ Strongly } \\
\hline Verbal/Social Persuasion & Disagree & 1 & 2 & 3 & 4 & 5 & 6 & 7 & 8 & 9 & Agree & N/A \\
\hline 17. My friends think I am a good & 4.0 & 2.7 & 6.7 & 6.7 & 6.0 & 10.7 & 12.8 & 14.8 & 16.8 & 8.7 & 9.4 & 0.7 \\
\hline 18. Members of my family believe & 4.0 & 2.7 & 4.7 & 6.7 & 2.7 & 9.4 & 8.7 & 11.4 & 19.5 & 10.7 & 18.1 & 1.3 \\
\hline 19. My arts teacher has & 8.1 & 2.7 & 6.7 & 3.4 & 7.4 & 11.4 & 8.7 & 12.1 & 11.4 & 10.1 & 15.4 & 2.7 \\
\hline
\end{tabular}


Table 5 Continued

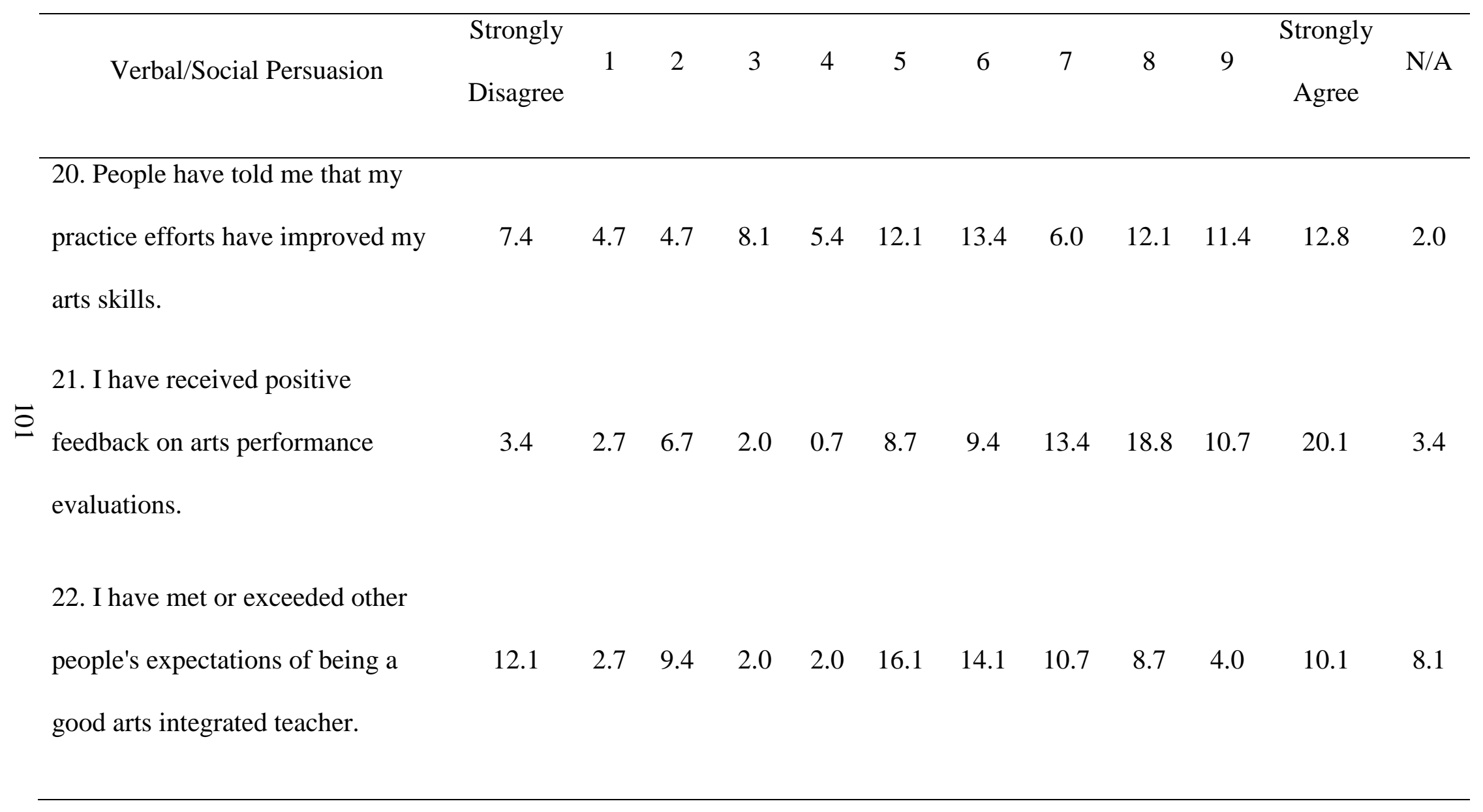


Questions 24-28 (Q24-Q28) related to the physiological state of individuals in the arts. Of the 149 teacher candidates who took the survey, the highest percentage of responses, $36.9 \%$ of the respondents, signified that they strongly agree that participating in the arts makes them feel good (Q24). The mean value of the 149 who answered questions from $\mathrm{Q} 24$ was $7.6(\mathrm{SD}=2.58)$. For question $25,34.9 \%$ of all the participants noted a level of strongly agree, which asked if they enjoy participating in the arts. The mean difference was 7.7 with a standard deviation of 2.46 .

When asked if they are learning or have learned to control nervousness during a performance, 148 teacher candidates responded with $18.1 \%$ designating strongly agree (Q26). In addition, one person noted that the question was not applicable. The mean value was 6.69 ( $\mathrm{SD}=2.84)$. All 149 participants responded to Question 27 with a mean result of $5.17(\mathrm{SD}=2.84)$. The results showed that $16.1 \%$ responded at a level of 5 regarding if they worry about small mistakes during a performance or lesson for Q27. Lastly $26.2 \%$ of the participants strongly agree for having positive memories of most or all of their arts experiences (Q28). The mean result was 7.11 with a standard deviation of 2.57 .

Questions 24-28 of the survey also had a low percentage of responses for each of the questions under physiological state. Of the respondents, $0.0 \%$ of the respondents indicated a level of not applicable for Q24; $0.0 \%$ of individuals answered either a level of 1 or not applicable for Q25; 0.7\% was found at a level of 1 and not applicable for Q26; $0.0 \%$ responded with a level of not applicable for Q27; and $0.0 \%$ of the responses were distributed among a level of 1 and not applicable for Q28 (See Table 6). 
Table 6

Pre- Survey Response Percentages for Physiological State (Q24-Q28)

\begin{tabular}{llllllllllllll}
\hline & Strongly & & & & & & & & Strongly & N/A \\
Physiological State Questions & Disagree & & & & & & & & & & Agree
\end{tabular}

24. Participating in the arts

makes me feel good (Return

to using 0-10 rating).

ம்

25. I enjoy participating in the arts.

$\begin{array}{llllllllllll}0.7 & 0.0 & 4.7 & 4.7 & 2.7 & 5.4 & 8.1 & 9.4 & 20.1 & 9.4 & 34.9 & 0.0\end{array}$

26. I am learning, or have

learned, to control

$\begin{array}{llllllllllll}4.7 & 0.7 & 5.4 & 5.4 & 6.7 & 6.0 & 10.7 & 12.8 & 14.8 & 14.1 & 18.1 & 0.7\end{array}$

nervousness during a

performance. 
Table 6 Continued

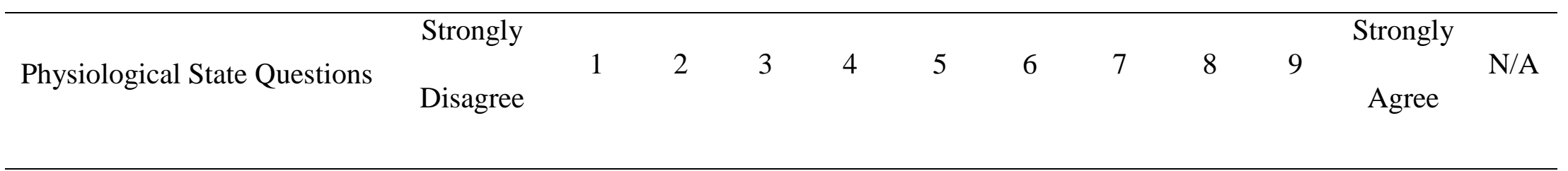

27. I do not worry about

small mistakes during a

performance or lesson.

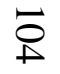

28. I have positive memories

of most, or all, of my arts

2.0

0.

4.0

5.4

4.7

8.7

11.

experiences. 
In addition to the individual means for each question, a composite mean was determined for each of the four pillars of Bandura's self-efficacy. These composite means combined the questions' results and determined a composite mean value for each of the areas of self-efficacy: mastery experience, vicarious experiences, verbal/social persuasion, and physiological state.

The composite mean of the mastery experience questions of Q6-Q11 was 6.69 $(\mathrm{SD}=2.04)$. The composite mean score from vicarious experiences (Q12-Q16) was 6.19 ( $\mathrm{SD}=2.32)$. For $\mathrm{Q} 17-\mathrm{Q} 22$ the composite mean from verbal/social persuasion was determined as $6.15(\mathrm{SD}=2.52)$. Physiological state composite mean was determined for Q24-Q28. The mean result was $6.87(\mathrm{SD}=2.21)$.

Figure 2 demonstrates the results of the composite means of each of Bandura's pillars of self-efficacy: mastery experience (ME), vicarious experiences (VE), verbal/social persuasion (VSP), and physiological state (PS).

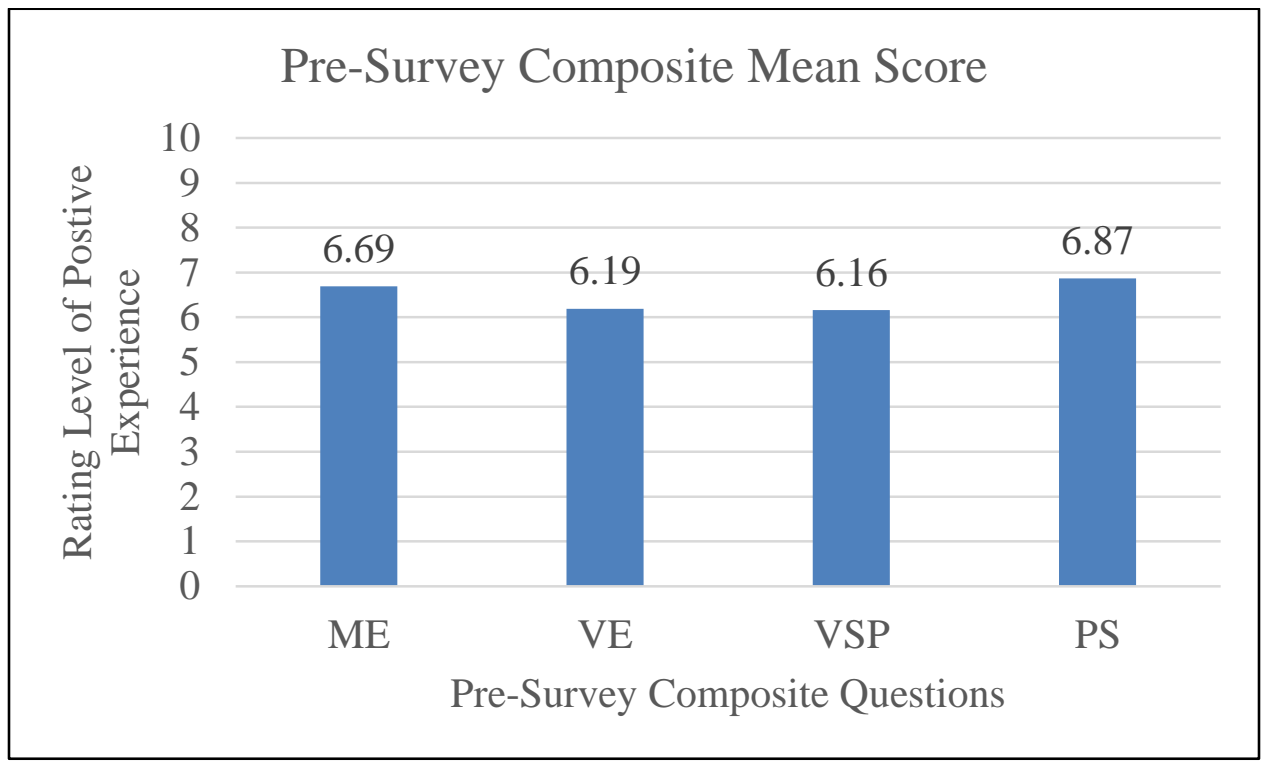

Figure 2. Pre-Survey Composite Mean Scores 


\section{Mastery Experiences Written Responses}

In addition to the quantitative data, participants were asked to respond to written prompts regarding their experiences in the arts. Many of the participants who responded to the prompt questions indicated their mastery experiences in the arts. These responses ranged from a few experiences to years of study in an art form. One participant clearly identified this range of master experience by stating, "I have been in the church choir all my life and my school's choir for a year" (ID\# 1066).

Mastery experience specifically refers to the performing or presenting in the arts either in a group or individually along with rehearsing or practicing their skills in the arts. Several of the teacher candidates recognized experiences in performing and presenting. They stated:

I think competing was a positive experience because it forced me to practice and perfect my craft and perform it for the enjoyment of others. Practicing was just as fun for me as performing. I think spending two hours in a studio running steps and routines is just as fun and important as a big performance (ID\# 1061).

My favorite part was when we had recitals and competitions and we got to showcase everything that we had learned. I wasn't the best in my class, but I definitely improved over the years. Also, in elementary school and junior high I was in a few musicals (ID\# 1149).

These individuals above specifically identified the rehearsal and presenting process as it relates to mastery experience, however others indicated their involvement in 
marching band, wind, concert, or chorus ensembles participation in plays and musicals dance recitals, and visual arts opportunities. All of these experiences either raise or lower the self-efficacy of teacher candidates as related to their mastery experience in terms of knowing and teaching the arts. However, two students indicated that they did not have much prior experiences in the arts, which demonstrates a lower level of mastery experience in the arts. The next section looks at the vicarious experiences of the participants.

\section{Vicarious Experiences Written Responses}

Participants recognized three areas of vicarious experiences that include, experiences with friends or peers, adult role models such as parents and teachers, and the use of examples to enhance self-efficacy.

Experiences with Friends or Peers. Participant \#1024 particularly remarked on an experience with friends by writing, "I've always enjoyed my time on stage and just having fun with my friends." Another participant indicated that she "...made many connections with students also in orchestra" (ID \# 1112). Yet, three participants compared themselves to others. One individual wrote, "I know that there are many people out there who are more creative than me, but I like thinking outside of the box" (ID\# 1014). Another teacher candidate participant acknowledged, "I have always enjoyed being in the audience and secretly desired to be on stage. ... I suppose I have too many friends that have higher artistic qualities and tendencies than myself”' (ID\#1017).

These participants all identified their abilities or vicarious self-efficacy to their peers as it relates to their ability to perform or engage in the arts. 
Adult Role Models. Participants were also affected by their teachers or other adults in their lives. One participant wrote, "In high school. . . . I liked 3D art much better. I think that this is because my teacher in high school knew more about working with 3D materials and how to make them look good" (ID\# 1001). While another participant directly made a correlation between her abilities in the arts and that of her mother by stating, "I think I got my creative side from my mom because she always had my two sisters and I doing fun crafts while we were growing up" (ID\# 1036). Yet, one participant noted the opposite. She discontinued participating in the arts because of another individual, her teacher. This participant (ID\# 1015) noted, “...once I hit high school marching band (it) got negative because of the instructor and I quit the program." In addition to individuals, participants indicated that their self-efficacy was affected by examples and models.

Examples as Models. Some of the participants indicated that they enjoyed do-ityourself arts projects through on-line examples. They wrote, "I love Pinterest crafting when time permits" (ID\# 1056); along with,

Currently I'm not involved with anything serious in the arts, but I still love to express myself artistically. One of my favorite ways to do this is through "DIY" projects that I find on Pinterest (ID\# 1149).

It is evident that vicarious experiences in the arts are exhibited through peer interactions, teacher and parents, as well as models and examples. The next section examines the role of verbal/social persuasion with regards to self-efficacy to participating with and in the arts. 


\section{Verbal/Social Persuasion Written Responses}

The participants who responded to the written prompts indicated many positive experiences regarding verbal/social persuasion by their teachers of the arts subjects. About $52 \%$ of the respondents indicated a verbal or social experience that affected their self-efficacy in participating in the arts. One individual responded with, "I had very encouraging teachers that would push me to do something more advanced or more creative with the works I made" (ID\# 1061). This sentiment was echoed in the majority of the $52 \%$ of responses. One of the participants reminisced about a negative experience turned positive regarding verbal/social persuasion. The participant stated,

I did dance at a dance studio down the street from my house. I did tap for about 13 years and jazz for 14 years. There were times when it was negative because the teacher would sit on a chair and tell us what to do and get mad at the class when we can't [sic] figure it out since she didn't show us. She would also get mad at us for not learning as much as we needed to during that class because she would talk to the parents for half the class. When she retired, I got another dance teacher and that was definitely a positive experience. She made sure we knew what we were doing and asked us if we needed to go over anything before moving on (ID\# 1008).

Verbal and social persuasion as it relates to individuals self-efficacy in participating in the arts appears to fall heavily on the role of the arts educator of the subject and affects the confidence of the participant. The next session concludes the four pillars of Bandura's self-efficacy with the notion of the physiological state as it relates to the teacher candidates' self-efficacy in engaging with the arts. 


\section{Physiological State Written Responses}

For the physiological state of participants, many included their general feelings or reactions to their abilities regarding the arts. Several participants indicated a feeling of enjoyment when participating in the arts (ID\# 1061, 1036, 1014). One participant acknowledged the calming sensation that the arts can possess. She stated, "I will definitely use art because it is calming and gives everyone (teachers and students) a break from reality" (ID\# 1066). Another individual commented on the distracting ability the arts retain by stating, "I always thought of the arts, music specifically, as a place to escape from reality" (ID\# 1011).

A common theme that emerged within the physiological state category related to the individuals' belief in their abilities to perform or execute the arts. Although the enjoyment of participating in the arts is evident, the participants' belief in their ability was not evident. Many of the responses echoed the sentiment of one individual who wrote, "I feel like I have creative ideas, but no artistic ability to execute them" (ID\# 1107). This notion of enjoying the arts, but not having the ability to perform or participate in the arts, was evident and reiterated approximately 18 times from the 23 responses.

This concludes the results to the second research question, which asked, what are teacher candidates' levels of self-efficacy prior to enrolling in an arts integration course? Chapter five analyzes and interprets the results to the Arts Performance Self-Efficacy Scale (APSES) and responses to prompts. The next section reflects the results to research question three. 


\section{Research Question 3. Does teacher candidate's level of self-efficacy change as a result of participation in an arts integration course?}

To determine if there was a change, as a result of the participants taking an arts integration course, the preliminary and post APSES results were compared to one another to determine if there was a change in the students' self-efficacy to engage with and teach the arts. A paired-sample t-test was conducted to compare the pre-survey responses against the post-survey responses.

There was a significant difference in the scores for the composite pre-survey mastery experience in the arts $(\mathrm{M}=6.87, \mathrm{SD}=1.95)$ and the composite post-survey mastery experience in the arts $(\mathrm{M}=8.07, \mathrm{SD}=1.60)$ conditions; $\mathrm{t}(134)=-8.14, \mathrm{p}=.00$. In addition, there was also a significant difference in the scores for the composite pre-survey vicarious experiences in the arts $(\mathrm{M}=6.21, \mathrm{SD}=2.29)$ and the composite post-survey vicarious experiences in the arts $(\mathrm{M}=7.90, \mathrm{SD}=1.67)$ conditions; $\mathrm{t}(134)=-8.57, \mathrm{p}=.00)$.

For verbal/social persuasion in the arts there was a significant difference in the scores for the composite pre-survey $(\mathrm{M}=6.43, \mathrm{SD}=2.37)$ and the composite post-survey for verbal/social persuasion in the arts $(\mathrm{M}=7.66, \mathrm{SD}=1.88)$ conditions; $\mathrm{t}(132)=-7.84$, $\mathrm{p}=.00$. Also, for the physiological state there was a significant difference in the scores for the composite pre-survey $(\mathrm{M}=7.08, \mathrm{SD}=2.06)$ and the composite post-survey for physiological state in the arts $(\mathrm{M}=8.09, \mathrm{SD}=1.64)$ conditions; $\mathrm{t}(132)=-6.87, \mathrm{p}=.00$ (See Table 7). 
Table 7

Pre/Post Comparison

\begin{tabular}{lccc}
\hline Pillars of & $\begin{array}{c}\text { Pre-Survey } \\
\text { Composite Mean }\end{array}$ & $\begin{array}{c}\text { Post Survey } \\
\text { Composite Mean }\end{array}$ & t-value \\
\hline Mastery & 6.87 & 8.07 & -8.14 \\
Experiences & & & \\
Vicarious & 6.21 & 7.9 & -8.57 \\
Experiences & & & \\
Verbal/Social & 6.43 & 7.66 & -7.84 \\
Persuasion & & & -6.87 \\
Physiological State & 7.08 & 8.09 & \\
\hline
\end{tabular}

These results indicate that after taking an arts integration course in music, drama, or visual arts that there is a change in the level of self-efficacy for engaging, teaching, or participating in the arts. Specifically, participants develop a higher level of self-efficacy in the arts after participating in an arts integration course. The next section examines research question four.

Research Question 4. How do teacher candidates describe changes in their perceived self-efficacy experience in an arts integration course?

Participants were asked to respond to prompts at the conclusion of the arts integration course (see Appendix A). These questions specifically asked the participants if their personal feelings towards their self-efficacy changed in regards to integrating the arts, their level of creativity, and their arts ability after taking the arts integration course. 
Of the 149 participants, 77 participants completed the written responses. After reviewing the responses, five categories emerged from the respondents. These five areas were: confidence in integrating the arts, level of creativity, confidence in arts abilities, a feeling of more confidence/comfortability/lower level of inhibitions, and gaining subject knowledge. The following addresses each of these areas.

\section{Confidence in Integrating the Arts}

Of the 77 respondents to the post written prompts, 49 of the individuals specifically indicated gaining more confidence in integrating the arts in a classroom environment. One participants specifically noted, "After completing this class, I feel that my level of self-efficacy in integrating the arts into a classroom environment has changed. I am much more comfortable with integrating arts and it is much easier for me to add it into a classroom" (ID\# 1025). This sentiment was reiterated by others in the study who also found more confidence and comfortability in using and integrating the arts into the classroom curriculum.

One individual recalled her previous experiences with arts integration and recognized how the arts can have purpose in the classroom after taking the arts integration course. She stated,

I'm more confident in integrating the arts after taking this class. Before this class, it never seemed like my previous teachers had a purpose in giving us "arts and crafts" activities. I felt like it was an activity just to waste time. After this class, I feel like I can incorporate the arts and make sure there is a purpose for the activity" (ID\# 1008). 
However, one individual found the opposite to be true. She stated, "I understand art instruction but not much about how to incorporate it in a general education classroom. I am not very sure how to apply it to specific subjects" (ID\# 1155). This comment, however, was the minority of responses where overwhelming written responses specifically indicating a higher level of confidence and comfortability in integrating the arts in the classroom curriculum.

\section{Level of Creativity}

Participants also indicated a higher level of creativity after completing the arts integration course. Approximately half of the respondents reported that their creativity level increased. One student, who previously thought she was creative found that she developed even more creative abilities. She noted, "I feel that my creativity level has only increased throughout this course. I am a naturally creative person to begin with, but I feel that my eyes have widened to more creativity" (ID\# 1048).

Participants have also come to realize their need or desire to become more creative. One individual wrote, "I feel that I use to be super creative and have amazing art skills. However, taking this course has allowed me to realize that I need to start doing more to improve my skills and creativity. I have a strong desire now to start engaging in art more" (ID\# 1067).

However, a few individuals recognized that their creativity level has remained the same and that they still feel they are not creative. One individual bluntly stated, "I'm not very creative" (ID\# 1152) while another individual believes that her original creativity is lacking by stating: 
I was never really a creative person and I'm still not. I don't think this class helped with that. This class did give me ideas of what I can use in my future classroom. I can always tweak those activities to fit a lesson that I'm doing, but I can never come up with my own activities to do (ID\#1008).

Overall, a majority of the participants who completed the post written responses indicated a growth in their personal feelings towards their personal level of creativity.

\section{Confidence in Arts Abilities}

Students also indicated their feelings towards their abilities to engage with the arts. Several respondents felt like their arts abilities increased. One teacher candidate personally felt a higher increase in her abilities. She stated,

Before this class I would have put my level of creativity high but my level of arts ability low. Now, I would put creativity high and arts average.... to me this is a big improvement and I also now have the right footing to be able to take hold of my knowledge and excel further (ID\# 1003).

This feeling of increased artistic ability was reiterated in several other responses specifically recognizing artistic skills such as, highlighting and shadowing while coloring. However, several of the individuals still note a lack in their artistic abilities (ID\# 1133, \#1136, \#1146, and \#1152). Yet, one of these individuals felt that it would not hinder their implementation of the arts in their classroom (ID \#1152).

\section{A Feeling of More Confidence/Comfortability/Lower Level of Inhibitions}

Participants also reported a feeling of generalized confidence and comfortability with engaging with the arts. One participant indicated that, "It (the arts course) has been an extremely positive and important course in my career as a student. It allowed me to be 
creative and build my own confidence towards the arts" (ID\# 1127). This comment demonstrates an increased confidence in engaging with the arts. Another participant recognized how her level of inhibition or nervousness changed as a result of the course. She stated,

When I was in elementary school, we rarely used art concepts in the classroom so I was worried about how I would do that as a teacher. Now, after seeing all the different techniques that can be used, I feel confident that those theatre strategies will actually help teach lessons to my future students (ID\# 1024).

Several other participants resonated with the notion that there was a generalized increase in confidence, comfortably, and a lessening of nerves as a result of their participation in an arts integration course. However, one individual noted that her level of arts self-efficacy had, "stayed constant throughout the class" (ID\#1136).

\section{Subject Knowledge}

Participants also noted their feelings of increased general knowledge of the arts.

One student indicated that, "This class has greatly changed my perspective and viewpoint" (ID\# 1017). Additional respondents indicated that they now know more about various artistic techniques, materials, and artists. Participants also indicated that they became more knowledgeable about pedagogical techniques for using and teaching the arts in their classroom.

Overall, it is evident that teacher candidates describe changes in their perceived self-efficacy experiences after an arts integration course. These include a confidence in integration the arts, level of creativity, confidence in arts ability, a feeling of more confidence/comfortability/lower level of inhibitions, and a change in subject knowledge. 


\section{Summary}

This chapter revealed the results to the four research questions, which examined teacher candidates' self-efficacy, in the arts, through inquiring about their prior participation in the arts and their confidence in teaching the arts. The participants' responded to self-efficacy in the arts surveys and written reflections to written prompts regarding their engagement and involvement with the arts during the first week of classes and during the final week of classes, which revealed a wide range of experiences from involvement in arts classes to community and extra-curricular arts experiences.

Overall, the results determined that the participants' prior experiences with the arts and their self-efficacy level of teaching the arts, prior to enrolling in an arts integration course, differed significantly from their experiences with the arts and their self-efficacy level of teaching the arts after enrolling in an arts integration course.

Participants were also asked to respond to written prompts at the beginning of the semester and again at the end of the semester. These prompts were compared and analyzed using thematic coding to determine if participants' self-efficacy in the arts and teaching the arts shifted with enrollment in the arts integration course. The results indicated an increase in confidence and creativity in participating and teaching the arts. The following chapter analyzes and interprets the results of the four research questions. 


\section{CHAPTER V \\ SUMMARY, DISSCUSSION, IMPLICATIONS, LIMITATIONS, AND RECOMMENDATIONS}

The purpose of this mixed-method study was to determine the role of arts integration courses in the preparation of teacher candidates' self-efficacy in utilizing the arts in their future classroom. Through examining the teacher candidates' self-efficacy prior to and after taking an arts integration course, the researcher determined the effectiveness of the course on their self-efficacy and confidence in teaching and engaging in/with the arts. This study also examined students' prior experience in the arts, which determined their overall preparation for the arts integration course. In addition, this study was designed to answer the following research questions:

1) What is the level of teacher candidates' prior experiences with the arts?

2) What are teacher candidates' levels of teaching arts self-efficacy prior to enrolling in an arts integration course?

3) Does teacher candidates' level of arts teaching self-efficacy change as a result of participation in an arts integration course?

4) How do teacher candidates describe changes in their perceived self-efficacy experience in an arts integration course? 
Participants of the study were teacher candidates in early childhood education and elementary education who were enrolled in an arts integration course with a focus area in either visual arts, drama, or music. Of the 175 eligible participants, 149 teacher candidates participated in a pre-survey Arts Performance Self-Efficacy Scale (APSES) as well as responded, in writing, to prompts. Of the 145 who participated in the pre-survey, 135 individuals completed the post APSES survey and short-answer questions at the end of the semester.

The data gathered by way of the surveys and written prompts were analyzed both quantitatively and qualitatively to answer the four research questions posed in the study. The first two questions addressed the preliminary data from the pre-survey and written responses and the last two questions addressed any change from participating in an arts integration class. In the following section, a summary of the results obtained from the data analysis are discussed and the findings are compared with past research on teacher self-efficacy in the arts. Following the discussion section, the implications of the findings for teacher arts integration in the classroom, limitations of the study, and recommendations for practice and future research are outlined and presented.

\section{Discussion}

Teacher candidates who enroll in an arts integration course, during their time at university, bring with them a variety of experiences and confidences in teaching and participating in the arts. Through their previous experiences and exposure to the arts, their self-efficacy is affected to engage with and teach the arts in their future classrooms. The first two questions of this research study aimed to examine what the teacher 
candidates' arts experience level was, prior to taking an arts integration course, and to determine the level of teaching arts self-efficacy prior to enrolling in the class.

A pre APSES survey was used to examine the first question, which asked what the teacher candidates' arts experience level was prior to taking an arts integration course. Participants indicated positive prior experiences in the arts, in general, and each of the fine arts areas (dance, music, theatre, and visual arts). The results show that many of the individuals had above-average positive experiences in one or more of the arts with a higher percentage reflected in music.

These results indicate that teacher candidates often recalled enjoyable experiences and a sense of overall positive feelings towards their time in the arts. This higher than average positive feelings may be reported because of the affluent opportunities many of the students experienced in their community as youth. The most significant results of the data indicated that teacher candidates, prior to enrolling in an arts integration course, had a more positive overall experience in music than visual arts, dance, or theatre and a less positive overall experience in theatre than music, dance, or visual arts. The reason for the overall more positive experiences in music and least positive experience in theatre could correlate to two factors including, access to the arts and exposure to the arts.

Participants may have indicated a lower positive experience in theatre than music because individuals may not have had access to theatre education in their schools. With public schools narrowing the curriculum, less time is available for arts courses (Common Core, 2012; Engebretsen, 2013). Americans for the Arts indicate that $45 \%$ of secondary schools offer theatre and 91\% of secondary schools offer music (Engebretsen, 2013). This limited access to the arts affects an individual's positive experiences in all arts areas. 
Garvis (2012) indicated that when individuals are engaged in a supportive environment to discover and explore the arts as a means to communicate concepts and ideas individuals find themselves with more confidence in those art forms. Therefore, with a limited access to theatre education, students may feel less confident in participating and engaging with theatre in their arts integration courses.

Participants also indicated that not all of their exposure to the arts experiences came from a school environment, which may be another factor as to why there was a higher level of positive experiences in music than the other arts, with theatre being the least positive. Teacher candidates indicated separate venues where they were exposed to and engaged with arts. These venues included extra-curricular school endeavors, and community arts experiences. According to the U.S. Census Bureau, fifty-seven percent of children between 6 and 17 years old participate in at least one after-school extracurricular activity (Laughlin, 2014). In addition, the report indicated that students were more likely to participate in sports than clubs such as the arts (2014). Yet, 63\% of those individuals who participated in after-school arts programs engaged in music or art while dance and theatre were not calculated (Afterschool, 2014). Lummis, Morris, \& Paolino (2014) stated that the level of exposure to the arts affects the self-efficacy of participating, engaging, and teaching the arts. When teacher candidates are not exposed to positive arts experiences their overall self-efficacy of engaging with and in teaching the arts is affected. Without opportunities and exposure to theatre or dance, individuals will not feel as comfortable in their interactions with those art forms.

In addition, extra-curricular activities and community events in music or theatre offer a variety of opportunities that are taught by individuals or groups that have a wide- 
range of arts education experience and training. These experiences can range from afterschool programs to arts camps or professional training in the arts. Teens, who are engaged in after-school or community experiences in the arts prefer to be taught by individuals who are professionals or expert instructors of their craft and engage in experiential learning in inspiring spaces (Montgomery, Rogovin, \& Persaud, 2013). Although all experiences in the arts can enrich the lives of students and teachers, it is more beneficial to experience and learn about the arts with a teaching artist who can teach the arts along with the skills and abilities of an educator (Booth, 2003).

Research question 2 asked about the participants' level of teaching arts selfefficacy prior to enrolling in an arts integration course. Participants' responses to survey items related to each of Bandura's pillars of self-efficacy from the APSES and were used to assess teaching self-efficacy in the arts.

The data shows that the majority of participants reported neutral self-efficacy in teaching the arts indicating neither positive nor negative confidence in teaching and engaging with the arts, in their future classrooms. Teacher candidates, who are expected to teach the arts in their profession, only felt adequate in their abilities to engage with the arts. Without additional resources or arts courses, in their preparation to becoming future practicing teachers, their confidence will not improve and their students may be affected. Russell-Bowie and Dawson (2005) reiterate the importance of training and education in the arts for future and practicing teachers to increase confidence in teaching the creative arts. When teacher candidates have access to arts courses they are better prepared to teach the arts. 
The most significant result was that the teachers' self-efficacy appeared to be lowest in verbal/social persuasion and highest in the physiological state pillar. This demonstrates that teacher candidates, prior to taking an arts integration course, enjoy and have fond memories of participating in the arts, but feel that they have not received as much positive feedback or believe that they do not possess quality skills in the arts by themselves, or as their friends, family, or other teachers. One individual encapsulated this idea in her response to the prompts by stating, "I know that there are many people out there who are more creative than me, but I like thinking outside of the box." This response reinforces the notion that the individual feels an appreciation and satisfaction for being creative in the arts but has not received the positive influence by others who could encourage her to pursue her passions more deeply. In addition, students naturally compare themselves to others and although this individual enjoys being creative she is not at the point of adopting an arts-centered identity.

Garvis $(2009 ; 2012)$ also attributes teacher candidates' confidence in teaching the arts to their prior experiences with others in the arts. She identified that when a teacher candidate encounters negative feedback, on arts abilities, the individual is less likely to participate or engage with the arts. It is therefore important for teacher candidates, who have a desire and appreciate participating in the arts to be encouraged and fostered by their teachers, friends, and family to further their skills and exploration into the arts. This may help explain why students' self-efficacy remains in the neutral zone.

The last two, of the four, research questions asked if teacher candidates' level of arts teaching self-efficacy changed as a result of participating in an arts integration course 
and how teacher candidates described changes in their perceived self-efficacy experience in an arts integration course.

In order to examine the change of teacher candidates' level of arts teaching selfefficacy, as a result of participating in an arts integration course, the teacher participants' were asked to respond to survey items related to each of Bandura's four pillars of selfefficacy on an APSES post survey. The results showed that overall teacher responses were mostly positive, indicating that the teacher candidates who matriculated through an arts integration course demonstrated a higher level of self-efficacy in engaging with and teaching the arts after completing the course.

Teachers demonstrated significant and positive changes on all four areas of Bandura's pillars of self-efficacy (mastery experience, vicarious experiences, verbal/social persuasion, and physiological state) with the greatest amount of change found in vicarious experiences. Vicarious experiences related to the teacher candidates' reactions to how they engaged and compared their skills in the classes' material presented to them and related their skills and abilities to their peers, professionals, and instructor. Because of the communicative and interconnected material that the arts employ, participants naturally adopted artistic skills and abilities by observing their peers, instructor, and examples of the art form being used, which therefore increased selfefficacy. The increased vicarious experiences were clearly significant as one student remarked, "Working on the same project as my classmates encourages me to be more creative so that my project is unique and stands out." Tschannen-Moran, Hoy, and Hoy (1998) reinforced this notion by identifying that the closer the relationship between individuals, the stronger the impact on self-efficacy that can occur. When educators an 
arts courses can connect with students, provide a nurturing environment, and offer positive influence they are able to instill confidence and reassurance to guide the learners and encourage them to recognize their success in the arts.

The fourth and last research question asked how teacher candidates described changes in their perceived self-efficacy experience in an arts integration course. Five categories emerged from the qualitative data gathered from the teachers, which included: confidence in integrating the arts, level of creativity, confidence in arts abilities, a feeling of more confidence/comfortability/lower level of inhibitions, and subject knowledge.

Of these reactions, participants indicated more frequently that their confidence in integrating the arts in their classroom and their level of creativity increased after taking an arts integration course. These were the top two responses out of the five categories. The teacher candidates specifically recognized that they were more comfortable and confident in understanding how to teach and use the arts in their future classrooms. They also found that the work in the arts can be purposeful and impactful for their students. This sentiment was echoed by many of the participants with one individual stating, "After completing this class, I feel that my level of self-efficacy in integrating the arts into classroom environment has changed. I am much more comfortable with integrating arts and it is much easier for me to add it into a classroom." This understanding of the arts and how to use the arts is important to the future teacher because it allows educators to connect with their students through the material that is meaningful and accessible.

These results suggest similar conclusions as other arts programs such as Arts for Academic Achievement (AAA) and Creative Partnership. These programs also identify how the arts can connect with students and enhance learning in both the arts and non-arts 
subjects. When teacher candidates see the connection that the arts can play in their classroom with learning, they are more willing to try new approaches to engage the students (Hoy \& Woolfolk, 1990). However, unlike other studies, the researcher demonstrates a statistically significant difference coupled with qualitative determinants that clearly articulate the increase in confidence for teacher candidates to integrate the arts in their future classrooms.

The second of the two most pertinent responses were participants' feelings towards creativity. Teacher candidates felt that they had increased their level of creativity after taking this course. They recognized that they have more resources available to them, as future educators, and are willing to explore more opportunities to develop and create more creative lessons. Creative individuals can "benefit from opportunities, find new solutions for hardships they face, be curious and ask questions and speculate, tend to research and experiment, and have a strong imagination" (Sahin Zeteroglu; Dogan, \& Taner Derman, 2012, p. 3136). Therefore, this study's results suggest that teacher candidates, who acknowledge their increased level of creativity, will be more willing to develop and implement lessons that also instill creativity in their students.

It was also recognized that several of the individuals indicated a lack of change in their artistic ability in the arts after taking an arts integration course. This reaction is echoed by other researchers who recognized that teacher candidates often feel less confident in their artistic ability and are fearful of teaching the arts because they are not artistic (Ashworth, 2012; Davies, 2009; Oreck, 2004). However, some of the participants in this study realized that their artistic abilities could be improved, but did not believe that 
their teaching of the arts would be affected due to their increased confidence in creativity. One student clearly stated this directly by writing, "I have felt a boost in my creative abilities to be creative. I learned you don't need to perform like Picasso to be creative and have art ability." This recognition suggests that boosting students' confidence in using the arts may translate into greater arts integration in their future classroom, regardless of artistic ability. A feeling of more confidence in their creative growth can be a gateway into artistic skill development through continued engagement with the arts.

\section{Implications and Recommendations for Practice}

When teachers perceive their self-efficacy, in the arts, as limited or lower they are less likely to engage in in-depth and cross curricular arts experiences (Ashworth. 2012; Garvis \& Pendergast, 2010). Therefore, understanding teacher candidates' self-efficacy in teaching and engaging in the arts is crucial for positive arts integration in the classroom. The results of this study yielded two main implications on teacher preparation and the field of education. The first of these implications is the finding that taking an arts integration course increases self-efficacy in engaging and teaching the arts for teacher candidates, which boosts reciprocity of arts self-efficacy. The second implication is the need for more school-based arts classes with positive experiences from teachers to teach the arts in a manner that makes individuals feel confident and reinforces positive experiences in the arts.

This research supplies evidence that the result of taking an arts integration course increases self-efficacy in engaging and teaching the arts for teacher candidates. Teacher candidates need the skills, knowledge, and disposition of the arts in order to feel confident in teaching the arts and engage in interdisciplinary arts experiences. An arts 
integration course reinforces the education of the arts in a manner that is beneficial to general elementary and early childhood teachers. Arts integration courses provide teacher candidates a venue where they can learn about the arts in a safe and conducive manner that is constructive for them as future educators (Catterall, 1999). When teacher candidates feel that they are being nurtured in the arts-process through practical exercises, connections to classroom curriculum, and benefit from the positive feedback of their peers and professors they are more likely to embrace the arts in their future classrooms (Garvis, 2012). When teacher candidates have their own classroom, it is likely that their positive self-efficacy of teaching and embracing the arts will create an art-conscious classroom where students can also develop positive self-efficacy related to the arts. This reciprocity of arts self-efficacy develops citizens who are more confident to embrace the world in which they live. An arts-confident individual is more willing to try something new, work harder and longer to discover answers or solutions (Garvis, 2009; Mayesky, 2009).

The third implication is the need for more school-based arts classes with positive experiences from teachers to teach the arts in a manner that makes individuals feel confident and reinforces positive experiences in the arts. Teacher candidates, prior to enrolling in an arts integration course, signified that they were at a neutral level of confidence in the arts and had a basic understanding of their skills in the art forms. This research indicates that influence from outside and internal pressures affects teacher candidates' skill level, which, in turn, affects their teaching of the art form. Such evidence suggests that verbal/social persuasion and physiological states influence selfefficacy of the teacher candidates to teach and engage with the arts. Therefore negative 
rhetoric about the arts affects an individuals' understanding of the arts and how they see themselves participating in the arts. If teacher candidates are told that they are not good at an art form, their likelihood of teaching that art discipline, with a positive demeanor, is less likely. When teacher candidates are in an environment, such as an arts integration course, they are in an atmosphere where they can be positively influenced on their skills, knowledge, and disposition about the arts.

Participants also indicated a sense of well-being and enjoyment when they participated in the arts. Through participation in the arts, teacher candidates can experience gratifying opportunities, which creates a positive and more conducive environment for learning. Teacher candidates who have positive memories of participating in the arts will be able to teach the arts in their classrooms with a passion to recreate positive experiences for their students (Pajaras, 1992). When students experience curriculum that incorporates the arts they are more likely to be engaged in the learning process (Brouillette, 2010).

\section{Recommendations for Future Research}

This study specifically looked at the teacher candidates' self-efficacy in engaging with and teaching the arts prior-to and after taking an arts integration course. The study focused on the arts as a collective form. Based on the results of this study, the researcher recommends further investigation in each of the arts discipline (i.e., music, theater, etc.). By examining the individual art forms, further conclusions can be reached that directly affect students' preparation in teaching the arts.

In addition, further research should look at the teacher candidates' prior experiences in the arts. Through additional investigation, it would be beneficial to 
identify which experiences, in the arts, made the most impact on teacher candidates' appreciation or self-efficacy in engaging with the art form. This includes where, how, and what the students' arts involvements were. Prior experiences in the arts may be further studied regarding the age of the individuals when they were exposed to the arts opportunities. Formative arts experiences in early childhood and adolescence may be identified as points of investigation. Understanding the types and varieties of arts experiences available to the students will further connect teacher candidates' self-efficacy to the implications of resources and availability for learning in the arts.

Additional research on the long-term effects of an arts integration course in a teacher preparation program should also be considered for further research. Following teacher candidates into their future classrooms and researching their arts integration processes would provide insight into the long-term effects a university arts integration course has had on teachers' preparation for teaching and integrating the arts.

Understanding how teachers implement the arts and their sense of preparation to integrate the arts would be valuable information to the field of arts education.

\section{Limitations}

While the study yielded interesting outcomes, it is important to note the limitations of the study and highlight how that might influence the interpretation of the findings of the study. For instance, the sample size of this study was restricted by the number of students enrolled in arts integration courses available during the Fall semester of 2015. The one-semester sample size may have affected the findings as it is not representative of the teacher education program as a whole. A larger sample size would yield greater results and provide a precision of accuracy to detect the differences in 
levels. However, the results of this study provided a snapshot of students' levels of confidence in the arts that may be transferrable to the larger understanding of arts integration education.

The amount of courses available in each discipline was limited by the available faculty to teach those classes and amount of student interest in the arts class that they chose: music, visual arts, or drama. Dance integration courses were not offered during the semester which may have limited students' change in level of dance without the exposure to the art form. In addition, an unequal amount of courses and unequal dissemination of student enrollment in the courses may have limited the study. The unbalanced course offerings and amount of students enrolled may have affected the level change in self-efficacy as it relates to engaging and teaching the arts.

In addition, a balance of race, ethnicity, and gender was limited by the students who choose to enroll in the course at the time of the study. An overwhelming majority of the students identified as white female. This imbalance limits the study to the majority without equal representation of gender and race. Additionally, there was an assumption that respondents in this study would answer the questions accurately and truthfully.

As an educator of the arts integration theatre course, I realize that my relationship with the course may hold bias and the participants had the potential to be influenced by my involvement in their survey responses and lesson plans. To minimize bias an outside individual administered the survey and collected prompts for the research. Participants were assigned an identification number, by the outside individual, and names were removed from their responses. In addition, steps were taken, by the researcher, to reduce bias by implementing thematic coding and analysis in concluding the results. 
Interpretation of the coding and analysis was lessened by following Bandura's four pillars of self-efficacy. By categorizing the results into Bandura's four categories, the researcher reduced personal bias of interpretation.

\section{Conclusions}

In examining the experiences of teacher candidates' self-efficacy in the arts, the research found the importance and benefit of an arts integration course in the preparation of teacher candidates' abilities to teach the arts in their future classroom. Teacher candidates' self-efficacy with the arts, as well as, teaching the arts is evident through Bandura's four pillars of efficacy: mastery experience, vicarious experiences, verbal/social persuasion, and physiological state. Prior to participating in an artsintegration course participants indicated a variety of experiences in the arts from school classes, extra curricula activities, and community arts events with a neutral level of selfefficacy.

At the conclusion of the arts integration course, it was deduced that there was an increase in level of self-efficacy from neutral to positive in teacher candidates' selfefficacy in working with and teaching the arts. Participants indicated a higher level of integrating the arts in their future classrooms as well as their level of creativity. These findings suggest that arts-integration courses do, in fact, make a significant difference on teacher candidates' preparation for the classroom environments.

The results of this study mended a gap in research by verifying, through a mixedmethod study, that teacher candidates increase their level of self-efficacy in engaging with and teaching the arts after taking an arts integration course. Offering arts courses, at 
all levels of education, adds to the reciprocity of arts integration confidence and fosters both the arts and non-arts topics. 


\section{REFERENCES}

Adomat, D. S. (2012). Drama's Potential for Deepening Young Children's Understandings of Stories. Early Childhood Education Journal, 40, 343-350.

Afterschool Alliance. (2014). America After 3PM: Afterschool Programs in Demand. Washington, D.C

Allinder, R. (1994). The relationship between efficacy and the instructional practices of special education teachers and consultants. Teacher Education and Special Education, 17(2), 86-95.

Alter, F., Hays, T., \& O'Hara, R. (2009). The challenges of implementing primary arts education: What our teachers say. Australasian Journal of Early Childhood, 34(4), 22-31.

Americans for the Arts. (2014). Twenty years of government support for the arts: Federal, state and local. Washington D.C.: Americans for the Arts. Retrieved December 6, 2014, from http://www.americansforthearts.org/sites/default/files/pdf/2014/by_program/resea rch_studies_and_publications/one_pagers/2.\%20Government $\% 20$ Funding $\% 20 \mathrm{fo}$ r\%20the\%20Arts\%20\%2820\%20Years\%29.pdf

Andersen, M. (2009). Sociology: The essentials. Belmont CA: Thomson Wadsworth.

Anderson. (2003). Art education for life. International Journal of Art and Design, 22(1), 58-66.

Anderson, S., Walch, N., \& Becker, K. (2004). The power of art: The arts as an effective intervention strategy for at-risk youth. Los Angeles: California Endowment for the Arts.

Aprill, A. (2001). Toward a finer description of the connection between arts education and student achievement. Arts Education Policy Review, 102(5), 11-14.

Artful Learning Inc. (2008). Artful learning: A transformative learning system that simulates and deepens academic learning through the arts. New York: Leonard Bernstein Center. Retrieved December 7, 2014, from http://issuu.com/leonardbernstein/docs/al_brochure1/6?e=0 
Arts Alliance Illinois. (2009). Arts Alliance. Retrieved from Arts at the Core: Every School, Every Student: http://beta.artsalliance.org/sites/default/files/Arts\%20at\%20the\%20Core\%20Rese arch.pdf

Arts Education Partnership. (2006). Making a case for the arts. Retrieved December 16, 2014, from aep-arts: http://aep-arts.org/files/publications/MakingaCaseforarts.pdf

Asbury, C., \& Rich, B. (Eds.). (2008). Learning, arts and the brain: The Dana Consortium report on arts and cognition. New York, NY: Dana Press. Retrieved December 5, 2014, from http://www.dana.org/uploadedfiles/news_and_publications/special_publications/1 earning,\%20arts\%20and\%20the\%20brain_artsandcognition_compl.pdf

Ashford, E. (2004). NCLB's unfunded arts programs seek refuge. Education Digest, $70(2), 22-26$.

Ashworth, E. (2012). Informing art education practice: Perspectives of elementary teachers in northeastern Ontario. Canadian Review of Art Education: Research \& Issues, 39(1), 64-81.

attidudes. ((n.d.)). Dictionary.com Unabridged. Retrieved June 8, 2014, from Dictionary.com: http://dictionary.reference.com/browse/Attitudes

$\mathrm{Au}, \mathrm{W}$. (2007). High-stakes testing and curricular control: A qualitative metasynthesis. Educational Researcher, 36(5), 258-267.

Baker, D. (2013). Art integration and cognitive development. Journal for Learning through the Arts, 9(1), 1-15.

Bandura. (1971). Social Learning Theory. New York: General Learning Press. Retrieved October 13, 2014, from http://www.esludwig.com/uploads/2/6/1/0/26105457/bandura_sociallearningtheor y.pdf

Bandura. (1977). Self-efficacy: Toward a unify theory of behavioral change. Psychology Review, 191-215.

Bandura. (1986). Social foundation of thought and action: A social cognitive theory. Englewood Cliffs, NJ: Prentice-Hall.

Bandura. (1988). Organizational applications of social cognitive theory. Australian Journal of Management, 13(2), 275-302. 
Bandura. (1995). Self-efficacy in Changing Societies. New York: Cambridge University Press.

Bandura. (1997). Self-efficacy: The exercise of control. New York: W.H. Freeman.

Bandura. (2001). Social Cognitive Theory: An agentic perspective. Annual Review of Psychology, 52(1), 1-26.

Bandura. (2006). Toward a psychology of human agency. Perspectives on Psychological Science, 2, 164-180.

Bandura, A., Grusec, J., \& Menlove, F. (1966). Observatioanl learning as a function of symbolization and incentive set. Child Development, 3, 499-506.

Bandura, A., Ross, D., \& Ross, S. (1961). Transmission of aggression through imitation of aggressive models. Journal of Abnormal and Social Psychology, 63, 575-82. Retrieved October 13, 2014, from http://psychclassics.yorku.ca/Bandura/bobo.htm

Baranowski, T. (1989). Reciprocal determinism at the stages of behavior change: an integration of community, personal and behavioral perspectives. International Quarterly of Community Health Education, 10(4), 297-327.

Bauerlein, M., \& Grantham, E. (2009). National Endowment for the Arts: A history, 1965-2008. Washington, DC: National Endowment for the Arts.

Bayron, C. (2013). Social cognitive theory, entrepreneurial self-efficacy and entrepreneurial intentions: Tools to maximize the effectiveness of formal entrepreneurship education and address the decline in entrepreneurial activity. Griot, 6(1), 66-77.

Beveridge, T. (2010). No Child Left Behind and Fine Arts Classes. Arts Education Policy Review, 111(1).

Bicard, S. C., Bicard, D. F., \& IRIS Center. (2012). Defining behavior. Retrieved September 14, 2014, from http://iris.peabody.vanderbilt.edu/case_studies/ICS015.pdf

Booth, E. (2003). What is a teaching artist? Teaching Artist Journal, 1(1), 5-12.

Bordelon, T. D., Phillips, I., Parkison, P. T., Thomas, J., \& Howell, C. (2012). Teacher efficacy: How teacher rate themselves and how students rate their teachers. Action in Teacher Education, 34(1), 14-25. 
Bornfreund, L. (2013). An ocean of unknowns: Risks and opportunities in using student achievement data to evaluate preK-3rd grade teachers. New America Foundation. Retrieved December 6, 2014, from

http://earlyed.newamerica.net/sites/newamerica.net/files/policydocs/OceanofUnk nowns-LBornfreund.PDF

Boyatzis, R. (1998). Transforming qualitative information: Thematic analysis and code development. Thousand Oaks CA: Sage Publications.

Braun, V., \& Clarke, V. (2006). Using thematic analysis in psychology. Qualitative Research in Psychology, 3(2), 77-101.

Brien, D. (2011). Learning the "Lessons of the Arts": Creativity, creative arts education and creative arts educators today. Studies in Learning, Evaluation, Innovation, \& Development, 8(2), 96-108.

Brouillette, L. (2010). How the arts help children to create healthy social scripts:

Exploring the perceptions of elementary teachers. Arts Education Policy Review, 111(1), 16-24.

Brown, E. D., Benedett, B., \& Armistad, M. E. (2010). Arts enrichment and school readiness for children at risk. Early Childhood Research Quarterly, 25, 112-124.

Burnaford, G. (2007). Arts integration frameworks, research, and practice: A literature review. Washington D.C.: Arts Education Partnership.

Burton, J. M., Horowitz, R., \& Abeles, H. (2000). Learning in and through the arts: The question of transfer. Studies in Art Education, 41(3), 228-257.

Catterall. (1998). Does experience in the arts boost academic achievement? A response to Eisner. Art Education, 4, 6-11.

Catterall. (1999). Champions of change: The impact of the arts on learning. Washington D.C: Washington, D Arts Education Partnership: President's Committee on the Arts and the Humanities.

Catterall. (2002). The arts and the transfer of learning. In R.J. Deasy (Ed.). Critical Links: Learning in the Arts and Student Academic and Social Development, 162-168. Retrieved December 6, 2014, from http://www.gpo.gov/fdsys/pkg/ERICED466413/pdf/ERIC-ED466413.pdf

Catterall. (2005). Conversation and silence: Transfer of learning through the arts. Journal for Learning through the Arts: A Research Journal on Arts Integration in Schools and Communities, 1(1), 1-12. 
Chapman, L. (2004). No child left behind in art? Arts Education Policy Review, 106(2), 3-17.

Charmaz, K. (2010). Grounded Theory: Objectivist and constructivist methods. In W. Luttrell, Qualitative educational research: Readings in reflexive methodology and transformative practice (pp. 183-207). New York: Routledge.

Civic Impulse. (2016). S. 1177 - 114th Congress: Every Student Succeeds Act. Retrieved from https://www.govtrack.us/congress/bills/114/s1177

Collins, E., \& Chandler, S. (1993). Beyond arts as product: Using an artistic perspective to understand classroom life. Theory into Practice, 32(4), 199-203.

Common Core. (2012). Learning Less: Public School Teachers Describe a Narrowing Curriculum. The Farkas Duffett Research Group. Retrieved December 6, 2014, from http://commoncore.org/maps/documents/reports/cc-learning-less-mar12.pdf

Creative Partnerships. (n.d.). Creative Partnerships Program Brochure. England: Creative Culture and Education. Retrieved December 7, 2014, from http://creativepartnerships.com/wp-content/uploads/Creative_Partnerships_brochure.pdf

Creswell. (2015). A concise introduction to mixed methods research. Los Angeles: Sage.

Creswell, J. (2003). Research design qualitative, quantitative, and mixed methods approach (2nd ed.). London: Sage Publications.

Curva, F; et al. (2005). Artful Citizenship Project three-year project report. Tallahassee, FL.: Unpublished evaluation report. Retrieved February 16, 2015, from www.artfulcitizenship.org/pdf/full_report.pdf

Darling-Hammond, \& Bransford. (2005). Preparing Teachers for a Changing World: What teachers should learn and be able to do. San Francisco: Jossey-Bass.

Davies, D. (2009). Enhancing the role of the arts in primary pre-service teacher education. Teaching and Teacher Education, 26, 630-638.

Davis, J. (1999). Nowhere, Somewhere, Everywhere: The Arts in Education. Education Policy Review, 100(5), 23-28.

Deasy. (2003). Creating quality integrated and interdisciplinary arts programs: A report of the Arts Education National Forum. Washington D.C.: Arts Education Partnership. 
Deasy, R., et al., (2002). Critical links: Learning in the arts and student academic and social development. Washington D.C.: Arts Education Partnership.

DeMoss, K., \& Morris, T. (2002). How arts integration supports student learning: Students shed light on the connections. Chicago: Chicago Arts Partnerships in Education (CAPE). Retrieved December 6, 2014, from http://www.capeweb.org/wp-content/uploads/2011/05/support.pdf

Denler, H. (2014, January 28). Social Cognitive Theory. Retrieved February 20, 2015, from education.com: http://www.education.com/reference/article/socialcognitive-theory/

DeSantis, K., \& Housen, A. (2007). Aesthetic development and creative and critical thinking skills study. Visual Understanding in Education. Retrieved from http://artsed.issuelab.org/resource/aesthetic_development_and_creative_and_criti cal_thinking_skills_study

D'Esposito, M. (2008). Developing and implementing neuroimaging tools to determine if training in the arts impacts the brain. In C. Asbury, \& B. Rich (Eds.), Learning, arts, and the brain: The Dana consortium report on arts and cognition (pp. 71-80). New York/ Washington D.C.: Dana Press.

Dietrich, A. (2004). The cognitive neuroscience of creativity. Psychonomic Bulletin \& Review, 11(6), 1011-1026.

Dimitriadis, G., Cole, E., \& Costello, A. (2009). The social field(s) of arts education today: Living vulnerability in neo-liberal times. Discourse: Studies in the Cultural Politics of Education, 30(4), 361-379.

Donahue, D., \& Stuart, J. (2008). Working towards balance: Arts integration in preservice teacher education in an era of standardization. Teaching and Teacher Education: An International Journal of Research and Studies, 343-355.

Dwyer, C. (2011). Reinvesting in arts education: Winning America's future through creative schools. Washington D.C.: President's Committee on the Arts and the Humanities.

Ebert, C. (2013, December 11). Comprehensive Arts Ed Plan. Retrieved December 9, 2014, from North Carolina Legislation: http://ances.ncdpi.wikispaces.net/Comprehensive+Arts+Ed+Plan 
Editorial Projects in Education Research Center. (2011, July 18). Adequate Yearly Progress. Retrieved December 6, 2014, from Education Week: http://www.edweek.org/ew/issues/adequate-yearly-progress/

Efland, A. (1989). A History of Art Education: Intellectual and social currents in teaching the visual arts. New York: Teachers College Columbia University c1989.

Eisner. (1988). The Role of Discipline-based Art Education in America's Schools. Los Angeles: Getty Center for Education in the Arts.

Eisner. (1998). Does experience in the arts boost academic achievement. Art Education, 51(1), 7-15.

Eisner. (2002). What can education learn from the arts about the practice of education? Journal of Curriculum \& Supervision, 18(1), 4-16.

Eisner. (2005). Reimagining schools: The selected works of Ellliot W. Eisner. New York: Routledge.

Eisner, E. (1974). Is the artist in the school program effective? Art Education, 2, 19.

Eisner, E. W. (1988). The Role of Discipline-based Art Education in America's Schools. Los Angeles: Getty Center for Education in the Arts.

Engebretsen, K. (2013). Arts Education Navigator: Facts \& Figures. Washington D.C.: Americans for the Arts. Retrieved January 15, 2016. http://sasymphony.org/wpcontent/uploads/2015/03/AFTA_Navigator_Facts-and-Figures.pdf

Ennis, C. D. (1999). A theoretical framework: The central piece of a research plan. Journal of Teaching in Physical Education, 18, 129-140.

Ertmer, P. A., Conklin, D., Lewandowski, J., Osika, E., Selo, M., \& Wignall, E. (2003). Increasing preservice teachers' capacity for technology integration through the use of electronic models. Teacher Education, 30(1), 95-112.

Fraenkel, J., Wallen, N., \& Hyun, H. (2014). How to design and evaluate research in education (8th ed.). New York, NY: McGraw Hill.

Furman, L. (2000). In support of drama in early childhood education, again. Early Childhood Education Journal, 27(3), 173-179.

Gadsden, V. (2008). The arts and education: Knowledge generation, pedagogy, and the discourse of learning. Review of Research in Education, 32, 29-61. 
Garvis, S. (2009). Improving the teaching of the arts: Pre-service teacher self-efficacy towards arts education. US-China Education Review, 6, 23-28.

Garvis, S. (2012). A Self-study in Teacher Education: learning to teach in higher education after teaching the arts to young children. US-China Education Review, B(3), 298-304.

Garvis, S. (2012). These children aren't creative: Insights from beginning teachers on early childhood arts education. Australasian Journal of Early Childhood, 37(1), 161-165.

Garvis, S., \& Pendergast, D. (2010). Middle years teachers' past experiences of the arts: Implications for teacher education. Australian Journal of Music Education, 2, 2840.

Garvis, S., Twigg, D., \& Donna, P. (2011). Breaking the Negative Cycle: The formation of self-efficacy beliefs in the arts. A focus on professional experience in preservice teacher education. Australasian Journal of Early Childhood, 36(2), 36-41.

Gibson, S., \& Dembo, M. (1984). Teacher Efficacy: A construct validation. Journal Of Educational Psychology, 4, 569-82.

Goddard, R. D., Hoy, W. K., \& Hoy, A. (2000). Collective teacher efficacy: Its meaning, measure, and impact on student achievement. American Educational Research Journal, 37(2), 479-507.

Goddard, R. D., LoGerfo, L., \& Hoy, W. K. (2004). High school accountability: The role of perceived collective efficacy. Educational Policy, 18(3), 403-425.

Goff, R., \& Ludwig, M. (2013). Teacher practice and student outcomes in arts-integrated learning settings: A review of literature. Washington D.C.: American Institutes for Research.

Goldblatt, P. (2006). How John Dewey's theories underpin art and art education. Education and Culture, 22(1), 17-34.

Gouzouasis, P., Guhn, M., \& Kishor, N. (2007). The predictive relationship between achievement and participation in music and achievement in core Grade 12 academic subjects. Music Education Research, 9(1), 81-92.

Green, S., \& Salkind, N. (2009). Using SPSS for Windows and Macintosh analyzing and understanding data. Boston, MA: Pearson. 
Griffin, N., \& Miyoshi, J. (2009). Third year report: Evaluation of the Artful Learning Program. Los Angeles: National Center for Research on Evaluation, Standards, and Student Testing; Center for the Study of Evaluation.

Grumet, M. (2004). No one learns alone. In N. Rabkin, \& R. Redmond (Eds.), Putting the arts in the picture: Reframing education in the 21st century (pp. 41-80). Chicago, IL: Columbia College Chicago.

Guba, E., \& Lincoln, Y. (1981). Effective evaluation: Improving the usefulness of evaluation results through responsive and naturalistic approaches. San Francisco: Jossey-Bass.

Gullatt, D. (2007). Research links the arts with student academic gains. The Educational Forum, 71(3), 211-220.

Hallam, J., Gupta, M., \& Lee, H. (2008). An exploration of primary school teachers' understanding of art and the place of art in the primary school curriculum. Curriculum Journal, 19(4), 269-281.

Harris, E. L. (2006). Mary Dourglas's typology of grid and group. In V. A. Anfara, \& N. Mertz, Theoretical Frameworks in Qualitative Research (pp. 129-154). London: Sage Publications.

Heilig, J. V., Cole, H., \& Aguilar, A. (2010). From Dewey to No Child Left Behind: The evolution and devolution of public arts education. Arts Education Policy Review, 111(4), 136-145.

Hetland, L., \& Winner, E. (2000). The arts and academic achievement: What the evidence shows. Arts Education Policy Review, 102(5), 3-6.

Hoy. (2000). Changes in teacher efficacy during the early years of teaching. American Educational Research Association (pp. 1-26). New Orleans: Qualitative and Quantitative Approaches to Examining Efficacy in Teaching and Learning.

Hoy, W. K., \& Woolfolk, A. (1990). Socialization of student teachers. American Educational Research Journal, 93, 279-300.

Illinois, A. A. (2009). Arts Alliance. Retrieved from Arts at the Core: Every School, Every Student:

http://beta.artsalliance.org/sites/default/files/Arts\%20at\%20the\%20Core\%20Rese arch.pdf 
Ingram, D., \& Seashore, K. (2003). Arts for academic achievement: Summative evaluation Report. Minneapolis: Center for Applied Research and Educational Improvement.

Issue Brief. (2014). Funding the arts in education program at the U.S. Department of Education. Improving Access to Arts Education for all Students. Arts Advocacy. Retrieved December 7, 2014, from http://www.tcg.org/pdfs/advocacy/AIE_2014.pdf

Ivankova, N. V., Creswell, J. W., \& Stick, S. (2006). Using mixed-methods sequential explanatory design: From theory to practice. Field Methods, 18(1), 3-20.

Kaufmann, K. (2006). Inclusive Creative Movement and Dance. Champaign, IL: Human Kinetics.

Keinanen, M., Hetland, L., \& Winner. (2000). Teaching cognitive skill through dance: Evidence for near but not far transfer. Journal of Aesthetic Education, 34, 295306.

Kliebard, H. M. (2004). The Struggle for the American Curriculum, 1893-1958 (3rd ed.). New York, NY: RoutledgeFalmer.

Koster, J. B. (2014). Growing Artists: Teaching Art to Young Children (6th ed.). Boston, MA: Cengage Learning.

Lackey, L., Chou, C., \& Hsu, P. (2010). Seeking coalitions between certified and noncertified art educators. Studies in Art Education, 51(4), 315-326.

Laughlin, L. (2014). A Child's Day: Living Arrangements, Nativity, and Family Transitions: 2011. Current Population Reports. U.S. Census Bureau, Washington, DC. $70-139$.

Learning Through the Arts. (2002). Learning through the arts: A guide to the National Endowment for the Arts and Arts Education. Washington, DC: National Endowment for the Arts Office of Communications.

Lee, Y. Y., \& Ertmer, P. A. (2006). Increasing the impact of vicarious learning experiences through the use of small group discussions and question prompts. Technology and Teacher Education Annual, 3, 1685-1689.

Lemon, N., \& Garvis, S. (2013). What is the role of the arts in a primary school?: An investigation of perceptions of pre-service teachers in Australia. Australian Journal of Teacher Education, 38(9), 1-9. 
Likert, R. (1932). A technique for the measurement of attitudes. Archives of Psychology, $140,1-55$.

Lovley, E. (2007, November 5). Arts Educators Battle No Child Left Behind. Retrieved September 29, 2014, from Policico.com: http://www.politico.com/news/stories/1107/6715.html

Lummis, G., Morris, J., \& Paolino, A. (2014). An investigation of Western Australian pre-service primary teachers' experiences and self-efficacy in the arts. Australian Journal of Teacher Education, 39(5), 50-64.

May, B. (2013). Arts integration: What's the problem? General Music Today, 2, 5-8.

Mayesky, M. (2009). Creative activities for young children. Clifton Park, NY: Delmar.

McCown, R., Driscoll, M., \& Roop, P. G. (1996). Educational psychology: A learningcentered approach to classroom practice (2nd ed.). Needham Heights, MA: Allyn $\&$ Bacon.

McLeod, S. A. (2008). Likert Scale. Retrieved December 16, 2014, from Simply Psychology: http://www.simplypsychology.org/likert-scale.html

McLeod, S. A. (2010). Sensorimotor Stage. Retrieved November 25, 2014, from Simply Psychology: http://www.simplypsychology.org/sensorimotor.html

Melnick, S. J., Witmer, J., \& Strickland, M. (2011). Cognition and student learning through the arts. Arts Education Policy Review, 112(3), 154.

Merriam, S. (2007). Qualitative research and case study applications in education (2nd ed.). San Francisco CA: Jossey-Bass.

Miller, M. (1993). Efficacy strength and performance in competitive swimmers of different skill levels. International Journal of Sport Psychology, 24, 284-296.

Montgomery, D., Rogovin, Peter, P., \& Persaud, N. (2013). Something to say: Success principles for afterschool arts programs from urban youth and other experts. The Wallace Foundation

Moscowitz, G. (2005). Social cognition: Understanding self and others. New York: Guilford Press.

National Governors Association Center for Best Practices \& Council of Chief State School Officers. (2010). Common Core State Standards. Washington, DC: Authors. 
National Governors Association Center for Best Practices, C. o. (2010). Common Core State Standards. Washington D.C.: National Governors Association Center for Best Practices, Council of Chief State School Officers.

Nespor, J. (1987). The role of beliefs in the practice of teaching. Journal of Curriculum Studies, 19, 317-328.

No Child Left Behind Act of 2001. (2002). P.L. 107-110, 20 U.S.C. § 6319.

Onosko, J. (2011). Race to the Top leaves children and future citizens behind: The devastating effects of centralization, standardization, and high stakes accountability. Democracy and Education, 19(2), 1-11.

Oreck, B. (2004). The artistic and professional development of teachers. Journal of Teacher Education, 55(1), 55-69.

Ozdemir, S., \& Cakmak, A. (2008). The effect of drama education on prospective teachers' creativity. International Journal of Instruction, 1(1), 13-30.

Pajares. (1997). Current directions in self-efficacy research. (Vol. 10). (P. Pintrich, \& M. Maehr, Eds.) Greenwich, CT: JAI Press.

Pajares, M. (1992). Teachers' beliefs and educational research: Cleaning up a messy construct. Review of Educational Research, 62, 307-332.

Parsad, B., \& Spiegelman, M. (2012). Arts Education in Public Elementary and Secondary Schools: 1999-2000 and 2009-10. Washington D.C.: National Center for Education Statistics Institute of Education Sciences U.S. Department of Education.

Patton, M. (2002). Qualitative research \& evaluation methods (3rd ed.). London: Sage Publications.

perceptions. ((n.d.)). Collins English Dictionary - Complete \& Unabridged 10th Edition. Retrieved June 8, 2014, from Dictionary.com:

http://dictionary.reference.com/browse/perceptions

Perez, J. (2014, October 20). Millions pledged to carry out CPS arts program. Retrieved December 7, 2014, from Chicago Tribune: http://www.chicagotribune.com/news/local/breaking/ct-cps-arts-educationfunding-met-20141020-story.html

Perkins, D. (1992, September 2). Transfer of Learning. Retrieved December 6, 2014, from Learn Web: https://learnweb.harvard.edu/alps/thinking/docs/traencyn.htm 
Podlozny, A. (2000). Strengthening verbal skills through the use of classroom drama: A clear link. Journal of Aesthetic Education, 34(3-4), 239-276.

Pool, J., Dittrich, C., \& Pool, K. (2011). Arts Integration in Teacher Preparation: Teaching the Teachers. eScholarship.

Posner, M., Rothbart, M., Sheese, B., \& Kieras, J. (2008). How arts training influences cognition. In C. Asbury, \& B. Rich (Eds.), Learning, arts, and the brain: The Dana consortium report on arts and cognition (pp. 1-10). New York/ Washington D.C.: Dana Press.

Protheroe, N. (2008, May/June). Teacher efficacy: What is it and does it matter? Principal, pp. 42-45.

Reardon, C. (2005). Deep in the arts of Texas: Dallas public schools are boosting student achievement by integrating the arts into the curriculum. Ford Foundation Report, 36(1), 23-29. Retrieved December 6, 2014, from http://www.creardon.com/archives/FFR/Deep_in_the_Arts_of_Texas.pdf

Riggs, I. M., \& Enochs, L. G. (1990). Toward the development of an elementary teacher's science teaching efficacy belief instrument. Science Education, 625-637.

Ruppert, S. (2006). Critical evidence: How the arts benefit student achievement. Washington DC: National Assembly of State Arts Agencies.

Russell-Bowie, D. (2009). Learning to teach the creative arts in primary schools through community engagement. International Journal Of Teaching And Learning In Higher Education, 20(2), 298-306.

Russell-Bowie, D. (2010). Cross-national comparisons of background and confidence in visual arts and music education of pre-service primary teachers. Australian Journal Of Teacher Education, 35(4), 65-78.

Russell-Bowie, D., \& Dowson, M. (2005). Effects of background and sex on confidence in teaching the creative arts: Tests of specific hypotheses. Paper presented at the Australian Association for Research in Education Conference. Sydney Australia. Retrieved December 7, 2014, from http://www.aare.edu.au/data/publications/2005/rus05351.pdf

Sabol, R. F. (2010). No Child Left Behind: A study of its impact on art education. West Lafayette, Indiana: Purdue University. 
Sahin Zeteroglu, E., Dogan, Y., \& Taner Derman, M. (2012). Determining the Opinions of Preschool and Primary School Teacher Candidates on Creativity and Metaphorical Perception. Educational Sciences: Theory and Practice, 12(4), 3135-3152.

Samuelsson, I. P., Carlsson, M. A., Olsson, B., \& Pramling, N. \&. (2009). The Art of Teaching Children the Arts: Music, dance and poetry with children aged 2-8 years old. International Journal of Early Years Education, 17(2), 119-135.

Schlegel, A., Alexander, P., Fogelson, S. V., Li, X., Lu, Z., Kohler, P. J., \& ... Meng, M. (2015). The artist emerges: Visual art learning alters neural structure and function. Neuroimage, 105, 440-451.

Schunk, D. H. (1983). Developing children's self-efficacy and skills: the roles of social comparative information and goal setting. Contemporary Educational Psychology, 8, 76-86.

Schussler, D. L., Stooksberry, L. M., \& Bercaw, L. A. (2010). Understanding teacher candidate dispositions: Reflecting to build self-awareness. Journal of Teacher Education, 61(4), 350-363.

Shaughnessy, M. F. (2004). An interview with Anita Woolfolk: The educational psychology of teacher efficacy. Educational Psychology Review, 16(2), 153-176.

Silverstein, L., \& Layne, S. (2010). Defining Arts Integration. Retrieved March 14, 2014, from ArtsEdge: http://artsedge.kennedy-center.org/educators/how-to/artsintegration-beta/what-is-arts-integration-beta

Sincero, S. (2011, March 11). Cognitive Learning Theory. Retrieved February 20, 2015, from Explorable.com: https://explorable.com/cognitive-learning-theory

Sincero, S. (2012, March 18). Advantages and Disadvantages of Surveys. Retrieved December 9, 2014, from Explorable: https://explorable.com/advantages-anddisadvantages-of-surveys

Sousa, D. (2006). How the arts develop the young brain. School Administrator, 63(11), 26-31.

South Arts. (2013). Principal perspectives on obstacles, barriers, and improvements to the arts in education. Retrieved December 6, 2014, from Alabama Data: http://www.southarts.org/resources/research-and-publications/research/artseducation/alabama-data/ 
Spelke, E. (2008). Effects of music instruction on developing cognitive systems at the foundations of mathematics and science. In C. Asbury, \& B. Rich (Eds.), Learning, arts, and the brain: The Dana consortium report on arts and cognition (pp. 17-49). New York/ Washington D.C.: Dana Press.

Stevenson, L. (2006, March). The arts: New possibilities for teaching and learning. Principal's Research Review, 1(2), 1-6. Retrieved December 6, 2014, from https://www.nassp.org/portals/0/content/53584.pdf

Stevenson, L., \& Deasy, R. J. (2005). Third space: When learning matters. Washington D.C.: Arts Education Partnership.

Strauss, A., \& Corbin, J. (1998). Basics of qualitative research: Grounded theory procedures and techniques (2nd ed.). Newbury Park, CA: Sage.

Stuht, A., \& Gates, J. (2007). The case for arts-based curriculum. Leadership, 30-33.

Taylor, I. M., \& Ntoumanis, N. (2007). Teacher motivational strategies and student selfdetermination in physical education. Journal of Educational Psychology, 99, 747-760

Tschannen-Moran, M., \& Hoy, A. (2001). Teacher efficacy: Capturing an elusive construct. Teaching and Teacher Education, 17(7), 783-805.

Tschannen-Moran, M., Hoy, W., \& Hoy, W. K. (1998). Teacher efficacy: Its meaning and measure. Review of Educational Research, 68(2), 202-248.

United States. (1983). A nation at risk: The imperative for education reform. Washington D.C.: National Commission on Excellence in Education.

Usher, E. L., \& Pajares, F. (2008). Sources of self-efficacy in school: Critical review of the literature and future directions. Review of Educational Research, 78(4), 751796.

Venkatesh, V., Brown, S. A., \& Bala, H. (2013). Bridging the qualitative-quantitative divide: Guidelines for conducting mixed methods research in information systems. MIS Quarterly, 37(1), 21-54.

Visual Thinking Strategies. (2014). What is VTS. Retrieved December 7, 2014, from VTS: http://www.vtshome.org/

Vogt, W., Gardner, D., \& Haeffele, L. (2012). When to use what research design. New York: The Guilford Press. 
Woolfolk, A., \& Hoy, W. (1990). Prospective teachers sense of efficacy and beliefs about control. Journal of Educational Psychology, 82(1), 81-91.

Wright, L. (1985). Preparing teachers to put drama in the classroom. Theory into Practice, 14(3), 205-210.

Zelenak, M. S. (2011). Self-efficacy in music performance: Measuring the sources among secondary school music students. Retrieved from Available from ProQuest Dissertations \& Theses Full Text: http://search.proquest.com/docview/884618089?accountid=11578

Zientek, L. (2007). Preparing high-quality teachers: Views from the classroom. American Educational Research Journal, 4, 959-1001.

Zimmerman, E. (2012, December 7). A case for integrating art into a variety of teaching and learning environments. Retrieved December 6, 2014, from Advocacy White Papers for Art Education:

http://www.arteducators.org/advocacy/NAEA_WhitePapers_4.pdf 


\title{
APPENDIX A \\ PROMPT QUESTIONS
}

\author{
Entry Prompts
}

- Discuss your prior experiences in the arts (music, dance, theatre, visual arts)? . Where they positive or negative?

- How do you feel about your own level of creativity and arts ability?

- Do you believe you will use the arts in an integrated manner in your future classroom? Why or why not?

\section{Exit Prompts}

- After completing this class, do you feel that your level of self-efficacy (confidence) in integrating the arts into a classroom environment has changed? If so, how do you feel it has changed?

- How do you feel about your own level of creativity and arts ability after taking this course?

- Do you believe you will use the arts in an integrated manner in your future classroom? Why or why not? 


\section{APPENDIX B DEMOGRAPHIC INFORMATION}

Privacy Protection: Only the principal investigator will have access to the information you provide in this survey. You will not be asked for your name, but will be asked for other information that will be used to compare groups of students.

Please tell me about yourself.

Name:

Age:

What is your gender?

Male Female

What is your race?

__ White__Black__Asian___Hispanic__Native American

What is your academic level?

__ Freshman ___Sophomore___Junior___Senior

Are you a Transfer Student? ___ Yes ___ No

What is your major?

Early Childhood ___ Elementary Education ___ Special Education

Other (explain)

In what arts integration class are you currently enrolled?

Visual Arts ___ Music ___ Drama ___ Dance 


\section{APPENDIX C}

\section{PRELIMINARY STUDY}

Identification Code:

Music Performance Self-Efficacy Scale

Directions: Respond to the following statements based on your current level of musical ability, experience, and primary instrument or voice. There is no right or wrong answers. Indicate to what degree you either agree or disagree with the statement by writing any number between 0 (Strongly Disagree) and 100 (Strongly Agree) on the line next to the statement. Carefully consider the number you choose.

0 10 20 30 40 50 60 70 80 90 100

Strongly Strongly

Disagree Agree

\section{$\underline{\text { Part I - (Mastery experiences) }}$}

1. I have had positive experiences performing music in the past.

2. I have had positive experiences performing in large ensembles.

3. I have had positive experiences performing solo, or, in a small ensemble.

4. I have had positive experiences performing simple music.

5. I have had positive experiences performing complicated music.

6. I have overcome musical challenges through hard work and practice.

7. I have used a practice routine to help me prepare for my performances. 


\section{$\underline{\text { Part II - (Vicarious experiences) }}$}

8. I have improved my music performance skills by watching professional musicians, who are similar to me in some way, perform well.

9. I have improved my music performance skills by watching other students, who are similar to me in some way, perform well.

10. I have used other music students as models to improve my performance skills.

11. I have compared my performance skills with those of other students who are similar in musical ability to me.

12. I have watched other students of similar musical ability as me perform a piece of music, and then decided whether I could, or could not, perform the same piece of music.

\section{$\underline{\text { Part III - (Verbal/Social persuasion) }}$}

13. My friends think I am a good performer on my primary instrument.

14. Members of my family believe I perform well.

15. My music teacher has complimented me on my musical performance.

16. People have told me that my practice efforts have improved my performance skills.

17. I have received positive feedback on music performance evaluations.

18. I have met or exceeded other people's expectations of being a good musician for someone of my age.

19. Write only the number 9 for this answer (not $0-100$ rating).

\section{$\underline{\text { Part IV - (Physiological state) }}$}

20. Performing with my instrument makes me feel good (Return to using 0-100 rating).

21. I enjoy participating in musical performances.

22. I am learning, or have learned, to control nervousness during a performance. 
23. I do not worry about small mistakes during a performance.

24. I have positive memories of most, or all, of my past musical performances.

Place an " $\mathrm{X}$ " next to the correct response. What is your gender? Male Female What is your race? Asian Black Hispanic Indian (American)

White Mixed Other

What is your grade level? 6 7 8 9 $10 \_11 \_12$

Are you enrolled in a music class at this school? Yes No If you answered "Yes," what is the name of the class? If you answered "Yes," what is your primary instrument? What is the teacher's name in whose class you took this survey? 
APPENDIX D

\section{COPYRIGHT APPROVAL}

$$
\text { michal vetere }
$$

PROPOSAL APPROVAI FORM

This is the first-time submission

(1) First Time Submission/Revision

$\square$ This is a revised submission

(2) Student Information

\begin{tabular}{|c|c|c|c|}
\hline Student's Name & UID & Student's ISU email & $\overline{\text { Department/School }}$ \\
\hline Degree Type Expected (e.g. M.A., M.S., Ph.D.) & Phone Number & & \\
\hline Mailing address & & & \\
\hline
\end{tabular}

(3) Tentative Title of Research Project

(4) Compliance Requirements

Does your research involve living human subjects or human subject records?

Does your research involve living animals in any way?

Does your research involve recombinant DNA and/or Infectious Agents?

Does your research involve radioactive materials?

If yes, name of faculty member who holds University approval for use of radioactive material

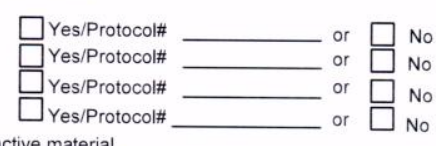

\section{(5) Copyright Checklist}

Please check the box preceding the statement if your thesis or dissertation does (or will) contain any of the following items. Check the box whether or not you purchased the item, received permission to use it in the research, and/or believe you may use it without permission).

Image/s originally produced by another person (including but not limited to photographs, graphs, graphics, charts, diagrams, ads, artwork, maps or drawings) whether found in print or online

Image/s that you traced, redrew, adapted from or based on images originally produced by someone else whether found in print or online

7 Survey/s, instrument/s, questionnaire or tool/s originally prepared by someone else, whether found in print or online

7 Any survey, instrument, questionnaire, tool, or image that you modified from, adapted from, or otherwise based on an item originally Entire poem or song/s, whether found in print or online

Segment/s from poems or songs, whether found in print or online

Significant portions of books or articles, whether literary or non-literary, whether found in print or online (generally "significant" is more than one and one half single-spaced pages)

Work that you produced for an employer or on a grant

Work that you previously published

Work that has been accepted for publication

Work produced with co-authors, whether published or unpublished

$\square$ I have not used or expect to use any of the items described above in my paper. Skip to section 6 if you did not check any of the items above. If you checked one or more items, you are required to consult with the copyright officer for advice and to obtain her/his signature before you submit this form. You may need to obtain permission letters to use the material described above.

To be completed by copyright officer:

$\square$ I have discussed this checklist with the student, and advised her/him that no permissions letters are required.

Dermissions are required. The student has now obtained all appropriate and necessary permission in writing and has attached them to this form. $8 R 7$ )

Arakinice

Copyright Officer Name, Printed

Proceed to the next page

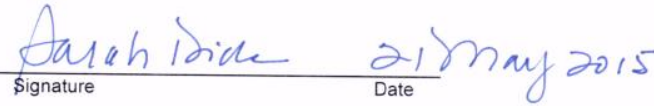

Proposal App Form 2/13 - pg. 2 


\section{APPENDIX E}

\section{ADAPTED SURVEY}

Identification Name/Code:

\section{Arts Performance Self-Efficacy Scale}

Directions: Respond to the following statements based on your current level of arts (music, dance, drama, visual arts) ability and experience. There is no right or wrong answers. Indicate to what degree you either agree or disagree with the statement by writing any whole number between 0 (Strongly Disagree) and 10 (Strongly Agree) on the line next to the statement. Carefully consider the number you choose.

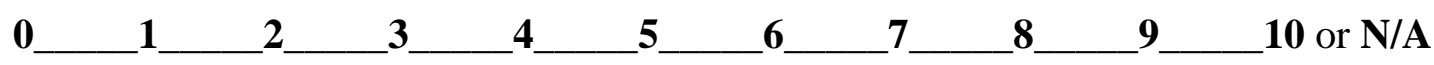

Strongly Strongly

Disagree Agree

Note: The arts refer to any or all areas of the arts: music, dance, theatre, visual arts

\section{$\underline{\text { Part I - (Mastery experiences) }}$}

1. I have had positive experiences participating in the arts (dance, music, theatre, and visual arts) in the past.

2. I have had positive experiences in Dance.

3. I have had positive experiences in Music.

4. I have had positive experiences in Theatre.

5. I have had positive experiences in Visual Arts.

6. I have had positive experiences performing or presenting art in large groups (5 or more).

7. I have had positive experiences performing or presenting art by myself, or, in small groups (4 or less). 
8. I have had positive experiences performing simple arts tasks.

9. I have had positive experiences executing complicated arts tasks.

10. I have overcome challenges related to the arts through hard work and practice.

11. I have used a practice routine to help me prepare for my performances or presentation in the arts.

\section{$\underline{\text { Part II - (Vicarious experiences) }}$}

12. I have improved my arts performance skills by watching professional artists perform well.

13. I have improved my arts performance skills by watching other students in my class perform well.

14. I have used other students' work as models to improve my arts integration skills.

15. I have compared my performance skills with those of other students who are similar in arts ability to me.

16. I have watched other students of similar arts ability as me perform an arts lesson plan, and then decided whether I could, or could not, perform the same lesson.

\section{$\underline{\text { Part III - (Verbal/Social persuasion) }}$}

17. My friends think I am a good performer/artist.

18. Members of my family believe I perform well in the arts.

19. My arts teacher has complimented me on my arts skills.

20. People have told me that my practice efforts have improved my arts skills.

21. I have received positive feedback on arts performance evaluations.

22. I have met or exceeded other people's expectations of being a good arts integrated teacher.

23. Write only the number 9 for this answer (not $0-10$ rating). 


\section{$\underline{\text { Part IV - (Physiological state) }}$}

24. Participating in the arts makes me feel good (Return to using 0-10 rating).

25. I enjoy participating in the arts.

26. I am learning, or have learned, to control nervousness during a performance.

27. I do not worry about small mistakes during a performance or lesson.

28. I have positive memories of most, or all, of my arts experiences. 